\title{
EFFECT OF SURFACE TREATMENTS ON MICROTENSILE BOND STRENGTH OF REPAIRED AGED SILORANE RESIN COMPOSITE
}

Jadesada Palasuk

Submitted to the Graduate Faculty of the School of Dentistry in partial fulfillment of the requirements for the Degree of Master of Science in Dentistry, Indiana University School of Dentistry, 2010 
Thesis accepted by the faculty of the Department of Prosthodontics, Indiana University School of Dentistry, in partial fulfillment of the requirements for the degree of Master of Science in Dentistry.

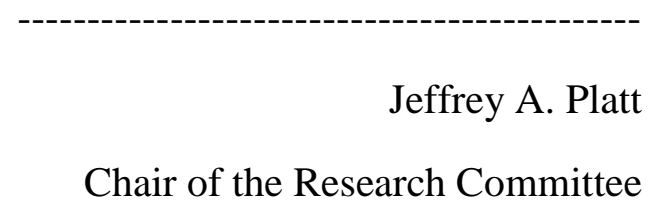

John A. Levon Program Director

David T. Brown

Suteera Hovijitra

Sopanis D. Cho

Date 
ACKNOWLEDGEMENTS 
It is a great experience and privilege to complete my MSD degree in the Division of Prosthodontics at Indiana University, School of Dentistry. Other than completing clinical requirements and coursework, doing the research is challenged. There are several people who helped and involved in my work.

First of all, I would like to begin by expressing my appreciation to the Royal Thai Government, Professor Dr. Visaka Limwongse and the former program director, Dr. Carl J Andres for giving me an opportunity to pursue my post-graduate education in the US.

And I also would like to thank my program director and my research mentor; Dr. John A. Levon and Dr. Jeffrey A. Platt for your valuable suggestions, assistance and supervision. Moreover, I also would like to thank my graduate committee members, Dr. Suteera Hovijitra, Dr. Sopanis D. Cho, Dr. David T. Brown. Your suggestions are very helpful.

And special thanks to Meoghan McPherson and Jeana Aranjo for their assistance.

Furthermore, this research would not have been possible without support from Delta Dental Foundation and 3M. And finally, I would like to thank my family, my classmates and my friends who support me during my training. 
TABLE OF CONTENTS 


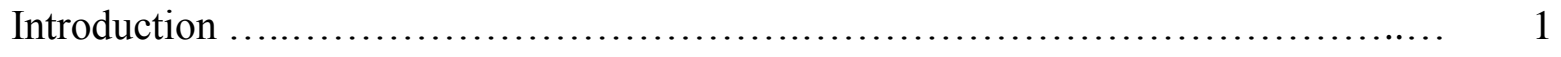

Statement of Problem................................................... 3

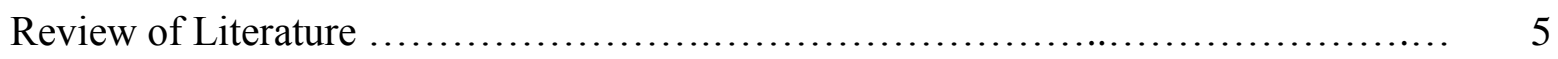

Materials and Methods................................................... 14

Results ............................................................ 22

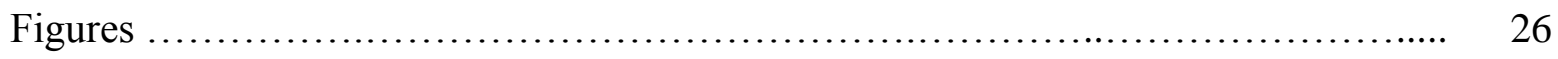

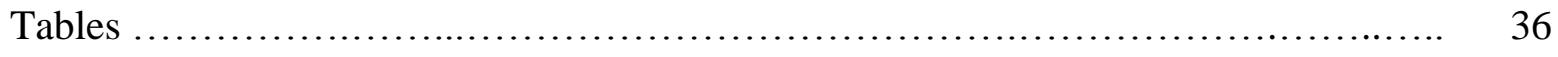

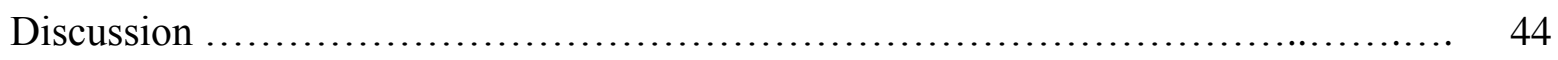

Summary and Conclusions............................................. 55

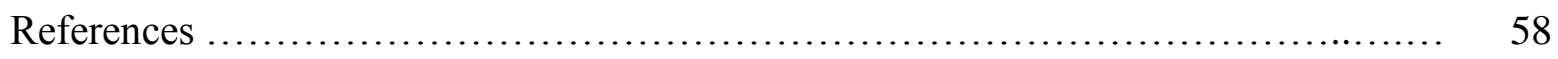

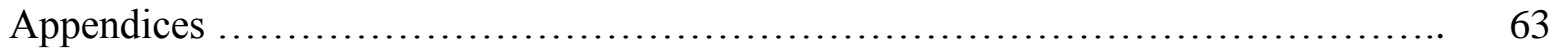

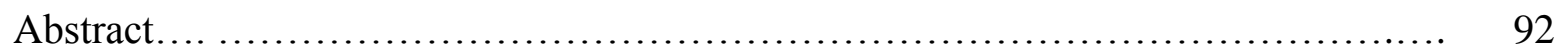

Curriculum Vitae 
LIST OF ILLUSTRATIONS 
FIGURE $1 \quad$ Silorane molecule ................................................ 27

FIGURE 2 Ring opening polymerization of silorane resin composite ............. 27

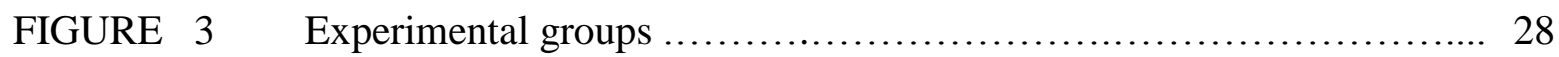

FIGURE $4 \quad$ Control and tested specimens................................... 29

FIGURE $5 \quad$ Non-trimming microtensile bond strength test ..................... 29

FIGURE $6 \quad$ Mean and standard deviation of experimental groups ................ 30

FIGURE 7 The survival probability of failure fitted by Weibull model ............ 31

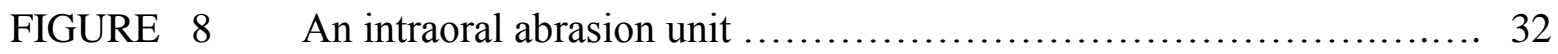

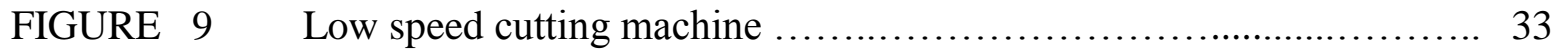

FIGURE $10 \quad$ Resin composite beam before microtensile testing .................... 34

FIGURE $11 \quad$ Fractured resin composite beam after testing ........................ 34

FIGURE 12 Mounted specimen on Universal testing machine before testing........... 35

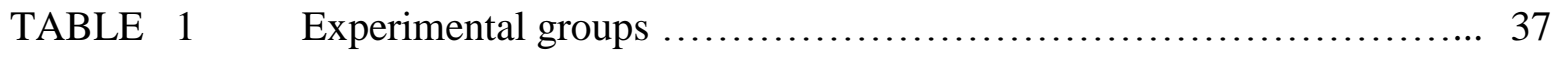

TABLE 2 Materials, batch numbers, type, general compositions ................... 38

TABLE 3 Mean, percent of cohesive strength, p-value of experimental groups... 39

TABLE 4 Descriptive statistics of experimental groups ....................... 40

TABLE 5 Statistical comparison of microtensile bond strength ................. 41

TABLE $6 \quad$ The incidence of failure mode ................................... 42

TABLE $7 \quad$ Statistical comparison of type of failure …......................... 43 
INTRODUCTION 
Resin composites have been widely used for several years. Currently, most commercially available resin composites have their common basis in the free radical polymerization of methacrylate. Despite significant improvement in resin composite formulations over the years, many modern systems are still based on variations of the bis-GMA molecule, which has been used for more than 30 years. One of the identifiable disadvantages of this material is high polymerization shrinkage. ${ }^{1}$ Different researchers have shown an average of 2.0-6.0 vol\% shrinkage. ${ }^{2-4}$ Polymerization shrinkage leads to clinical problems such as microleakage, postoperative sensitivity and secondary caries. ${ }^{5}$ 
STATEMENT OF PROBLEM 
To overcome polymerization shrinkage, a silorane based material was introduced. A silorane molecule is a product from the reaction of oxirane and siloxane molecules. ${ }^{2,6,7}$ Silorane based resin composite has shown approximately $0.94-1.5$ vol\% shrinkage ${ }^{2,4,8}$ and comparable flexural strength to methacrylate based resin composite. ${ }^{2}$ Because of improved polymerization shrinkage, silorane resin composite may become a material of choice for direct restorations. With the clinical use of the material, minor deterioration or fractured restorations are expected. Replacement of the restorations is not always necessary and is often discouraged. ${ }^{5}$ At present, there is no available information regarding the repair potential of silorane resin composite with the same material or with the methacrylate based resin composite. Determining the repair bond strength of new resin composite applied to aged silorane resin composite would be beneficial for the clinician. 
REVIEW OF LITERATURE 
Many factors affect the longevity of resin composite restorations such as patient's oral hygiene, clinician's clinical experience and age of patients. ${ }^{9}$ Normally, resin composite restorations are replaced at a median age of 7-8 years. ${ }^{9}$ Secondary caries and marginal discoloration are the most common reasons for replacement of resin composite restorations. ${ }^{10}$

Replacement of resin composite restoration has several disadvantages. It is time-consuming and additional cost is required. Gordan ${ }^{10,11}$ reported a significant increase in the size of the cavity preparation resulting from removal of more tooth structure. The re-restoration cycle generally results in weakening of the tooth structure and subsequently in tooth loss. ${ }^{9}$ An alternative and more conservative treatment such as repair should be considered.

Gordan et $\mathrm{al}^{5}$ reported a two year clinical evaluation of repair versus replacement of resin composite restorations. They found that repair had significant improvement of the margins of restorations. Moreover, repair treatment showed no significant difference when compared with the replacement and remained stable over two years. They concluded that repair should be considered whenever possible. ${ }^{5}$

Resin composites have been used to replace missing tooth structure, modify tooth color and contour, and enhance facial esthetics. In 1955, Buonocore ${ }^{12}$ introduced orthophosphoric acid etching technique to improve adhesion between acrylic resin and enamel. ${ }^{12}$ Development of dental resin composites has been dominated by the use of methacrylate resins.

One of the disadvantages of resin composite is the stress associated with polymerization shrinkage. Polymerization shrinkage of methacrylate based resin composite ranges between 2$6 \%$ by volume. ${ }^{3}$ Polymerization shrinkage of dental resin composite occurs as a result of 
monomer molecules are converted into a polymer network and interaction spaces change from van der Waals force dimensions to covalent bond dimensions. ${ }^{8}$ Reduction of polymerization shrinkage has been an important issue since this polymerization shrinkage leads to microleakage, postoperative sensitivity, secondary caries and marginal staining. ${ }^{5,13}$ Polymerization shrinkage also creates contraction stresses in the resin composite restoration and internal stress can cause deformation in the surrounding tooth structure. ${ }^{14}$

There have been several attempts to overcome polymerization shrinkage such as using an incremental layering technique, placing a stress absorbing liner and changing the light curing procedures. ${ }^{13,15}$ A recent one is the use of ring opening polymerization of the silorane molecules (Figure 1, 2). ${ }^{16}$ Silorane containing resins are being developed by $3 \mathrm{M}$-ESPE. ${ }^{1}$ Recently, Weinmann et $\mathrm{al}^{2}$ described the synthesis of this new monomer system. Silorane is derived from the combination of oxirane and siloxane molecules. ${ }^{2,6}$ The siloxane backbone was introduced in order to increase hydrophobicity. Hydrophobic materials are much less sensitive to exogenous staining than hydrophilic materials. ${ }^{2}$ Increased hydrophobicity of silorane resin composite was shown to have an advantageous effect on material properties such as water sorption and solubility. 6

Like methacrylate based resin composite, silorane resin composite (Filtek LS) consists of four main components. ${ }^{2,7,17}$ The filler is a combination of fine quartz particles and radiopaque yttrium fluoride. The polymer matrix is silorane and the photoinitiator is camphorquinone and iodonium salt. The use of fine particular quartz contributes to good esthetic performance and mechanical stability. The quartz surface is modified with a silane layer. As it is known for the methacrylates, 
the silane layer increases the hydrophobic character of the surface of the filler. At the same time, the silane layer acts as the interface between filler and matrix facilitating the reinforcement of the resin with the hard filler particles. The silane layer prevents an attack of the acidic $\mathrm{Si}-\mathrm{OH}$ groups of the quartz, which could potentially result in undesired initiation of the cationic polymerization process.

\section{Polymerization}

Whereas, the polymerization process of methacrylate based resin composite occurs via free radical polymerization, ${ }^{18,19}$ the polymerization of silorane resin composite is generated by the cationic ring opening polymerization of the cycloaliphatic oxirane molecule (Figure 2). ${ }^{2}$ The cationic polymerization starts with the initiation process of an acidic cation which opens the oxirane ring and generates a new acidic center, a carbocation. After the addition to an oxirane monomer, the epoxy ring is opened to form a chain, or in the case of bi- or multifunctional monomers a network is formed.

A three-component initiating system is made up of camphorquinone, an iodonium salt and an electron donor. Camphorquinone is used as a photoinitiator in order to match the emission spectra of the currently used dental lamps. ${ }^{2,17}$ In this reaction path, the electron donor acts in a redox process and decomposes the iodonium salt to an acidic cation which starts the ring opening polymerization process. The three component system provides for the optimal balance between high polymerization reactivity and light stability. The silorane resin composite has two main advantages ${ }^{16}$ : low polymerization shrinkage due to the ring opening oxirane monomer and increased hydrophobicity because of the siloxane molecules. ${ }^{16}$ 
Resin composite materials have relatively short clinical longevity. Mjör et al ${ }^{9}$ reported that the average lifetime of resin composites is $7-8$ years. ${ }^{9}$ Recurrent caries and discoloration are the main reasons for replacement of resin composite restorations in general dental practice. ${ }^{20}$ The other reasons include dislodgement, fracture of the tooth, and pain or discomfort leading to replacement. $^{20}$

Total replacement is not always necessary nor desirable. ${ }^{21}$ Replacement frequently involves the removal of additional tooth structure in order to optimize the new enamel bonding leading to a larger restoration with further loss of tooth structure. ${ }^{21}$ Bonding between a new layer of resin composite and aged resin composite may occur by two main mechanisms; micromechanical retention and chemical bonding. ${ }^{22}$

There is a consensus that the bonding of new to aged resin composite is micromechanical but chemical bonding should also be taken into consideration. ${ }^{22-24}$ When considering chemical bonding to aged methacrylate based resin composite, Padipatvuthikul and Mair ${ }^{25}$ proposed two possible mechanisms being promoted by a bonding agent. The first mechanism is micromechanical retention created by penetration of the unfilled resin into the surface irregularities or microdefects in the aged resin composite. The second may be related to the solvents in the adhesive systems. These solvents may cause swelling and gelation of the surface layer, allowing the monomer in the layer of the repair filling access to unconverted vinyl groups $(\mathrm{C}=\mathrm{C})$ in the substrate of the filling. ${ }^{25}$ 
As resin composite continues to mature after placement, the available vinyl group $(\mathrm{C}=\mathrm{C})$ for cross-polymerization to the new resin composite layer decreases over time. This might affect the ability of new resin composite to bond to the aged resin composite. Research has shown that the repair bond strength of aged resin composite was compromised with reduced numbers of unconverted carbon double bonds and lack of an oxygen inhibiting layer. ${ }^{25}$

Potential for chemical bonding to the aged silorane resin composite is unclear. Whether the presence of an oxygen inhibited layer on the polymerized surface of a silorane resin composite might be an important factor for chemical bonding to aged silorane resin composite is still in question. Tezvergil-Mutluay et $\mathrm{al}^{26}$ suggested that no oxygen inhibited layer existed at the surface of silorane resin composite because silorane undergoes cationic ring opening polymerization reactions which are not sensitive to oxygen. On the other hand, Shawkat et $\mathrm{al}^{27}$ have found that an oxygen inhibited layer was present although with minimal thickness after polymerization of silorane resin composite. They stated that iodonium salts are effective photoinitiators of cationic polymerization and absorb short wave length ultraviolet light. However, in dental applications, a wider spectrum of light source is used. This light source might be critical for the effectiveness of cationic polymerization. During the electron-transfer photoinitiation reaction, a redox reaction occurs creating a radical and a cation-radical which generates the cationic initiating species. The presence of this radical species may react with oxygen under conventional light curing conditions and results in an oxygen inhibited layer. More researches are needed to understand the role of an oxgen inhibited layer in repair of silorane resin composite. 
Several methods of surface treatment have been widely used to establish adequate bond strength between aged resin composite and new resin composite including surface hydrofluoric acid etching, sandblasting with aluminum oxide particles, abrasion with a diamond bur followed by silica coating, and the use of intermediate bonding agents. ${ }^{15-16,21,28-30}$ Surface treatment of aged resin composite has two main purposes ${ }^{30}$; to remove the superficial layer altered by the saliva exposing a clean, higher energy composite surface, and to increase the surface area through creation of surface irregularities. ${ }^{31}$

Papacchini et $\mathrm{al}^{21}$ compared the 24 hour microtensile bond strength of a microhybrid resin composite to the same material after different surface treatments. They found that air abrasion with aluminum oxide particles and the application of a bonding agent produced the highest microtensile bond strength, followed by a mix of hydrochloric acid and hydrofluoric acid, then a fine grit diamond bur, respectively.

Junior et $\mathrm{al}^{16}$ investigated the microtensile bond strength of the aged microhybrid and nanohybrid resin composites treated with different surface treatments; hydrofluoric acid etching, abrasion using a coarse diamond bur, sandblasting using alumina particles and silica coating. They concluded that sandblasting with aluminum oxide particles and silica coating produced the greatest microtensile bond strength value, irrespective of primer used. They also reported that a more even surface topography was achieved using aluminium oxide sandblasting in comparison with diamond bur abrasion resulting in greater microtensile bond strength value and suggesting a more effective pattern for mechanical retention. Moreover, they also found the etched aged resin composite with hydrofluoric acid produced the lowest microtensile bond strength value. 
Therefore, Junior et al ${ }^{16}$ stated that hydrofluoric acid should be avoided for repairing aged resin composite.

In addition, Ozcan et $\mathrm{al}^{30}$ stated that among the particle abrasion systems, aluminium oxide presents the best bond strength values compared to other methods since it provides microretention on the aged resin composite surface. Particle deposition, at the same time, increases the ability of the new resin composite to mechanically interlock to the substrate due to the increase in surface area. Moreover, these retentive surface textures favor the surface wettability that allows optimal adaptation of the resin composite.

Trajtenberg et al ${ }^{31}$ reported the opposite result. In their study, hydrofluoric acid produced the highest tensile bond strengths when used to prepare the three laboratory resin composites. Furthermore, they also investigated the repair bond strength of a laboratory processed resin composite treated with hydrofluoric acid gels with different concentrations and etching times. ${ }^{32}$ There was no significant difference in repair bond strength with respect to different acid concentrations or the etching times tested. ${ }^{32}$

There is currently no available data focusing on the effect of surface treatment on repair bond strength of aged silorane resin composite. The purposes of this in vitro study were to examine the microtensile bond strength of repaired aged silorane resin composite with different methods of surface treatment and to compare the microtensile bond strength of repaired aged silorane resin composite when repaired with silorane resin composite and with methacrylate based resin composite. 


\section{Null hypotheses:}

(1) There is no difference in microtensile bond strength of repaired aged silorane resin composite when tested after different methods of surface treatment.

(2) There is no difference in microtensile bond strength of repaired aged silorane resin composite when repaired with either silorane or methacrylate based resin composite.

\section{Alternative hypotheses:}

(1) Microtensile bond strength of repaired aged silorane resin composite will vary when aged silorane resin composite is treated with different methods of surface treatment.

(2) Microtensile bond strength of repaired aged silorane resin composite is lower when repaired with the methacrylate based resin composite. 
MATERIALS AND METHODS 
In this laboratory study, the repaired microtensile bond strengths of aged silorane resin composite using different methods of surface treatment and either silorane or methacrylate based resin composite were compared, and the types of failure were examined using light microscopy.

\section{Specimens:}

One hundred and eight silorane resin composite blocks (Filtek LS, shade A2, 3M ESPE, St. Paul, MN, USA) with dimensions of $6 \mathrm{~mm} \times 6 \mathrm{~mm} \times 12 \mathrm{~mm}$ for the control and $6 \mathrm{~mm} \times 6 \mathrm{~mm} \times 6 \mathrm{~mm}$ for the test specimens were fabricated using a silicone mold (Figure 3). The resin blocks were built in increments of $2 \mathrm{~mm}$ using a plastic instrument. Each layer was cured for 40 seconds using a Demetron LC curing unit (Kerr, Orange, CA USA) with the intensity of $600 \mathrm{~mW} / \mathrm{cm}^{2}{ }^{33}$ Tip of light curing unit was kept perpendicular to and in contact with Mylar strip in order to receive a maximum curing depth. The intensity of the LED curing light was monitored with a Cure Rite Visible Curing Light Meter (Dentsply, York, PA, USA). The top of each specimen was covered with a Mylar strip in order to obtain a flat surface and to aid in removal of excess material. All specimens were polished using 240, 320, 400 and 600 silicon carbide paper including the top surface in order to remove the excess of resin composite and to make the surface perpendicular to the specimen's long axis. All specimens were cleaned in tap water for 10 minutes in an ultrasonic device to remove loose particles and stored in distilled water for 24 hours.

\section{Aging method:}

After polishing and storing in distilled water for 24 hours, all specimens were aged by thermocycling (5000 cycles, $8^{\circ} \mathrm{C}$ to $48^{\circ} \mathrm{C}$, dwell time: $30 \mathrm{~s}$, transfer time of $10 \mathrm{~s}$ ). 


\section{Surface treatment procedures:}

The surface treatment procedure was performed 2 days after thermocycling was done (because of the weekend) and on the same day of repairing. Silorane resin composite blocks with dimensions of $6 \mathrm{~mm} \times 6 \mathrm{~mm} \times 12 \mathrm{~mm}$ were used as a control. All remaining resin composite blocks with dimensions of $6 \mathrm{~mm} \times 6 \mathrm{~mm}$ × $6 \mathrm{~mm}$ were randomly assigned into four groups. Surface treatment procedure was performed as described below:

\section{Control group:}

Solid silorane resin composite blocks were used as controls. This was done to determine the actual cohesive strength of the silorane resin composite.

\section{Group 1: no surface treatment}

Specimens received no surface treatment of the aged resin composite.

\section{Group 2: acid treatment}

The aged specimen surfaces were etched with 35\% phosphoric acid gel (Scotchbond, 3M ESPE, St. Paul, MN, USA) for 15 seconds for the group that was repaired with methacrylate based resin composite (group 2M). The aged specimen surfaces were etched with LS System self etch primer (LS System adhesive, 3M ESPE, St. Paul, MN, USA) for 15 seconds for the group that was repaired with silorane resin composite (group $2 \mathrm{~S}$ ). Then, all specimens were rinsed with water and excess water was removed with canned compressed oil-free air (Falcon Dust off Air Duster, Branchburg, NJ, USA). 


\section{Group 3: sandblasting with aluminum oxide (AO)}

Each resin composite specimen was abraded for 10 seconds with a distance approximately 10 $\mathrm{mm}$ perpendicular to the resin composite block using an intraoral air abrasion unit (Microetcher II, Danville Engineering INC., San Ramon, CA, USA) using $50 \mu \mathrm{m}$ aluminum oxide particles (Danville Engineering INC., San Ramon, CA, USA) with an air pressure of 60 psi. All specimens were rinsed with water and then excess water was removed with canned compressed oil-free air.

\section{Group 4: abrasion with a coarse diamond bur}

The aged specimen surfaces were roughened with a coarse-grit diamond bur for 10 seconds (No. 027, Brasseler, Savannah, GA, USA). A high speed handpiece with a water spray was used. The pressure equivalent to a mass of approximately $4.0 \pm 1.0 \mathrm{~g}$ was used. ${ }^{34}$ Before the roughening procedure, the operator was trained on the surface of an analytical balance (AE 100, MettlerToledo, Inc, Columbus, OH, USA) to determine the equivalent manual pressure that was placed on the surface of the resin composite. Then, the specimens were rinsed with water and then excess water was removed with canned compressed oil-free air.

\section{Application of adhesives and resin composites:}

After surface treatment, all specimens in each group except the control group were randomly assigned into 2 subgroups.

The first subgroup (1S, 2S, 3S, 4S) was repaired with new silorane resin composite (Filtek LS, Shade C2, 3M ESPE, St. Paul, MN, USA) using LS System adhesive (3M ESPE, St. Paul, MN, 
USA). The second subgroup ( $1 \mathrm{M}, 2 \mathrm{M}, 3 \mathrm{M}, 4 \mathrm{M})$ was restored with methacrylate based resin composite (Filtek Z250, Shade A4, 3M ESPE, St. Paul, MN, USA) using the fifth generation

one-bottle dentin adhesive agent (Adper ${ }^{\mathrm{TM}}$ Single Bond Plus, 3M ESPE, St. Paul, MN, USA). All adhesive systems were applied and polymerized on all aged resin composite specimens as described below.

\section{LS System adhesive:}

After the surface treatment procedure, the LS System adhesive self etch primer was applied on the surface treated resin composite for 15 seconds except for group 1S (no surface treatment group) and group $2 \mathrm{~S}$ (acid etching group) because group $2 \mathrm{~S}$ was previously etched from the surface treatment. Then, all etched specimens were gently dried with canned compressed oil-free air and 10 seconds of light cure (Demetron LC curing unit, Kerr, Orange, CA, USA). Then, LS adhesive bonding was applied on the surface of all resin composites (including group $1 \mathrm{~S}, 2 \mathrm{~S}$ ), followed by gentle air drying and 10 seconds of light cure.

\section{Adper $^{\text {TM }}$ Single Bond Plus System adhesive:}

After the surface treatment procedure, 35\% phosphoric acid gel (Scotchbond ${ }^{\mathrm{TM}}$ Etchant, 3M ESPE, St. Paul, MN, USA) was applied to the surface treated resin composite for 15 seconds except for group 1M (no surface treatment group) and group 2M (acid etching group) because group $2 \mathrm{M}$ was previously etched from the surface treatment. Then, the etched resin composites were rinsed for 10 seconds. Excess water was removed with canned compressed oil-free air. Then, Adper ${ }^{\mathrm{TM}}$ Single Bond Plus adhesive agent (3M ESPE, St. Paul, MN, USA) was applied in 3 consecutive coats for 15 seconds on the surface of all resin composites (including group 1M, 
$2 \mathrm{M}$ ) with gentle agitation using a fully saturated applicator, followed by air drying for 5 seconds to evaporate the solvent and 10 seconds of light cure.

Then, a new layer of resin composite was applied to the aged silorane resin composite with the aid of a silicone mold. Each increment was packed with a clean plastic instrument and light cured for 40 seconds. After repairing, all specimens were stored in $37{ }^{\circ} \mathrm{C}$ distilled water for 24 hours.

\section{Microtensile bond strength test: ${ }^{16,21,34}$}

After storing in $37^{\circ} \mathrm{C}$ distilled water for 24 hours, the resin composite blocks were cut using a slow speed water-cooled saw equipped with a diamond impregnated disk (Isomet, Buehler, Lake Bluff, IL, USA) at a speed of $300 \mathrm{rpm}$, producing 9 beams with an average area of $0.64 \mathrm{~mm}^{2}(0.8$ $\mathrm{mm} \times 0.8 \mathrm{~mm}$ ) for each beam (Figure 4,5 ). The beams located at the periphery of block were discarded.

After storing in $37^{\circ} \mathrm{C}$ distilled water for 24 hours, the beams were attached to the holder of a universal testing machine (MTS Sintech Renew 1123, Eden Prairie, MN, USA). All beams were loaded in tension until fracture at a crosshead speed of $1 \mathrm{~mm} / \mathrm{min}$ (Figure 5, 12).

A pilot study was done using this method to determine if solid silorane specimens could be used as a control group. The results indicated that the solid specimens could break in the gap between the upper and the lower jig of the Universal testing machine. 


\section{Failure analysis:}

Fracture surfaces of the repaired groups were examined using optical microscopy at 20X magnification. The type of failure was determined to be either adhesive failure (between aged and new repaired resin composites involving the intermediate layer); cohesive failure (within the aged or repairing resin composite); or mixed (combination of adhesive failure and cohesive failure).

\section{Statistical analysis:}

Comparisons between the groups for differences in microtensile bond strength were performed using a Weibull-distribution survival analysis, using the force required for failure in place of the usual 'time to event' seen in typical survival analyses. The analysis included a "frailty" term to correlate the measurements from beams coming from the same specimen. Specimens which failed before placement on the testing machine were accommodated in the survival analysis model as left-censored observations, and specimens which did not fail prior to the end of testing were accommodated as right-censored observations. Differences between the groups for type of failure were analyzed using generalized estimating equation methodology applied to cumulative logistic regression models.

\section{Sample size justification:}

Although the analyses were performed using survival analysis, the sample size calculations based on the t-test provided appropriate estimates. Based on the studies by Junior ${ }^{16}$ and Pappacchini ${ }^{21}$, the standard deviation of the microtensile bond strengths was expected to be approximately $20 \mathrm{MPa}$. Based on a prior study by Eckert and Platt ${ }^{35}$, within-specimen correlation 
among beams was approximately 0.3 . With a sample size of 12 specimens per group and 9 beams per specimen, the study had an $80 \%$ power to detect a difference of $15 \mathrm{MPa}$ between two groups, assuming a two-sided 5\% significance level for each comparison. 
RESULTS 


\section{$\underline{\text { Microtensile bond strength }}$}

When compared to the control group, the microtensile bond strength ranged from $50.2 \pm 1.6 \mathrm{MPa}$ or $80.19 \%$ of cohesive strength for the group $3 \mathrm{~S}$ to $37.2 \pm 1.6 \mathrm{MPa}$ or $59.42 \%$ of cohesive strength for the group $1 \mathrm{~S}$. The second highest microtensile bond strength was group $3 \mathrm{M}$ $(47.8 \pm 1.5 \mathrm{MPa}$ or $76.36 \%$ of cohesive strength), followed by group $2 \mathrm{M}(44.1 \pm 1.8 \mathrm{MPa}$ or $70.45 \%$ of cohesive strength), group $1 \mathrm{M}(40.8 \pm 1.9 \mathrm{MPa}$ or $65.18 \%$ of cohesive strength), group $4 \mathrm{~S}(39.0 \pm 1.7 \mathrm{MPa}$ or $62.30 \%$ of cohesive strength), group $4 \mathrm{M}(37.7 \pm 1.6 \mathrm{MPa}$ or $60.22 \%$ of cohesive strength), group $2 \mathrm{~S}(37.3 \pm 2.0 \mathrm{MPa}$ or $59.58 \%$ of cohesive strength), respectively. The lowest microtensile bond strength presented in group $1 \mathrm{~S}(37.2 \pm 1.6 \mathrm{MPa})$ or $59.42 \%$ of cohesive strength (Table 3, 4 and Figure 6).

After evaluation of the results using Weibull-distribution survival analysis (Table 3, Figure 7), it showed that group $1 \mathrm{M}, 1 \mathrm{~S}, 2 \mathrm{~S}, 4 \mathrm{M}$, and $4 \mathrm{~S}$ had significantly lower microtensile bond strength than the control with p-values of $0.03,0.006,0.008,0.007$ and 0.01 respectively. Thus, microtensile bond strength was marginally lower on group $2 \mathrm{M}$ than the control group $(\mathrm{p}=0.07)$. Moreover, microtensile bond strength of group $3 \mathrm{~S}$ and $3 \mathrm{M}$ was not significantly different from the control $(p>0.05)$. No other statistically significant differences were found among other groups.

The lowest microtensile bond strength was presented in the no surface treatment group which was repaired with silorane resin composite (group 1S). The highest microtensile bond strength was observed in the sandblasting surface treatment group irrespective of the material used. In addition, although this result showed that group $2 \mathrm{M}, 3 \mathrm{~S}$ and $3 \mathrm{M}$ produced microtensile bond 
strength as high as the cohesive strength of silorane resin composite, the repair bond strength was still lower than the cohesive strength of silorane resin composite.

\section{Type of failures}

As shown in Table 5, in the majority of tested beams, fractures developed at the resin compositeresin composite interface $(81 \%)$, followed by cohesive failure $(18 \%)$ and mixed failure (1\%), respectively. Group 4S showed the highest adhesive failure (94\%), followed by group 4M (88\%), group 1S $(87 \%)$, group 2M (82\%), group $2 \mathrm{~S}(80 \%)$, group $1 \mathrm{M}(77 \%)$, respectively. Surface treatment with sandblasting showed the lowest percent of adhesive failure (63\% for group $3 \mathrm{M}$ and $72 \%$ for group $3 \mathrm{~S}$ ).

Conversely, the highest percent of cohesive failure was found in the sandblasting groups (36\% for group $3 \mathrm{~S}$ and $24 \%$ for group $3 \mathrm{M}$ ). The lowest percent of cohesive failure presented in the surface treatment with abrasion with diamond bur ( $6 \%$ for group $4 \mathrm{~S}, 4 \mathrm{M})$. The cohesive failure of remaining groups was $13 \%$ (group 1S), 18\% (group 2M), 19\% (group 2S) and 22\% (group 1M). Mixed failure was also found in group 4M (6\%), group 3S (2\%), group 3M (1\%) and group 2S (1\%). There were only 3 beams that did not break during the testing because of glue separation (Table 5).

In addition, statistical analysis showed that group $4 \mathrm{~S}$ had a significantly higher proportion of adhesive failure than group $1 \mathrm{M}$, group $2 \mathrm{M}$, group $2 \mathrm{~S}$, group $3 \mathrm{~S}$, and group $3 \mathrm{M}$ with $\mathrm{p}$-values of $0.004,0.015,0.009,0.001$ and 0.001 , respectively. Group 4M had a significantly higher proportion of adhesive failure than group $3 \mathrm{~S}(\mathrm{p}=0.006)$ and group $3 \mathrm{M}(\mathrm{p}=0.001)$. Group $1 \mathrm{~S}$ 
had a significantly higher proportion of adhesive failure than group $3 \mathrm{~S}(\mathrm{p}=0.007)$ and group $3 \mathrm{M}$ $(\mathrm{p}=0.001)$. Group 3M had a significantly lower proportion of adhesive failure than group $2 \mathrm{M}(\mathrm{p}$ $=0.001)$ and group $2 \mathrm{~S}(\mathrm{p}=0.018)($ Table 6$)$. 


\section{FIGURES}


Figure 1: Silorane molecule ${ }^{2}$

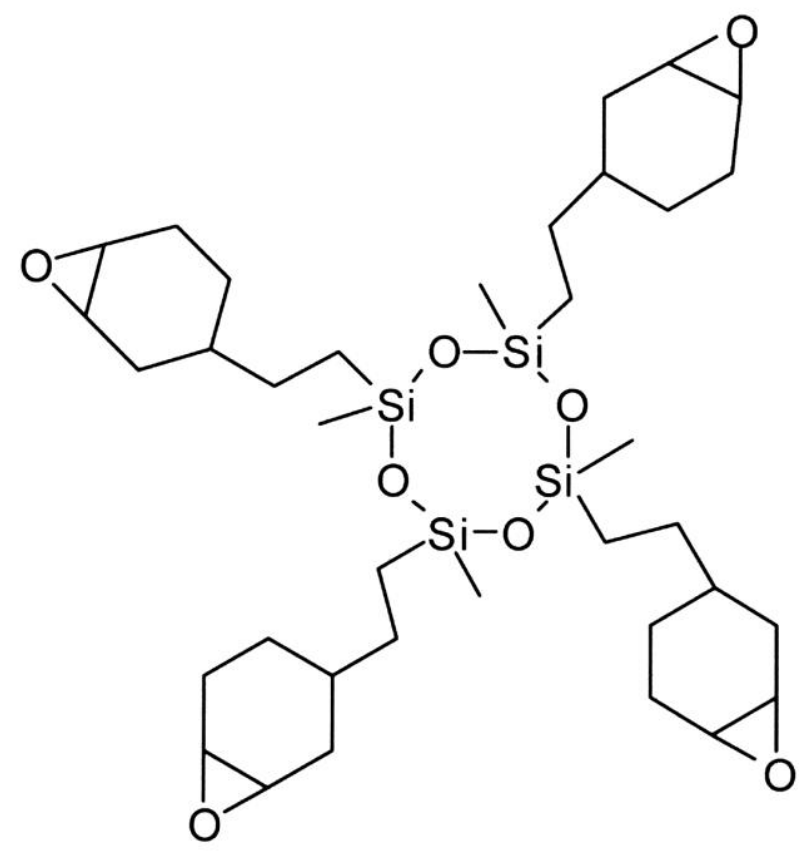

Figure 2: Ring opening polymerization of silorane resin composite ${ }^{2}$
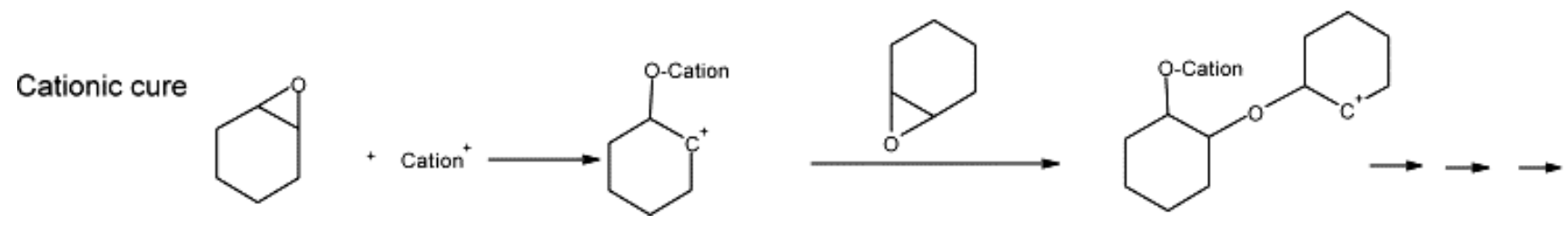
Figure 3: Experimental groups

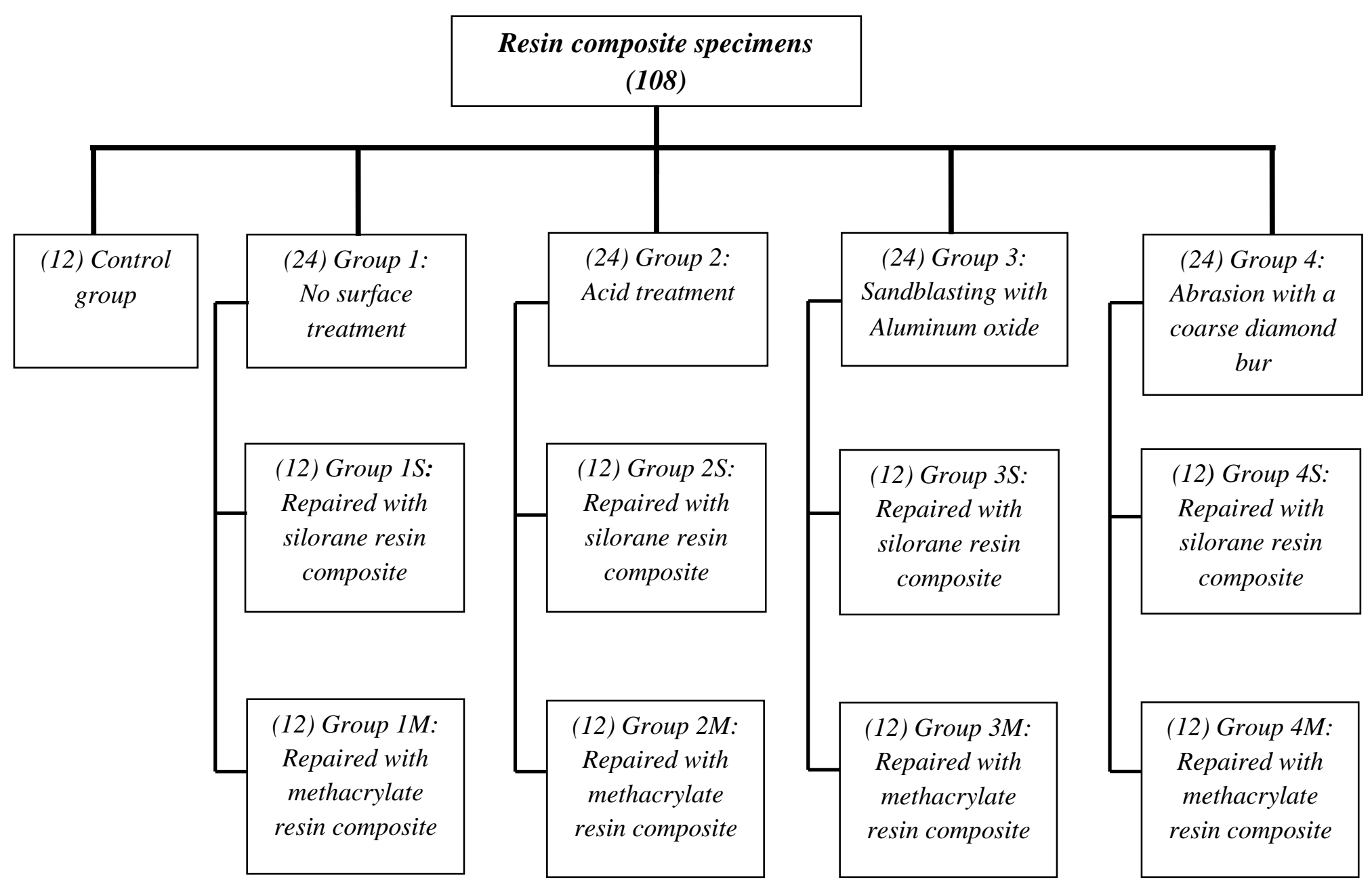


Figure 4: Control and tested specimens

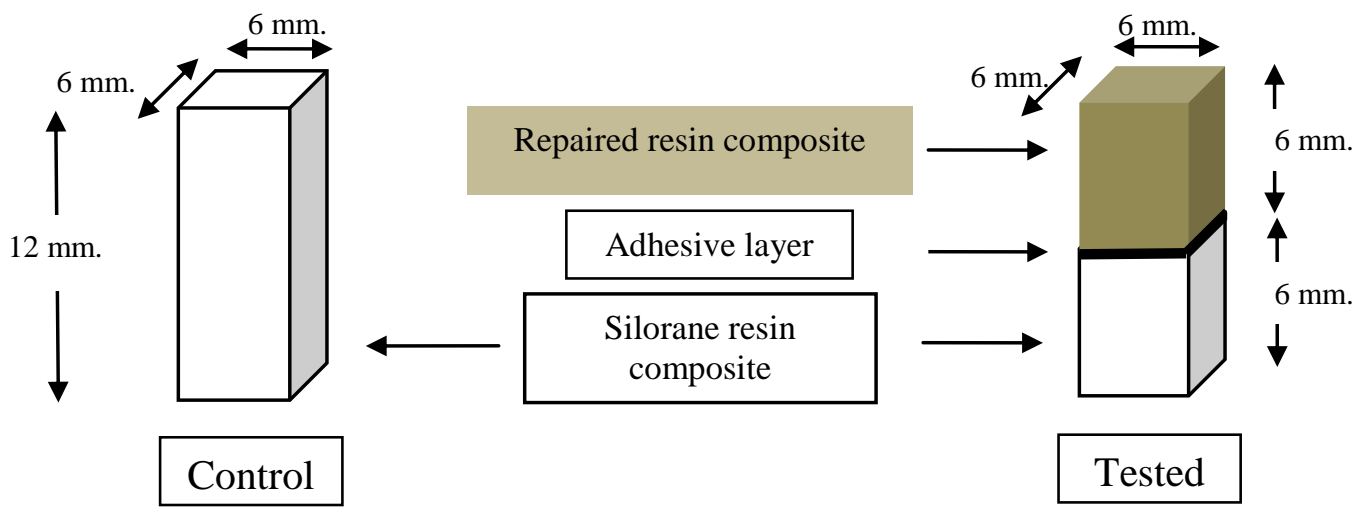

Figure 5: Non-trimming microtensile bond strength test
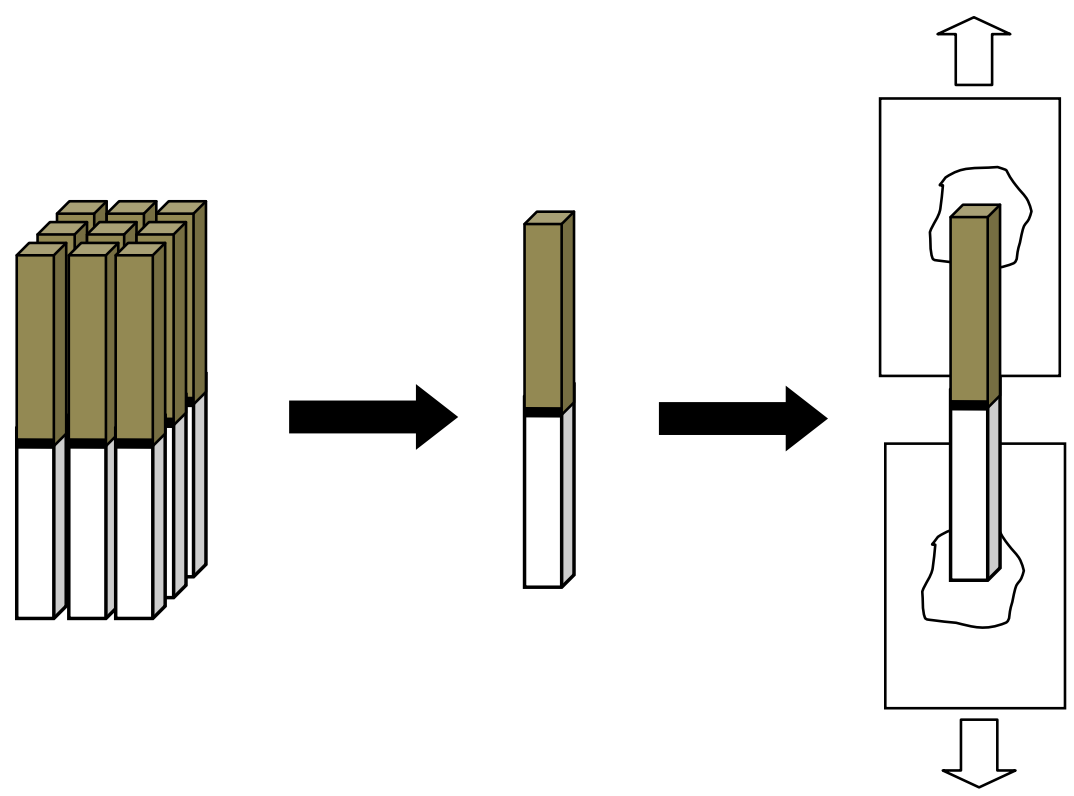
Figure 6: Mean and standard deviation of experimental groups

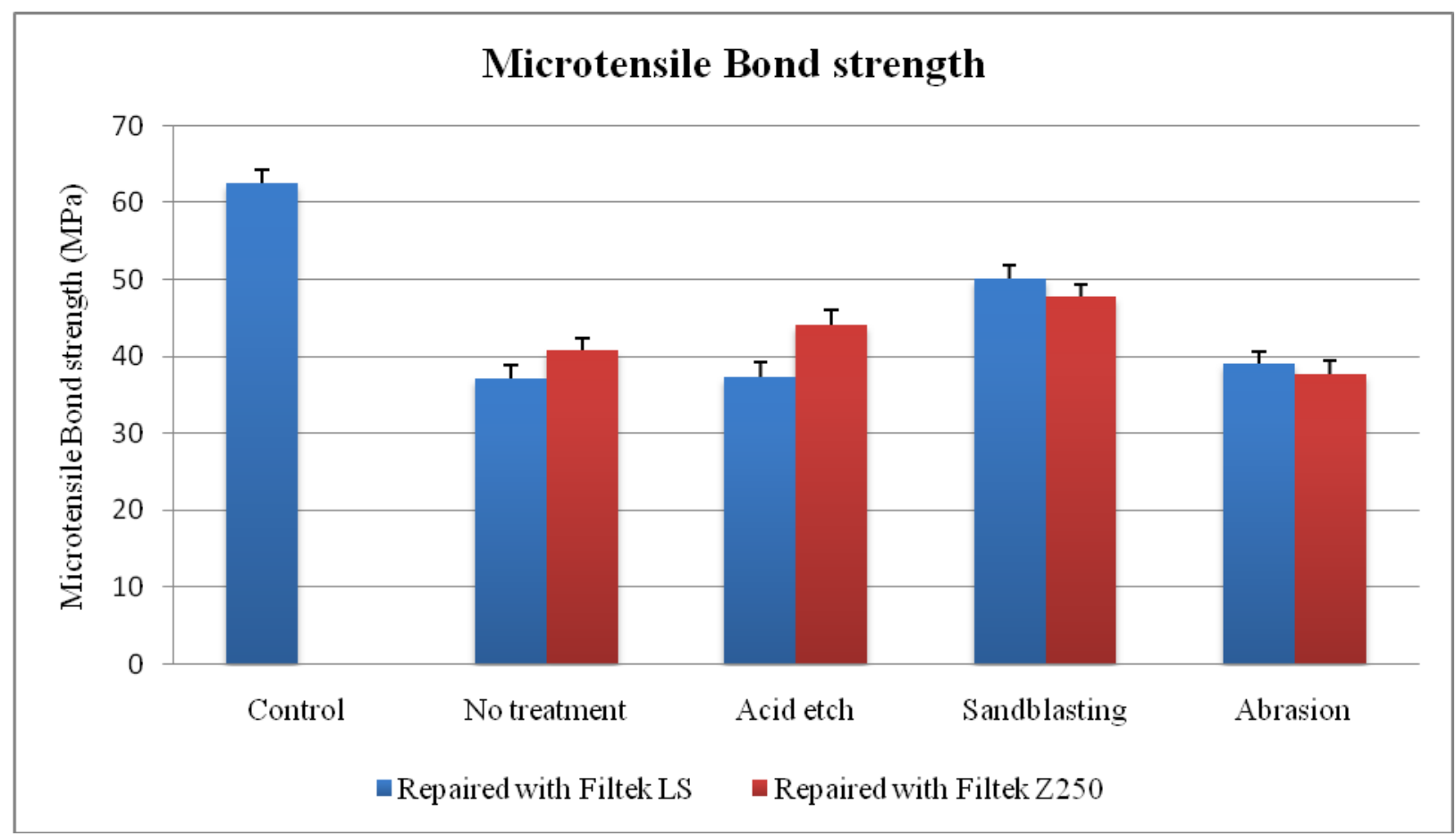


Figure 7: The survival probability of failure fitted by the Weibull model

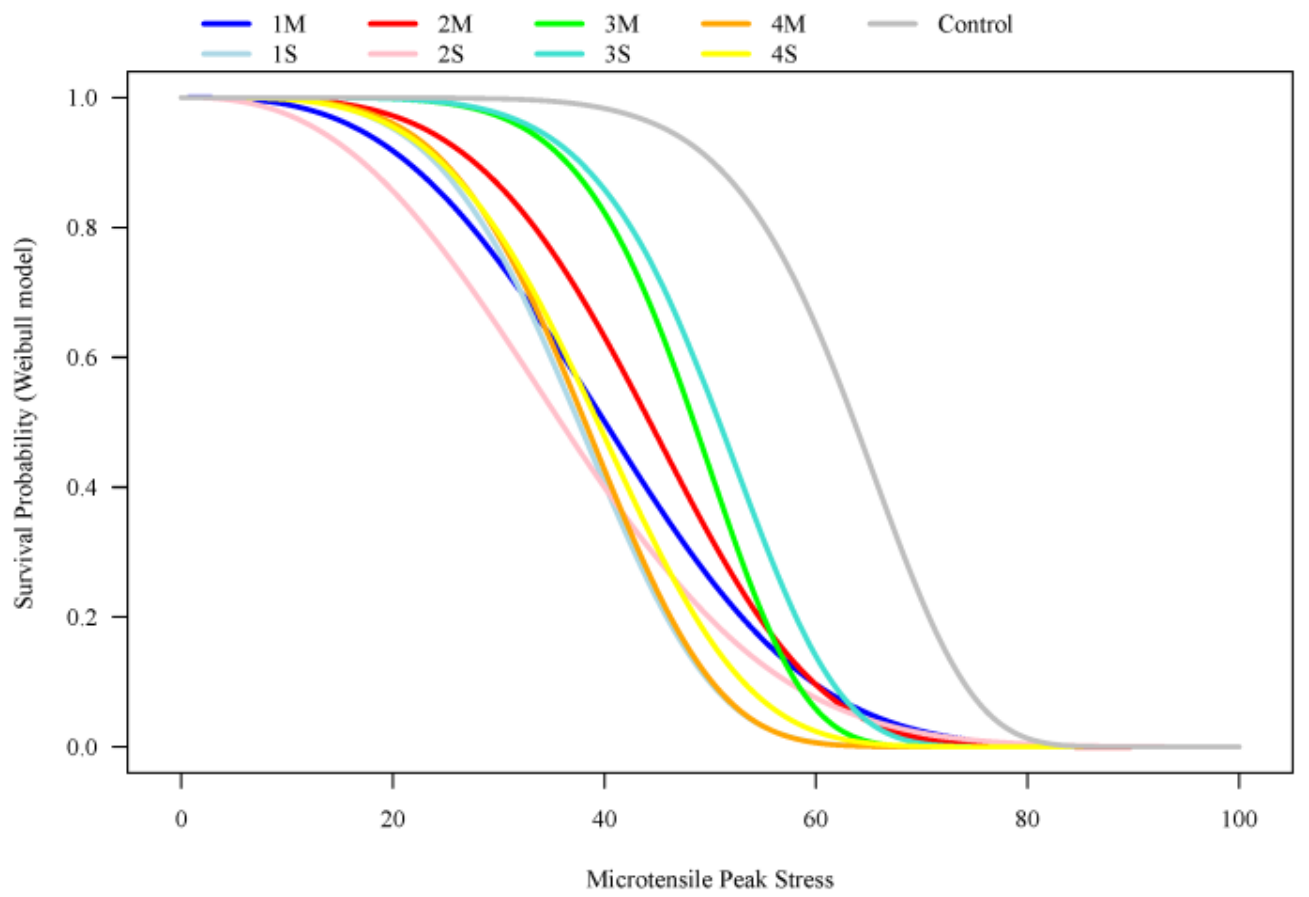


Figure 8: An intraoral air abrasion unit (Microetcher II, Danville Engineering INC., San Ramon, CA, USA)

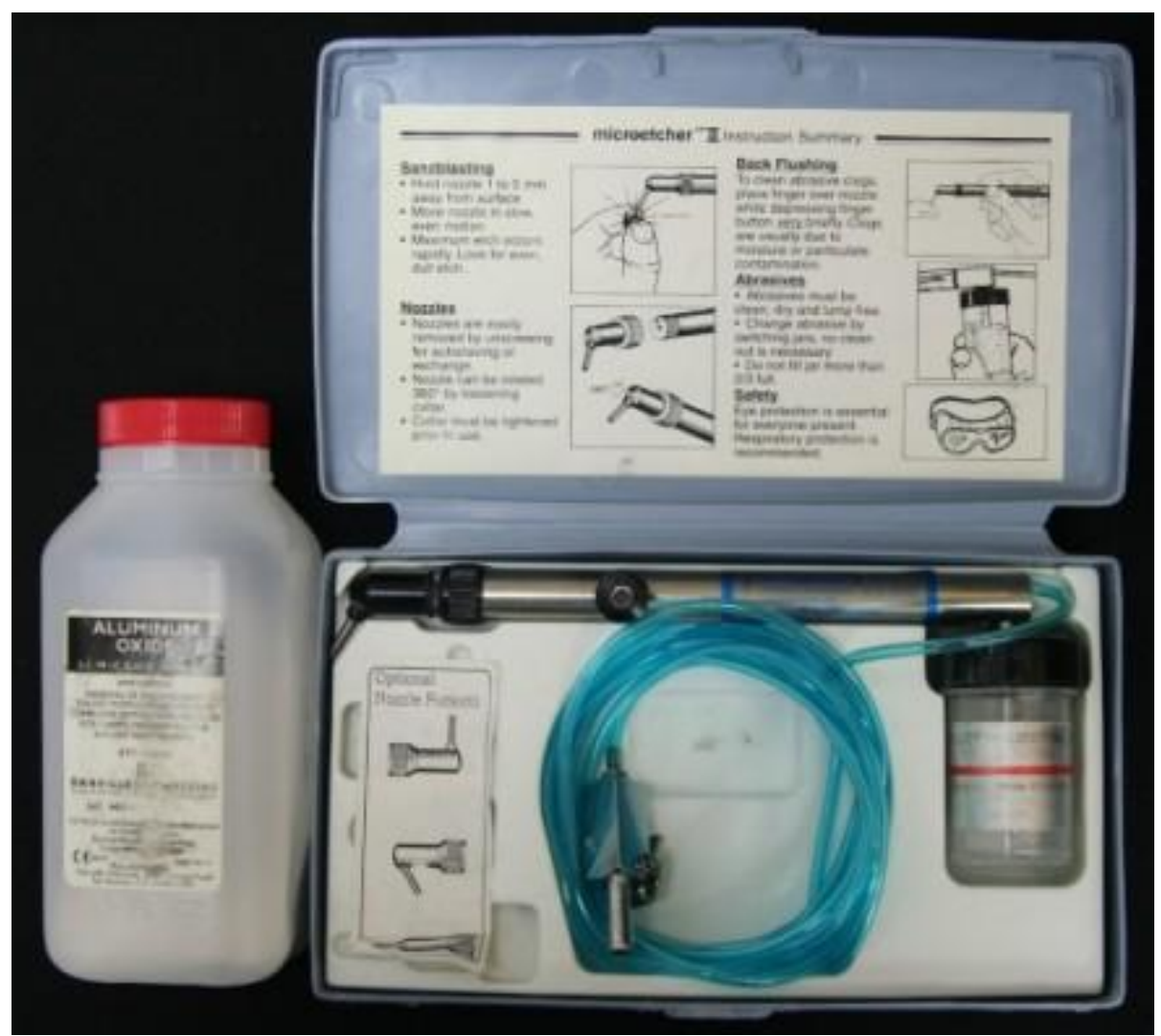


Figure 9: Low speed cutting machine (Isomet, Buehler, Lake Bluff, IL, USA)

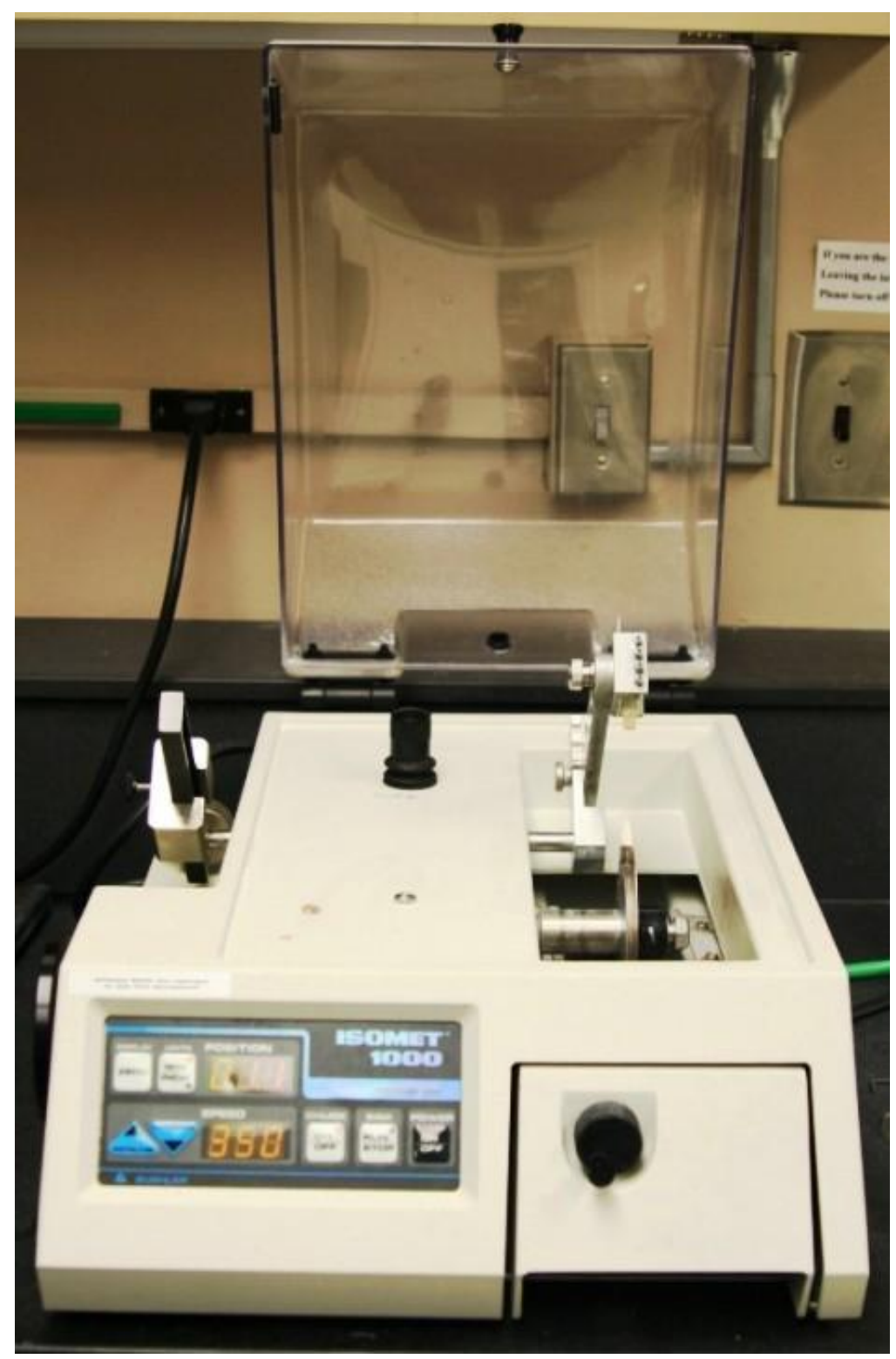


Figure 10: Resin composite beam before microtensile testing

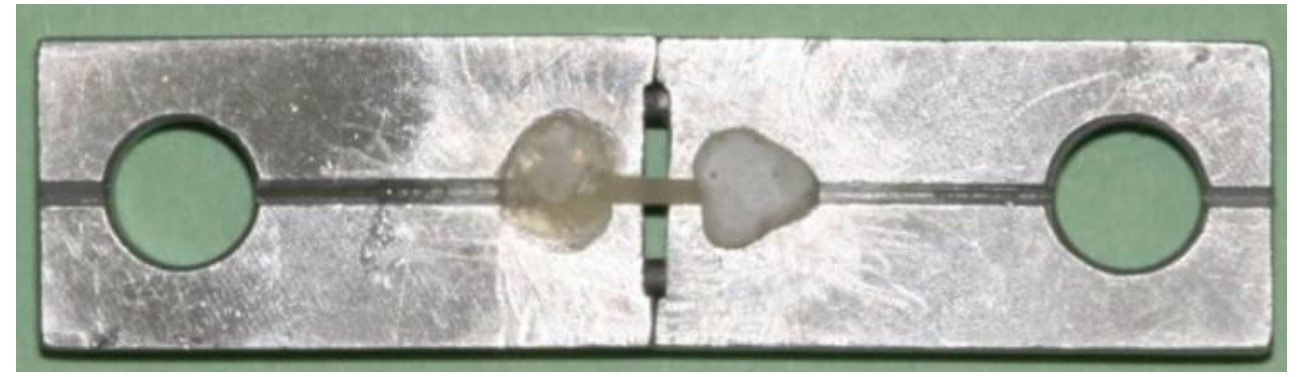

Figure 11: Fractured resin composite beam after microtensile testing

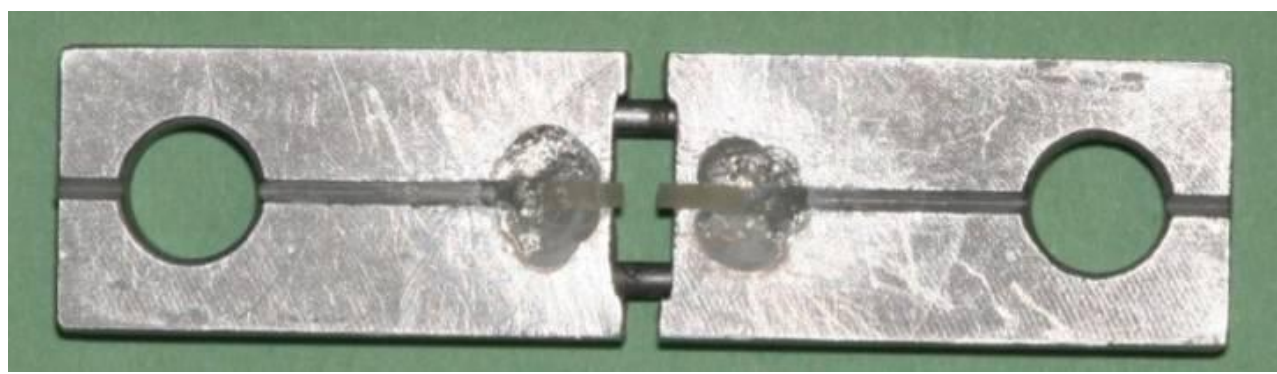


Figure 12: Mounted specimen on the Universal Testing Machine before testing (MTS Sintech Renew 1123, Eden Prairie, MN, USA).

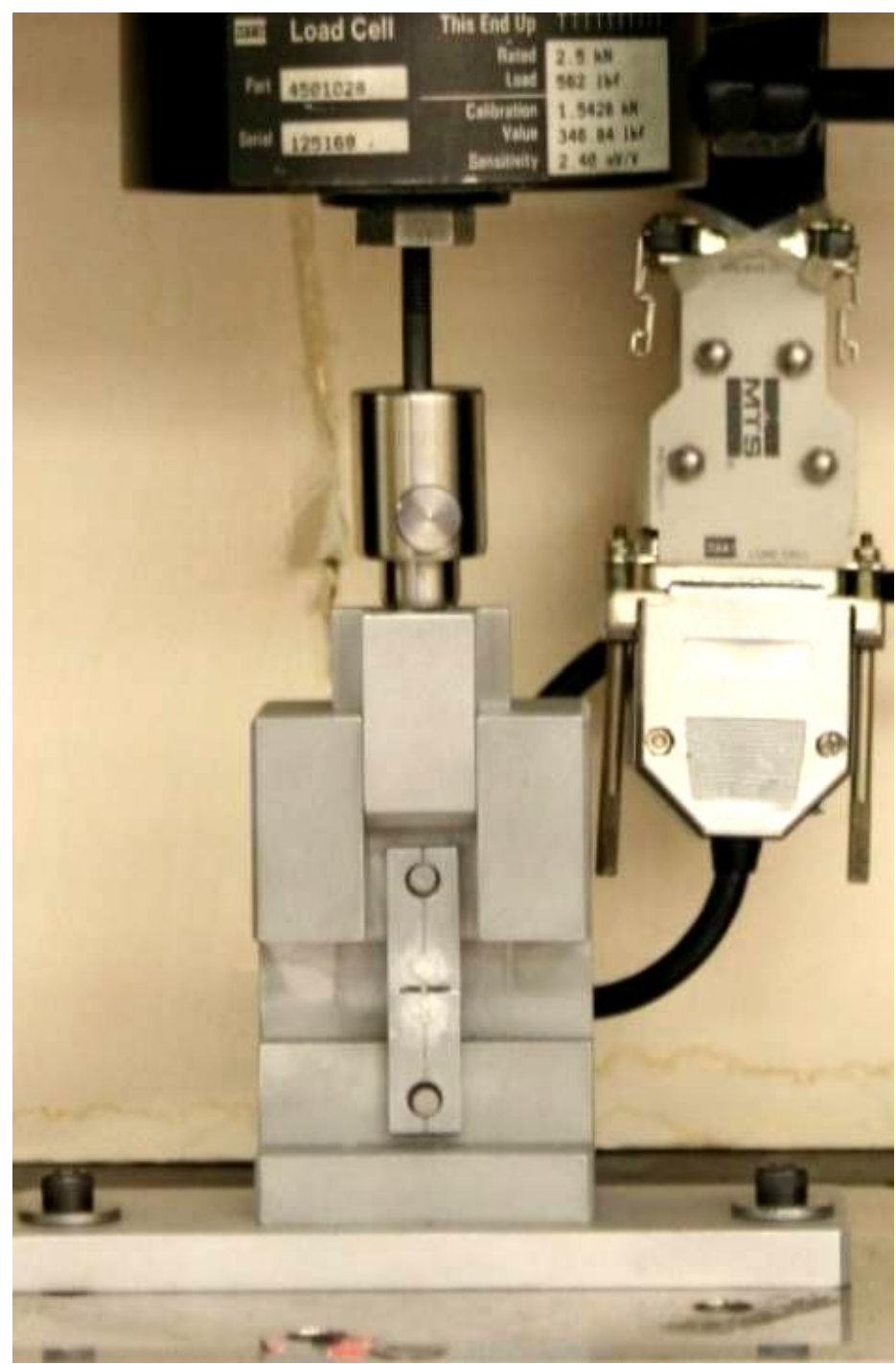


TABLES 
Table 1: Experimental groups

\begin{tabular}{|c|c|c|}
\hline Group & Surface Treatment & Bonding Procedure \\
\hline Control & - & LS adhesive bonding \\
\hline $\mathbf{1 S}$ & No surface treatment & Single Bond application \\
\hline $\mathbf{1 M}$ & No surface treatment & LS adhesive bonding \\
\hline $\mathbf{2 S}$ & LS System self etch primer & Single Bond application \\
\hline $\mathbf{2 M}$ & $35 \%$ Phosphoric acid etching & LS System self etch primer + LS adhesive bonding \\
\hline $\mathbf{3 S}$ & $\begin{array}{c}\text { Sandblasting with aluminum } \\
\text { oxide }\end{array}$ & 35\% Phosphoric acid + Single Bond application \\
\hline $\mathbf{3 M}$ & $\begin{array}{c}\text { Sandblasting with aluminum } \\
\text { oxide }\end{array}$ & LS System self etch primer + LS adhesive bonding \\
\hline $\mathbf{4 S}$ & Abrasion with Diamond bur & 35\% Phosphoric acid + Single Bond application \\
\hline $\mathbf{4 M}$ & Abrasion with Diamond bur & \\
\hline
\end{tabular}

Control $=$ Solid silorane resin composite blocks $($ Filtek LS)

$\mathbf{S}=$ The silorane resin composite (Filtek LS) blocks were repaired with silorane resin composite (Filtek LS)

$\mathbf{M}=$ The silorane resin composite (Filtek LS) blocks were repaired with methacrylate based resin composite (Filtek Z250) 
Table 2: Materials, batch number, type and general compositions

\begin{tabular}{|c|c|c|c|}
\hline Materials & Batch No. & Type & General composition \\
\hline $\begin{array}{c}\text { Filtek LS } \\
(3 \mathrm{M} \text { ESPE) }\end{array}$ & N18197 & Micro-hybrid & $\begin{array}{l}\text { Filler: Silanized quartz, yttrium fluoride } 76 \mathrm{wt} \% \\
\text { Resin matrix: 3,4-Epoxycyclohexylethyl- } \\
\text { cyclopolymethylsiloxane, } \\
\text { Bis-3,4-epoxycyclohexylethylphenylmethyl-silane }\end{array}$ \\
\hline $\begin{array}{l}\text { Filtek Z250 } \\
\text { (3M ESPE) }\end{array}$ & N163688 & Micro-hybrid & $\begin{array}{l}\text { Filler: Zirconia/silica } 85 \mathrm{wt} \% \\
\text { Resin matrix: Bis-GMA (bisphenol A diglycidyl } \\
\text { ether diemthacrylate) and a blend of UDMA } \\
\text { (urethane dimethacrylate) and Bis-EMA (bisphenol } \\
\text { A polyethylene glycol diether dimethacrylate) }\end{array}$ \\
\hline $\begin{array}{l}\text { LS System } \\
\text { adhesive } \\
\text { (3M ESPE) }\end{array}$ & N157377 & $\begin{array}{l}\text { Self-etch } \\
\text { Primer \& } \\
\text { bond }\end{array}$ & $\begin{array}{l}\text { Self etch primer: Phosphorylated methacrylates, } \\
\text { Vitrebond copolymer, Bis-GMA, HEMA (2- } \\
\text { hydroxyethyl methacrylate), water, ethanol, } \\
\text { camphorquinone and silane treated silica filler, } \\
\text { initiators, stabilizers } \\
\text { Bond: Hydrophobic methacrylate, phosphorylated } \\
\text { methacrylate, TEGDMA ( triethylene glycol } \\
\text { dimethacrylate), silane treated silica filler, initiators, } \\
\text { stabilizers, camphorquinone }\end{array}$ \\
\hline $\begin{array}{l}\text { Adper } \\
\text { Single Bond } \\
\text { Plus System } \\
\text { adhesive } \\
\text { (3M ESPE) }\end{array}$ & 393173 & $\begin{array}{l}\text { Total etch } \\
\& \text { bond }\end{array}$ & $\begin{array}{l}\text { Etchant: } 35 \% \text { phosphoric acid } \\
\text { Bond: Bis-GMA, HEMA, dimethacrylates, } \\
\text { ethanol, water, photoinitiator system, methacrylate } \\
\text { functional copolymer of polyacrylic and polyitaconic } \\
\text { acids, silica particles }\end{array}$ \\
\hline
\end{tabular}


Table 3: Mean, percent of cohesive strength and p-value of experimental groups

\begin{tabular}{|c|c|c|c|c|c|}
\hline \multirow{2}{*}{$\begin{array}{c}\text { Surface } \\
\text { treatment }\end{array}$} & Materials & Groups & Mean Bond & $\begin{array}{c}\text { Percent of } \\
\text { cohesive } \\
\text { strength }\end{array}$ & p-value \\
\hline \multirow{2}{*}{ Control } & & Control & $62.6 \pm 1.6$ & 100 & - \\
\hline \multirow{2}{*}{$\begin{array}{c}\text { No } \\
\text { treatment }\end{array}$} & Filtek Z250 & $1 \mathrm{M}$ & $40.8 \pm 1.9$ & 65.18 & $0.030^{*}$ \\
\cline { 2 - 6 } & Filtek LS & $2 \mathrm{~S}$ & $37.3 \pm 2.0$ & 59.58 & $0.008^{*}$ \\
\hline \multirow{2}{*}{\begin{tabular}{c} 
Acid etch \\
\cline { 2 - 6 } Sandblast
\end{tabular}} & Filtek Z250 & $2 \mathrm{M}$ & $44.1 \pm 1.8$ & 70.45 & 0.070 \\
\cline { 2 - 6 } & Filtek LS & $3 \mathrm{~S}$ & $50.2 \pm 1.6$ & 80.19 & 0.230 \\
\hline \multirow{2}{*}{ Abrasion } & Filtek Z250 & $3 \mathrm{M}$ & $47.8 \pm 1.5$ & 76.36 & 0.130 \\
\cline { 2 - 6 } & Filtek Z250 & $4 \mathrm{M}$ & $37.7 \pm 1.6$ & 60.22 & $0.007^{*}$ \\
\hline
\end{tabular}

*statistically significant difference $(P<0.05)$ when compared to the control

There was no other statistically significant difference among other groups. 
Table 4: Descriptive statistics of experimental groups

\begin{tabular}{|c|c|c|c|c|c|c|}
\hline \multirow{2}{*}{ Group } & \multicolumn{3}{|c|}{ Microtensile bond strength (MPa) } & \multicolumn{1}{c|}{$\begin{array}{c}\text { Weibull } \\
\text { Characteristic } \\
\text { Strength }\end{array}$} & $\begin{array}{c}\text { Weibull } \\
\text { Modulus }\end{array}$ \\
\cline { 2 - 6 } Control & 38.7 & 90.6 & 62.6 & 1.6 & 66.7 & 8.0 \\
\hline $\mathbf{1 S}$ & 13.1 & 66.8 & 37.2 & 1.6 & 41.0 & 4.2 \\
\hline $\mathbf{1 M}$ & 0.5 & 73.9 & 40.8 & 1.9 & 45.3 & 3.0 \\
\hline $\mathbf{2 S}$ & 3.8 & 73.1 & 37.3 & 2.0 & 41.5 & 2.6 \\
\hline $\mathbf{2 M}$ & 10.6 & 77.5 & 44.1 & 1.8 & 48.6 & 4.0 \\
\hline $\mathbf{3 S}$ & 18.0 & 90.0 & 50.2 & 1.6 & 54.0 & 6.3 \\
\hline $\mathbf{3 M}$ & 17.6 & 64.9 & 47.8 & 1.5 & 51.3 & 6.6 \\
\hline $\mathbf{4 S}$ & 11.9 & 64.3 & 39.0 & 1.7 & 43.2 & 4.0 \\
\hline $\mathbf{4 M}$ & 14.4 & 59.3 & 37.7 & 1.6 & 41.6 & 4.4 \\
\hline
\end{tabular}


Table 5: Statistical comparison of microtensile bond strength

\begin{tabular}{|c|c|}
\hline Comparison & p-value \\
\hline $1 \mathrm{M} \& 1 \mathrm{~S}$ & 0.58 \\
\hline $1 M \& 2 M$ & 0.69 \\
\hline $1 M \& 2 S$ & 0.63 \\
\hline $1 M \& 3 M$ & 0.48 \\
\hline $1 M \& 3 S$ & 0.33 \\
\hline $1 M \& 4 M$ & 0.63 \\
\hline $1 M \& 4 S$ & 0.79 \\
\hline $\mathbf{1 M}<$ Control & $0.030 *$ \\
\hline $1 S \& 2 M$ & 0.34 \\
\hline $1 S \& 2 S$ & 0.96 \\
\hline $1 S \& 3 M$ & 0.21 \\
\hline $1 S \& 3 S$ & 0.12 \\
\hline $1 S \& 4 M$ & 0.94 \\
\hline $1 S \& 4 S$ & 0.77 \\
\hline $1 \mathrm{~S}<$ Control & $0.006^{*}$ \\
\hline $2 M \& 2 S$ & 0.38 \\
\hline $2 M \& 3 M$ & 0.76 \\
\hline $2 M \& 3 S$ & 0.55 \\
\hline $2 M \& 4 M$ & 0.38 \\
\hline $2 M \& 4 S$ & 0.51 \\
\hline 2M \& Control & $0.07 *$ \\
\hline $2 S \& 3 M$ & 0.24 \\
\hline $2 S \& 3 S$ & 0.14 \\
\hline $2 S \& 4 M$ & 0.99 \\
\hline $2 S \& 4 S$ & 0.82 \\
\hline $2 \mathrm{~S}<$ Control & $0.008^{*}$ \\
\hline 3M \& 3S & 0.77 \\
\hline $3 M \& 4 M$ & 0.23 \\
\hline $3 M \& 4 S$ & 0.33 \\
\hline 3M \& Control & 0.13 \\
\hline $3 S \& 4 M$ & 0.14 \\
\hline $3 S \& 4 S$ & 0.21 \\
\hline 3S \& Control & 0.23 \\
\hline $4 M \& 4 S$ & 0.83 \\
\hline $4 \mathrm{M}<$ Control & $0.007 *$ \\
\hline $4 \mathrm{~S}<$ Control & $0.014 *$ \\
\hline
\end{tabular}

* statistically significant difference 
Table 6: The incidence of failure mode (N, \%)

\begin{tabular}{|c|c|c|c|c|}
\hline Group & Adhesive & Mixed & Cohesive & $\begin{array}{c}\text { Did not } \\
\text { break }\end{array}$ \\
\hline $\mathbf{1 S}$ & $94(87 \%)$ & & $14(13 \%)$ & \\
\hline $\mathbf{1 M}$ & $83(77 \%)$ & & $24(22 \%)$ & $1(1 \%)$ \\
\hline $\mathbf{2 S}$ & $86(80 \%)$ & $1(1 \%)$ & $21(19 \%)$ & \\
\hline $\mathbf{2 M}$ & $89(82 \%)$ & & $19(18 \%)$ & \\
\hline $\mathbf{3 S}$ & $78(72 \%)$ & $2(2 \%)$ & $26(24 \%)$ & $2(2 \%)$ \\
\hline $\mathbf{3 M}$ & $68(63 \%)$ & $1(1 \%)$ & $39(36 \%)$ & \\
\hline $\mathbf{4 S}$ & $102(94 \%)$ & & $6(6 \%)$ & \\
\hline $\mathbf{4 M}$ & $95(88 \%)$ & $6(6 \%)$ & $7(6) \%$ & \\
\hline Total & $695(81 \%)$ & $10(1 \%)$ & $156(18 \%)$ & $3(0 \%)$ \\
\hline
\end{tabular}


Table 7: Statistical comparison of type of failure

\begin{tabular}{|c|c|}
\hline Comparison & p-value \\
\hline $1 \mathrm{M} \& 1 \mathrm{~S}$ & 0.10 \\
\hline $1 M \& 2 M$ & 0.39 \\
\hline $1 M \& 2 S$ & 0.71 \\
\hline $1 M \& 3 M$ & 0.06 \\
\hline $1 M \& 3 S$ & 0.52 \\
\hline $1 M \& 4 M$ & 0.08 \\
\hline $1 M<4 S$ & $0.004 *$ \\
\hline $1 S \& 2 M$ & 0.33 \\
\hline $1 S \& 2 S$ & 0.20 \\
\hline $1 S>3 M$ & $0.001 *$ \\
\hline $1 S>3 S$ & $0.007^{*}$ \\
\hline $1 S \& 4 M$ & 0.84 \\
\hline $1 S \& 4 S$ & 0.09 \\
\hline $2 M \& 2 S$ & 0.65 \\
\hline $2 M>3 M$ & $0.001 *$ \\
\hline $2 M \& 3 S$ & 0.07 \\
\hline $2 M \& 4 M$ & 0.27 \\
\hline $2 \mathrm{M}<4 \mathrm{~S}$ & $0.015^{*}$ \\
\hline $2 S>3 M$ & $0.018 *$ \\
\hline $2 S \& 3 S$ & 0.28 \\
\hline $2 S \& 4 M$ & 0.16 \\
\hline $2 S<4 S$ & $0.009 *$ \\
\hline $3 M \& 3 S$ & 0.11 \\
\hline $3 M<4 M$ & $0.001 *$ \\
\hline $3 \mathrm{M}<4 \mathrm{~S}$ & $0.001 *$ \\
\hline $3 S<4 M$ & $0.006 *$ \\
\hline $3 S<4 S$ & $0.001 *$ \\
\hline $4 M \& 4 S$ & 0.13 \\
\hline
\end{tabular}

* statistically significant difference 
DISCUSSION 
The objective of this study was to compare the repaired microtensile bond strength of aged silorane resin composite using different surface treatments and either silorane or methacrylate based resin composite.

Microtensile bond strength testing was suggested by Sano et al. ${ }^{36}$ They found that there was an inverse relationship between tensile bond strength and bonded surface area. Smaller bonded surface area is associated with higher tensile bond strength which is adhesive failure in nature ${ }^{30}$, whereas larger bonded surface area showed lower tensile bond strength because of the presence of more defects/stress raisers at the interface or substrate in the larger specimens. Moreover, microtensile bond strength testing often results in higher bond strengths at failure than are found using larger specimens such as shear or tensile bond strength testing. Microtensile bond strength was chosen in the present study because the purpose of this experiment was to compare the repair bond strength which is at the interface between aged and a new repair resin composite. The bond strength values from microtensile bond strength testing are normally from adhesive failure, so the bond strength value will be the adhesive bond strength instead of cohesive strength from cohesive failure. In the present study, the microscopic study showed most failures resulted from adhesive failures. As approximately $81 \%$ of bond strength values were resulted from adhesive failure, it can be assumed that the bond strength values would be representing adhesive bond strength rather than cohesive bond strength. A concern was raised regarding internal flaws and microcracks within specimen beams. The serial cuts in order to obtain beams for testing might create internal flaws within the beams. ${ }^{37}$ In this study, the speed of the diamond saw was constant. In this way, the same internal flaws within the beams were created. 
At present, clinically sufficient repair bond strength is not known. Several studies have shown that the surface treatments of aged resin composite significantly affected the bond strength of newly repaired resin composite. Generally, the microtensile bond strength of resin composite to dentin ranges between 25.8-48.0 MPa. ${ }^{38,39}$ For enamel bonding, the microtensile bond strength of resin composite normally ranges between 33.8-55.6 $\mathrm{MPa} .{ }^{40}$ It is well known that resin composite seldom fails mechanically at the junction with etched enamel. Therefore, it can be surmised that a repair bond strength which is similar to that of resin composite to etched enamel would be clinically adequate. $^{41}$

\section{Surface treatment}

In the present study, silorane resin composite was repaired with either silorane resin composite or methacrylate based resin composite because in a clinical situation the clinician may have no information about the chemical composition of the existing resin composite. Repairing existing silorane restoration is critical because there is limited information regarding repair protocol of silorane resin composite.

In this study, microtensile bond strength of repaired aged silorane resin composite without any surface treatment (group 1S, 1M) was significantly lower than the cohesive strength of silorane resin composite (control group) indicating a weak repair bond strength. This might be because of the lack of surface irregularities from surface treatments. This result is in accordance with Luhrs et al's study. ${ }^{42}$ In their study, microtensile bond strength of aged silorane resin composite when repaired with the same material using only bonding was significantly lower than those from the solid specimens (control). 
A question arises in this study because the microtensile bond strength in the no surface treatment group (group 1M, 1S) was approximately the same as or even higher than the repair bond strength in abrasion with diamond bur group (no significant difference). This might be because of the following possible reasons.

Other than micromechanical retention, the chemical bonding on aged silorane resin composite to either silorane or methacrylate based resin composite is still unknown. But both mechanical and chemical bonding might be considered. First, polishing the top surface of the resin composite blocks with sandpapers infused with aluminum oxide particles prior to aging procedure might create surface roughness for further bonding. Furthermore, micromechanical retention might also come from penetration of the unfilled resin into the microdefect in the aged resin composite as described by Padipatvuthikul and Mair. ${ }^{25}$ Second, unreacted sites and the use of adhesive bonding might be considered. The solvent in both the silorane and methacrylate adhesive bonding might cause swelling and gelation of the surface layer ${ }^{25}$ allowing the monomer in the layer of the repair filling access to the unreacted functional group of the silorane. Third, this might be from an insufficient aging process. The cycles may not have been sufficient to create hydrolytic degradation on the resin composite surface so that the repair bond strength might have come from the remaining reactivity of the material.

In the acid treatment group, when compared to the control group, the use of 35\% phosphoric acid presented marginally significant lower microtensile bond strength when the silorane resin composite was repaired with the methacrylate based resin composite (group 2M). In addition, for the group $2 \mathrm{~S}$, etching the aged silorane resin composite with the self etching primer in the LS 
system adhesive produced significantly lower microtensile bond strength than the cohesive strength of silorane resin composite (control). The results of the present study agree with Luhrs et al's study. ${ }^{42}$ In their study, silorane resin composite (Filtek Silorane) was repaired with different surface treatment protocols. It was found that the use of only silorane bonding (group $1 \mathrm{~S}$ in this study) and the use of silorane self etch primer and bonding (group $2 \mathrm{~S}$ in this study) showed significantly lower microtensile bond strength compared to the solid silorane specimens (control). And also, there was no difference between the use of only silorane bonding (group 1S in this study) and the use of silorane self etch primer and bonding (group $2 \mathrm{~S}$ in this study). Therefore, the microtensile bond strength of the repaired specimens did not benefit from the additional use of silorane self etching primer.

This is in accordance with other studies ${ }^{15,16,21,43,44}$ because etching the aged resin composite surface with $37 \%$ phosphoric acid or self etch primer showed virtually no increase in repair bond strength compared to no surface treatment. Cavalcanti et $\mathrm{al}^{43}$ reported that $35 \%$ phosphoric acid and self etch primer used to treat the aged resin composite surface demonstrated no significant influence on the repair bond strength. Thus, in their study ${ }^{43}$, the microtensile bond strength was significantly lower than ultimate tensile strength of resin composite. Similarly, another study ${ }^{44}$ showed no increase in repair bond strength when the resin composite was prepared with $37 \%$ phosphoric acid.

According to Duarte et $\mathrm{al}^{45}$, etching dentin with phosphoric acid before the application of LS system self etch adhesive (primer and bonding) showed an increase of mean microtensile bond strength values compared to those of the silorane adhesive applied according to the 
manufacturer's instruction. Therefore, it may require additional phosphoric acid cleaning prior to application of LS self etch adhesive in order to increase the repair bond strength of aged silorane resin composite. But the literature has contradictory information regarding the surface treatment with acid etching because surface treatment with phosphoric acid is normally unable to increase repair bond strength of aged resin composite regardless of the use of an additional phosphoric acid cleaning step. In addition, Cavalcanti et $\mathrm{al}^{43}$ stated that the additional phosphoric acid cleaning seems to be an irrelevant procedure when self etching systems are used for resin composite repair because they found that the phosphoric acid cleaning procedure prior to the use of self etching system showed no significant influence on repair bond strength.

In the sandblasting with aluminum oxide particles group, the results of this study indicated that surface treatment using sandblasting with aluminum oxide particles is an effective surface treatment procedure for the repair of resin composite restorations. Either silorane resin composite specimens repaired with silorane resin composite (group 3S) or repaired with methacrylate based resin composite (group 3M) showed no significant difference in microtensile bond strength compared to the cohesive strength of silorane resin composite (control). This result indicates that surface treatment with aluminum oxide particles provides comparable microtensile bond strength to the solid silorane specimens. Air abrasion with aluminum oxide particles is the surface treatment that causes microretentive features. ${ }^{43}$ Although this study did not used scanning electron microscopy (SEM) to examine the surface topography, some authors have reported this information confirming high surface roughness with aluminum oxide sandblasting. ${ }^{26,34}$ Costa et $\mathrm{al}^{34}$ found that aluminum oxide sandblasting produced the significantly highest surface roughness compared to no surface treatment and roughening with a diamond bur. And this might 
be the reason why aluminum oxide sandblasting produced the highest repair bond strength compared to other groups. Furthermore, a more irregular surface topography was achieved using aluminum oxide sandblasting in comparison with abrasion with a diamond bur producing a more effective pattern for mechanical retention and resulting in greater microtensile bond strength values. $^{16}$

Ozcan et $\mathrm{al}^{30}$ stated that surface treatment using sandblasting with aluminum oxide particles presented the highest repair bond strength. They also proposed that this is because aluminum oxide sandblasting provides microretention on the aged resin composite surface. Deposition of the particles increases the ability of the new resin composite to mechanically interlock due to the increase in surface area. In addition, these retentive features favor the surface wettability of the resin composite allowing for optimal adaptation.

In the abrasion group, the use of a diamond bur on the aged silorane resin composite showed significantly weaker in repair bond strength than the cohesive strength of silorane resin composite (control group) regardless of the use of either silorane resin composite (group 4S) or methacrylate based resin composite (group 4M). The effect of surface abrasion with a diamond bur on the repair bond strength of aged resin composite is debated due to some studies not showing significantly improved repair bond strength while others did. Thus, this technique provides a less predictable outcome compared to sandblasting with aluminum oxide particles.

Lloyd et al ${ }^{46}$ found no difference between the repair bond strength of five chemically cured resin composites when the surface was ground or when it was not. Moreover, some authors have 
reported the reduction in repair bond strength after surface abrasion with a diamond bur. They proposed this reduction of bond strength due to the exposure of filler particles following surface abrasion and consequently decreased availability for primary bonding to the resin composite. Other possibilities are debris interference with the repair potential and the inclusion of air at the interface reducing the surface area available for bonding. ${ }^{41}$

In contrast, some studies have shown that surface abrasion with a diamond bur significantly improved the repair bond strength of resin composite specimens. This might be because of an increase in the surface area for micromechanical retention following abrasion. Crumpler et $\mathrm{al}^{47}$ concluded that surface roughness enhances the ability of new resin composite to mechanically interlock with the aged resin composite as an increased surface area available for bonding. Furthermore, Shahdad et $\mathrm{al}^{41}$ concluded that surface abrasion of a fractured resin composite surface produced a significant increase in repair bond strength.

\section{Repair materials}

Even though this study did not try to bond silorane resin composite using methacrylate based dentin adhesive (Adper ${ }^{\mathrm{TM}}$ Single Bond Plus System adhesive), Duarte et $\mathrm{al}^{45}$ found that there was no adhesion of Filtek LS applied directly over dentin surface treated with Adper ${ }^{\mathrm{TM}}$ Single Bond Plus. They reported that the total etch methacrylate based dentin adhesive was not able to produce sufficient bond strength to hold silorane resin composite on the dentin. Most of specimens spontaneously debonded after 24 hours and all remaining restorations debonded after water storage or thermocycling. 
In the present study, surface of aged silorane resin composite was prepared and restored with either silorane resin composite with LS system self etch adhesive or methacrylate based resin composite with Adper ${ }^{\mathrm{TM}}$ Single Bond Plus system adhesive. No spontaneous debonding was found. The repair microtensile bond strength (37.2-50.2 MPa) was in the same range as the bond strength of resin composite to enamel (33.8-55.6 $\left.\mathrm{MPa}^{40}\right)$. Moreover, the repair microtensile bond strength in group $3 \mathrm{M}$ and group $3 \mathrm{~S}$ was comparable to the cohesive strength of silorane resin composite $(80.19 \%$ and $76.36 \%$ of cohesive strength respectively). This might indicate that when the surface of silorane resin composite is prepared with aluminum oxide sandblasting, it can be repaired with either silorane resin composite with the LS system self etch adhesive or methacrylate based resin composite using a methacrylate based dentin adhesive.

A recent study ${ }^{26}$ showed that it is possible to bond methacrylate based resin composite to the silorane resin composite using a phosphate methacrylate intermediate resin (Silorane System Adhesive Bond) which was not performed in this study. In their study, they found an increase in shear bond strength between silorane resin composite (Filtek LS) and methacrylate based resin composite (Filtek Z250) using phosphate dimethacrylate based intermediate resin compared to the use of a dimethacrylate based intermediate resin (Adper Scotchbond Multipurpose Adhesive). Phosphate dimethacrylate based intermediate resin is based on methacrylate chemistry with phosphate group. The possible reaction of the phosphate group with oxirane and the acrylate group with dimethacrylate might be the reason. Although, this study did not use phosphate dimethacrylate intermediate with methacrylate based resin composite, their study is still unclear because silorane resin composite was a fresh bonding (no aging condition) so that 
greater reactivity of the material need to be taken into consideration. Further research on repairing aged silorane with phosphate dimethacrylate should be done.

It was interesting to see quite different results from the two subgroups that were etched prior to bonding. When repaired with Filtek Z250, the acid etch with 35\% phosphoric acid was able to produce the microtensile bond strength values that were not significantly different from the cohesive strength values of the silorane resin composite. For the subgroup that was etched with LS self etch primer and repaired with Filtek LS, the repaired microtensile bond strength was significantly lower than that of the cohesive strength of the material. Results from subgroups $1 \mathrm{M}$ and $1 \mathrm{~S}$ were interesting as well. Group $1 \mathrm{M}$ seemed to produce better microtensile bond strength than group $1 \mathrm{~S}$, even though values were not significantly different. Group $1 \mathrm{M}$ also resulted in higher numbers of cohesive failures, which suggested higher success in bonding of the two materials at their interfaces. From these results, methacrylate based resin composite seemed to be a better choice of repair material in the situation that the air abrasion unit was unavailable. Although the bonding between methacrylate based resin composite to the aged silorane resin composite without surface treatment mechanically is unknown, the chemical bonding was likely responsible for this increase in microtensile bond strength between the methacrylate base resin composite to the aged silorane resin composite (group no surface treatment and acid treatment).

\section{Failure mode}

In this study, $81 \%$ of repaired specimens failed adhesively, $18 \%$ failed cohesively and $1 \%$ failed mixedly. For the majority of failures, therefore, the weak link was the adhesive interface. Moreover, groups that presented with approximately equal microtensile bond strength did not 
always fail in the same manner such as groups $1 \mathrm{M}$ and $4 \mathrm{~S}$. The microtensile bond strength of group $1 \mathrm{M}$ and $4 \mathrm{~S}$ was $40.8 \mathrm{MPa}$ and $39.0 \mathrm{MPa}$, respectively. Although, both group $1 \mathrm{M}$ and $4 \mathrm{~S}$ presented closely similar repair bond strength, group 4S showed significantly higher adhesive failures than those of group 1M. Furthermore, in the groups that presented the highest microtensile bond strengths (group 3M, 3S) showed more cohesive failures than other groups.

The different results between subgroups within the same group ( $2 \mathrm{~S}$ and $2 \mathrm{M})$ suggested strongly that not only micromechanical retention was responsible for the repair. The chemical bonding was another factor that could not be overlooked, since it was capable of producing significantly different repair microtensile bond strength values. With either abrasion with a diamond bur or abrasion with air abrasion unit with aluminum oxide particles, silorane resin composite seemed to work better. Without any surface treatment mechanically, the chemical bonding between the methacrylate based resin composite and aged silorane resin composite produced better results than using its own type as a repair material. The chemical reaction between the methacrylate based resin composite to the aged silorane resin composite must be further explored to explain these results.

For the further research, determining the surface roughness of each surface treatment using SEM analysis or profilometry, using an intermediate agent such as a silane containing agent, using a phosphate dimethacrylate intermediate layer and clarifying the chemical bonding mechanism between silorane resin composite to either silorane or methacrylate based resin composite would give more information regarding the repair protocol for aged silorane resin composite. 
SUMMARY AND CONCLUSIONS 
The purpose of this study was to compare the repaired microtensile bond strength of aged silorane resin composite using different surface treatments and either silorane or methacrylate based resin composite. Silorane resin composite blocks (Filtek LS) were fabricated and aged by thermocycling between $8^{\circ} \mathrm{C}$ and $48^{\circ} \mathrm{C}$ (5000 cycles). A control (solid resin composite) and four surface treatment groups (no treatment, acid treatment, aluminum oxide sandblasting and diamond bur abrasion) were tested. Each treatment group was randomly divided in half and repaired with either silorane resin composite (LS adhesive) or methacrylate based resin composite (Filtek Z250/Single Bond Plus). After 24 hours in $37^{\circ} \mathrm{C}$ distilled water, microtensile bond strength testing was performed using a non-trimming technique. Fracture surfaces were examined using an optical microscope (20X) to determine failure mode.

Weibull-distribution survival analysis revealed that aluminum oxide sandblasting followed by silorane or methacrylate based resin composite and acid treatment with methacrylate based resin composite provided insignificant differences from the control $(\mathrm{p}>0.05)$. All other groups were significantly lower than the control. Failure was primarily adhesive in all groups. In general, aluminum oxide sandblasting produces the most desirable repair bond strength of aged resin composite. The result of this study agrees with the above statement regardless of whether the silorane or methacrylate based resin composite used. The conclusions that can be drawn from this study are:

1. Surface treatment on aged silorane resin composite using air abrasion with aluminum oxide particles resulted in microtensile bond strength values that were slightly lower, but were not significantly different from those resulted from cohesive strength of the silorane resin composite. 
2. After treating the resin composite surface with aluminum oxide sandblasting, aged silorane resin composite can be repaired with either silorane resin composite with LS system adhesive or methacrylate based resin composite with methacrylate based dentin adhesive. 
REFERENCES 
1. Davision CL. Feilzer AJ. Polymerization shrinkage and polymerization stress in polymerbased restoratives. J Dent. 1997 Nov;25(6):435-40.

2. Weinmann W, Thalacker C, Guggenberger R. Siloranes in dental composites. Dent Mater. 2005 Jan;21(1):68-74.

3. Labella R, Lambrechts P, Van Meerbeek B, Vanherle G. Polymerization shrinkage and elasticity of flowable composites and filled adhesives. Dent Mater. 1999 Mar;15(2):128-37.

4. Lien W, Vandewalle KS. Physical properties of a new silorane-based restorative system. Dent Mater. 2010 Apr;26(4):337-44. Epub 2010 Jan 6.

5. Gordan VV, Shen C, Riley J 3rd, Mjör IA. Two-year clinical evaluation of repair versus replacement of composite restorations. J Esthet Restor Dent. 2006;18(3):144-53; discussion 154

6. Ilie N, Hickel R. Macro-, micro- and nano-mechanical investigations on silorane and methacrylate-based composites. Dent Mater. 2009 Jun;25(6):810-9.

7. Guggenberger R, Weinmann W. Exploring beyond methacrylates. Am J Dent 2000; 13(SI):82-4.

8. Kleverlaan CJ, Feilzer AJ. Polymerization shrinkage and contraction stress of dental resin composites. Dent Mater. 2005 Dec;21(12):1150-7. Epub 2005 Jul 22

9. Mjör IA, Gordan VV. Failure, repair, refurbishing and longevity of restorations. Oper Dent. 2002 Sep-Oct;27(5):528-34.

10. Gordan VV. Clinical evaluation of replacement of class V resin based composite restorations. J Dent. 2001 Sep;29(7):485-8.

11. Gordan VV. In vitro evaluation of margins of replaced resin-based composite restorations. J Esthet Dent. 2000;12(4):209-15.

12. Buonocore MG. A simple method of increasing the adhesion of acrylic filling materials to enamel surfaces. J Dent Res 1955;34(6):849-53.

13. Schneider LF, Cavalcante LM, Silikas N. Shrinkage Stresses Generated during ResinComposite Applications. J Dent Biomech. 2010;2010. pii: 131630. Epub 2009 Sep 30. 
14. Suliman AH, Boyer DB, Lakes RS. Polymerization shrinkage of composite resins: comparison with tooth deformation, J Prosthet Dent 71 (1994), pp. 7-12.

15. Teixeira EC, Bayne SC, Thompson JY, Ritter AV, Swift EJ. Shear bond strength of selfetching bonding systems in combination with various composites used for repairing aged composites J Adhes Dent. 2005 Summer;7(2):159-64.

16. Junior SA, Ferracane JL, Della Bona A. Influence of surface treatments on the bond strength of repaired resin composite restorative materials. Dent Mater. 2009 Apr;25(4):442-51.

17. http://multimedia.3m.com/mws/mediawebserver?mwsId=SSSSSu7zK1fslxtUNY_9M8_Sev7 qe17zHvTSevTSeSSSSSS--

18. Powers JM, Sakaguchi RL. Craig's Restorative Dental Materials. 12 ed. St. Louis Mosby Elsevier; 2006.

19. Summitt, JB. Fundamentals of operative dentistry: a contemporary approach. 3 ed. Chicago, Quintessence Pub., 2006

20. Mjör IA. The reasons for replacement and the age of failed restorations in general dental practice. Acta Odontol Scand. 1997 Jan;55(1):58-63.

21. Papacchini F, Dall'Oca S, Chieffi N, Goracci C, Sadek FT, Suh BI, Tay FR, Ferrari M. Composite-to-composite microtensile bond strength in the repair of a microfilled hybrid resin: effect of surface treatment and oxygen inhibition. J Adhes Dent. 2007 Feb;9(1):25-31.

22. Maneenut C, Sakoolnamarka R, Tyas MJ. The repair potential of resin composite materials. Dent Mater. 2010 Oct 8. [Epub ahead of print]

23. Yesilyurt C, Kusgoz A, Bayram M, Ulker M. Initial repair bond strength of a nano-filled hybrid resin: effect of surface treatments and bonding agents. J Esthet Restor Dent 2009;21:251-60.

24. Frankenberger R, Kramer N, Ebert J, Lohbauer U, Kappel S, ten Weges S, et al. Fatigue behavior of the resin-resin bond of partially replaced resin-based composite restorations. Am J Dent 2003;16:17-22.

25. Padipatvuthikul P, Mair LH. Bonding of composite to water aged composite with surface treatments. Dent Mater. 2007 Apr;23(4):519-25. Epub 2006 Jun 9. 
26. Tezvergil-Mutluay A, Lassila LV, Vallittu PK. Incremental layers bonding of silorane composite: the initial bonding properties. J Dent. 2008 Jul;36(7):560-3.

27. Shawkat ES, Shortall AC, Addison O, Palin WM. Oxygen inhibition and incremental layer bond strengths of resin composites. Dent Mater. 2009 Nov;25(11):1338-46.

28. Hannig C, Sebastian L, Hahn P, Attin T. Shear bond strength of repaired adhesive filling materials using different repairprocedures. J Adhes Dent 2006;8:35-40.

29. Brosh T, Bichacho N, Blutstein R. Effect of combinations of surface treatments and bonding agents on the bond strength of repaired composites. J Prosthet Dent 1997;77:122-6.

30. Ozcan M, Barbosa SH, Melo RM, Galhano GA, Bottino MA. Effect of surface conditioning methods on the microtensile bond strength of resin composite to composite after aging conditions. Dent Mater. 2007 Oct;23(10):1276-82.

31. Trajtenberg CP, Powers JM. Bond strengths of repaired laboratory composites using three surface treatments and three primers. Am J Dent. 2004 Apr;17(2):123-6.

32. Trajtenberg CP, Powers JM. Effect of hydrofluoric acid on repair bond strength of a laboratory composite. Am J Dent. 2004 Jun;17(3):173-6.

33. http://www.kerrdental.com/index/kerrdental-smallequipment-demetron-lc-2

34. Costa TR, Ferreira SQ, Klein-Júnior CA, Loguercio AD, Reis A. Durability of surface treatments and intermediate agents used for repair of a polished composite. Oper Dent. 2010 Mar-Apr;35(2):231-7

35. Eckert GJ, Platt JA. A statistical evaluation of microtensile bond strength methodology for dental adhesives. Dent Mater. 2007 Mar;23(3):385-91.

36. Sano H, Shono T, Sonoda H, Takatsu T, Ciucchi B, Carvalho R, Pashley DH. Relationship between surface area for adhesion and tensile bond strength-evaluation of a micro-tensile bond test. Dent Mater. 1994 Jul;10(4):236-40.

37. Sadek FT, Goracci C, Cardoso PE, Tay FR, Ferrari M. Microtensile bond strength of current dentin adhesives measured immediately and 24 hours after application. J Adhes Dent. 2005;7(4):297-302.

38. Scherrer SS, Cesar PF, Swain MV. Direct comparison of the bond strength results of the different test methods: a critical literature review. Dent Mater. 2010 Feb;26(2):e78-93. 
39. Inoue S, Vargas MA, Abe Y, Yoshida Y, Lambrechts P, Vanherle G, Sano H, Van Meerbeek B. Microtensile bond strength of eleven contemporary adhesives to dentin. J Adhes Dent. 2001;3(3):237-45.

40. Brackett WW, Tay FR, Looney SW, Ito S, Haisch LD, Pashley DH. Microtensile dentin and enamel bond strengths of recent self-etching resins. Oper Dent. 2008 Jan-Feb;33(1):89-95.

41. Shahdad SA, Kennedy JG. Bond strength of repaired anterior composite resins: an in vitro study. J Dent. 1998 Nov;26(8):685-94.

42. Lührs AK, Görmann B, Jacker-Guhr S, Geurtsen W. Repairability of dental siloranes in vitro. Dent Mater. 2010 Nov 1.

43. Cavalcanti AN, De Lima AF, Peris AR, Mitsui FH, Marchi GM. Effect of surface treatments and bonding agents on the bond strength of repaired composites. J Esthet Restor Dent. 2007;19(2):90-8

44. Fawzy AS, El-Askary FS, Amer MA. Effect of surface treatments on the tensile bond strength of repaired water-aged anterior restorative micro-fine hybrid resin composite. J Dent. 2008 Dec;36(12):969-76.

45. Duarte S Jr, Phark JH, Varjão FM, Sadan A. Nanoleakage, ultramorphological characteristics, and microtensile bond strengths of a new low-shrinkage composite to dentin after artificial aging. Dent Mater. 2009 May;25(5):589-600.

46. Lloyd CH, Baigrie DA, Jeffrey IW. The tensile strength of composite repairsJ Dent. 1980 Jun;8(2):171-7.

47. Crumpler DC, Bayne SC, Sockwell S, Brunson D, Roberson TM. Bonding to resurfaced posterior composites. Dent Mater. 1989 Nov;5(6):417-24.

48. Bonstein T, Garlapo D, Donarummo J Jr, Bush PJ. Evaluation of varied repair protocols applied to aged composite resin. J Adhes Dent. 2005;7(1):41-9. 
APPENDICES 
Table 1: Data from control group: Solid silorane resin composite

\begin{tabular}{|c|c|c|c|c|c|}
\hline Block & Beam & Peak Load & Peak Stress & Strain & Modulus \\
\hline 1 & 1 & 44.110 & 68.9 & 0.002 & 42888.474 \\
\hline 1 & 2 & 33.051 & 51.6 & 0.001 & 45665.262 \\
\hline 1 & 3 & 36.371 & 56.8 & 0.001 & 47166.405 \\
\hline 1 & 4 & 40.729 & 63.6 & 0.002 & 32725.321 \\
\hline 1 & 5 & 41.997 & 65.6 & 0.002 & 37055.080 \\
\hline 1 & 6 & 43.034 & 67.2 & 0.002 & 35998.002 \\
\hline 1 & 7 & 50.590 & 79.0 & 0.002 & 40245.157 \\
\hline 1 & 8 & 44.342 & 69.3 & 0.002 & 42352.001 \\
\hline 1 & 9 & 52.084 & 81.4 & 0.003 & 31687.162 \\
\hline 2 & 1 & 51.120 & 79.9 & 0.003 & 27665.535 \\
\hline 2 & 2 & 48.212 & 75.3 & 0.003 & 28924.627 \\
\hline 2 & 3 & 45.735 & 71.5 & 0.002 & 37285.449 \\
\hline 2 & 4 & 37.329 & 58.3 & 0.003 & 31425.466 \\
\hline 2 & 5 & 45.808 & 71.6 & 0.003 & 30264.547 \\
\hline 2 & 6 & 46.114 & 72.1 & 0.003 & 29933.280 \\
\hline 2 & 7 & 39.442 & 61.1 & 0.003 & 25992.834 \\
\hline 2 & 8 & 43.571 & 68.1 & 0.003 & 28846.675 \\
\hline 2 & 9 & 50.342 & 78.7 & 0.004 & 32251.707 \\
\hline 3 & 1 & 24.952 & 39.0 & 0.001 & 27886.638 \\
\hline 3 & 2 & 33.390 & 52.2 & 0.002 & 31792.798 \\
\hline 3 & 3 & 45.185 & 70.6 & 0.003 & 30238.247 \\
\hline 3 & 4 & 25.991 & 40.6 & 0.001 & 30635.440 \\
\hline 3 & 5 & 42.664 & 66.7 & 0.002 & 29561.342 \\
\hline 3 & 6 & 41.389 & 64.7 & 0.002 & 34411.408 \\
\hline 3 & 7 & 30.624 & 47.8 & 0.001 & 39352.262 \\
\hline 3 & 8 & 43.992 & 68.7 & 0.002 & 33496.506 \\
\hline 3 & 9 & 33.972 & 53.1 & 0.002 & 29181.355 \\
\hline 4 & 1 & 44.880 & 70.1 & 0.002 & 35833.075 \\
\hline 4 & 2 & 35.062 & 54.8 & 0.002 & 35872.464 \\
\hline 4 & 3 & 47.530 & 74.3 & 0.002 & 36132.267 \\
\hline 4 & 4 & 36.549 & 57.1 & 0.002 & 32124.756 \\
\hline 4 & 5 & 47.404 & 74.1 & 0.002 & 34858.751 \\
\hline 4 & 6 & 34.858 & 54.5 & 0.003 & 24490.437 \\
\hline 4 & 7 & 46.352 & 72.4 & 0.002 & 36122.400 \\
\hline 4 & 8 & 33.116 & 51.8 & 0.002 & 31316.785 \\
\hline 4 & 9 & 38.449 & 60.1 & 0.003 & 34038.751 \\
\hline
\end{tabular}


Table 2: Data from control group: Solid silorane resin composite (cont.)

\begin{tabular}{|c|c|c|c|c|c|}
\hline Block & Beam & Peak Load & Peak Stress & Strain & Modulus \\
\hline 5 & 1 & 31.650 & 49.5 & 0.002 & 33751.118 \\
\hline 5 & 2 & 38.917 & 60.8 & 0.002 & 42477.946 \\
\hline 5 & 3 & 43.043 & 67.3 & 0.001 & 50323.172 \\
\hline 5 & 4 & 39.670 & 62.0 & 0.001 & 45774.126 \\
\hline 5 & 5 & 29.470 & 46.0 & 0.001 & 42507.966 \\
\hline 5 & 6 & 39.078 & 61.1 & 0.002 & 44746.663 \\
\hline 5 & 7 & 45.726 & 71.4 & 0.003 & 42557.656 \\
\hline 5 & 8 & 24.756 & 38.7 & 0.001 & 37697.766 \\
\hline 5 & 9 & 46.101 & 72.0 & 0.002 & 44555.287 \\
\hline 6 & 1 & 49.345 & 77.1 & 0.003 & 34268.021 \\
\hline 6 & 2 & 27.791 & 43.4 & 0.001 & 37279.549 \\
\hline 6 & 3 & 44.415 & 69.4 & 0.002 & 38617.817 \\
\hline 6 & 4 & 35.421 & 55.3 & 0.002 & 41466.255 \\
\hline 6 & 5 & 48.995 & 76.5 & 0.002 & 35979.879 \\
\hline 6 & 6 & 43.793 & 68.4 & 0.002 & 35429.963 \\
\hline 6 & 7 & 44.183 & 69.0 & 0.002 & 40280.838 \\
\hline 6 & 8 & 41.249 & 64.5 & 0.002 & 31940.104 \\
\hline 6 & 9 & 57.979 & 90.6 & 0.003 & 36446.476 \\
\hline 7 & 1 & 39.854 & 62.3 & 0.002 & 35007.932 \\
\hline 7 & 2 & 45.564 & 71.2 & 0.002 & 36030.007 \\
\hline 7 & 3 & 39.223 & 61.3 & 0.002 & 35679.394 \\
\hline 7 & 4 & 29.467 & 46.0 & 0.001 & 40877.813 \\
\hline 7 & 5 & 36.697 & 57.8 & 0.001 & 39541.026 \\
\hline 7 & 6 & 44.223 & 69.1 & 0.002 & 60327.492 \\
\hline 7 & 7 & 34.649 & 54.1 & 0.001 & 44216.644 \\
\hline 7 & 8 & 40.050 & 62.6 & 0.001 & 44223.310 \\
\hline 7 & 9 & 33.070 & 51.7 & 0.001 & 46414.137 \\
\hline 8 & 1 & 45.828 & 71.6 & 0.002 & 37686.793 \\
\hline 8 & 2 & 36.923 & 57.7 & 0.001 & 43535.344 \\
\hline 8 & 3 & 44.703 & 69.8 & 0.002 & 37966.985 \\
\hline 8 & 4 & 38.592 & 60.3 & 0.002 & 29728.297 \\
\hline 8 & 5 & 38.104 & 59.5 & 0.002 & 40645.777 \\
\hline 8 & 6 & 32.596 & 50.9 & 0.001 & 37815.747 \\
\hline 8 & 7 & 51.073 & 79.8 & 0.002 & 37493.717 \\
\hline 8 & 8 & 46.035 & 71.9 & 0.002 & 43064.373 \\
\hline 8 & 9 & 51.079 & 79.8 & 0.002 & 36746.766 \\
\hline
\end{tabular}


Table 3: Data from control group: Solid silorane resin composite (cont.)

\begin{tabular}{|c|c|c|c|c|c|}
\hline Block & Beam & Peak Load & Peak Stress & Strain & Modulus \\
\hline 9 & 1 & 36.314 & 56.7 & 0.002 & 34223.153 \\
\hline 9 & 2 & 43.709 & 68.3 & 0.002 & 32006.865 \\
\hline 9 & 3 & 44.963 & 70.3 & 0.003 & 35248.526 \\
\hline 9 & 4 & 31.986 & 50.0 & 0.002 & 36105.448 \\
\hline 9 & 5 & 40.060 & 62.6 & 0.002 & 42475.322 \\
\hline 9 & 6 & 29.835 & 46.6 & 0.003 & 30781.298 \\
\hline 9 & 7 & 36.498 & 57.0 & 0.003 & 36488.951 \\
\hline 9 & 8 & 41.673 & 65.1 & 0.002 & 37455.748 \\
\hline 9 & 9 & 39.723 & 62.1 & 0.002 & 45527.248 \\
\hline 10 & 1 & 37.864 & 59.2 & 0.002 & 43450.248 \\
\hline 10 & 2 & 36.701 & 57.3 & 0.002 & 40322.097 \\
\hline 10 & 3 & 36.346 & 56.8 & 0.002 & 48368.482 \\
\hline 10 & 4 & 39.791 & 62.2 & 0.003 & 39746.752 \\
\hline 10 & 5 & 29.626 & 46.3 & 0.001 & 35451.888 \\
\hline 10 & 6 & 39.913 & 62.4 & 0.003 & 44314.799 \\
\hline 10 & 7 & 28.570 & 44.6 & 0.002 & 25527.999 \\
\hline 10 & 8 & 37.171 & 58.1 & 0.002 & 37862.715 \\
\hline 10 & 9 & 44.420 & 69.4 & 0.002 & 35104.126 \\
\hline 11 & 1 & 47.956 & 74.9 & 0.002 & 42559.144 \\
\hline 11 & 2 & 34.926 & 54.6 & 0.002 & 41610.193 \\
\hline 11 & 3 & 42.967 & 67.1 & 0.002 & 35159.319 \\
\hline 11 & 4 & 46.427 & 72.5 & 0.002 & 40625.874 \\
\hline 11 & 5 & 29.549 & 46.2 & 0.001 & 42748.355 \\
\hline 11 & 6 & 27.932 & 43.6 & 0.001 & 33449.401 \\
\hline 11 & 7 & 28.175 & 44.0 & 0.001 & 33863.420 \\
\hline 11 & 8 & 39.382 & 61.5 & 0.002 & 33739.934 \\
\hline 11 & 9 & 48.679 & 76.1 & 0.003 & 35670.452 \\
\hline 12 & 1 & 45.055 & 70.4 & 0.003 & 40787.272 \\
\hline 12 & 2 & 43.965 & 68.7 & 0.002 & 42265.612 \\
\hline 12 & 3 & 39.721 & 62.1 & 0.002 & 36028.364 \\
\hline 12 & 4 & 43.737 & 68.3 & 0.002 & 48576.747 \\
\hline 12 & 5 & 37.052 & 57.9 & 0.001 & 45511.795 \\
\hline 12 & 6 & 43.114 & 67.4 & 0.002 & 44230.834 \\
\hline 12 & 7 & 39.506 & 61.7 & 0.002 & 43364.658 \\
\hline 12 & 8 & 37.333 & 58.3 & 0.002 & 30692.069 \\
\hline 12 & 9 & 39.388 & 61.5 & 0.002 & 39200.566 \\
\hline
\end{tabular}


Table 4: Data from group 1S: Silorane resin composite repaired with silorane resin composite with no surface treatment

\begin{tabular}{|c|c|c|c|c|c|c|}
\hline Block & Beam & Peak Load & Peak Stress & Strain & Modulus & Failure type \\
\hline 1 & 1 & 11.989 & 18.7 & 0.001 & 19659.396 & adhesive \\
\hline 1 & 2 & 14.873 & 23.2 & 0.001 & 29926.384 & adhesive \\
\hline 1 & 3 & 18.003 & 28.1 & 0.001 & 29971.736 & adhesive \\
\hline 1 & 4 & 23.974 & 37.5 & 0.001 & 30167.574 & cohesive \\
\hline 1 & 5 & 24.163 & 37.8 & 0.001 & 35229.828 & adhesive \\
\hline 1 & 6 & 21.012 & 32.8 & 0.001 & 28346.456 & cohesive \\
\hline 1 & 7 & 16.191 & 25.3 & 0.001 & 25860.259 & adhesive \\
\hline 1 & 8 & 21.285 & 33.3 & 0.001 & 27705.852 & adhesive \\
\hline 1 & 9 & 25.219 & 39.4 & 0.001 & 26987.274 & adhesive \\
\hline 2 & 1 & 38.002 & 59.4 & 0.006 & 21959.415 & adhesive \\
\hline 2 & 2 & 30.998 & 48.4 & 0.002 & 29255.643 & adhesive \\
\hline 2 & 3 & 31.196 & 48.7 & 0.003 & 20135.514 & adhesive \\
\hline 2 & 4 & 31.647 & 49.4 & 0.002 & 27290.709 & adhesive \\
\hline 2 & 5 & 22.926 & 35.8 & 0.001 & 28295.338 & adhesive \\
\hline 2 & 6 & 31.366 & 49.0 & 0.002 & 26106.402 & cohesive \\
\hline 2 & 7 & 37.387 & 58.4 & 0.003 & 23919.905 & adhesive \\
\hline 2 & 8 & 34.834 & 54.4 & 0.003 & 26736.131 & adhesive \\
\hline 2 & 9 & 9.220 & 14.4 & 0.001 & 21205.412 & cohesive \\
\hline 3 & 1 & 20.587 & 32.2 & 0.001 & 24495.529 & adhesive \\
\hline 3 & 2 & 17.123 & 26.8 & 0.001 & 25128.480 & adhesive \\
\hline 3 & 3 & 25.755 & 40.2 & 0.001 & 27875.945 & adhesive \\
\hline 3 & 4 & 28.100 & 43.9 & 0.002 & 27256.718 & adhesive \\
\hline 3 & 5 & 23.856 & 37.3 & 0.002 & 24287.606 & adhesive \\
\hline 3 & 6 & 14.649 & 22.9 & 0.001 & 23628.253 & adhesive \\
\hline 3 & 7 & 28.594 & 44.7 & 0.002 & 24736.240 & adhesive \\
\hline 3 & 8 & 15.077 & 23.6 & 0.001 & 25854.580 & adhesive \\
\hline 3 & 9 & 16.393 & 25.6 & 0.001 & 25045.739 & adhesive \\
\hline 4 & 1 & 37.702 & 58.9 & 0.003 & 25969.657 & cohesive \\
\hline 4 & 2 & 24.850 & 38.8 & 0.001 & 26678.862 & adhesive \\
\hline 4 & 3 & 27.395 & 42.8 & 0.002 & 30668.317 & adhesive \\
\hline 4 & 4 & 26.881 & 42.0 & 0.002 & 31018.868 & adhesive \\
\hline 4 & 5 & 28.207 & 44.1 & 0.002 & 23960.195 & adhesive \\
\hline 4 & 6 & 25.472 & 39.8 & 0.001 & 31885.178 & adhesive \\
\hline 4 & 7 & 35.375 & 55.3 & 0.002 & 29458.173 & adhesive \\
\hline 4 & 8 & 36.666 & 57.3 & 0.002 & 32029.385 & adhesive \\
\hline 4 & 9 & 34.250 & 53.5 & 0.002 & 28744.256 & adhesive \\
\hline
\end{tabular}


Table 5: Data from group 1S: Silorane resin composite repaired with silorane resin composite with no surface treatment (cont.)

\begin{tabular}{|c|c|c|c|c|c|c|}
\hline Block & Beam & Peak Load & Peak Stress & Strain & Modulus & Failure type \\
\hline 5 & 1 & 34.622 & 54.1 & 0.003 & 22770.473 & adhesive \\
\hline 5 & 2 & 19.884 & 31.1 & 0.002 & 23490.611 & adhesive \\
\hline 5 & 3 & 23.308 & 36.4 & 0.002 & 21869.225 & adhesive \\
\hline 5 & 4 & 28.058 & 43.8 & 0.002 & 27343.573 & adhesive \\
\hline 5 & 5 & 32.215 & 50.3 & 0.003 & 24186.103 & cohesive \\
\hline 5 & 6 & 16.852 & 26.3 & 0.001 & 23301.919 & adhesive \\
\hline 5 & 7 & 19.905 & 31.1 & 0.001 & 23620.430 & adhesive \\
\hline 5 & 8 & 18.323 & 28.6 & 0.001 & 26711.591 & adhesive \\
\hline 5 & 9 & 24.431 & 38.2 & 0.002 & 26684.649 & cohesive \\
\hline 6 & 1 & 28.846 & 45.1 & 0.003 & 22692.533 & adhesive \\
\hline 6 & 2 & 20.672 & 32.3 & 0.001 & 30029.849 & adhesive \\
\hline 6 & 3 & 8.373 & 13.1 & 0.000 & 24410.638 & adhesive \\
\hline 6 & 4 & 21.709 & 33.9 & 0.001 & 29833.679 & adhesive \\
\hline 6 & 5 & 17.632 & 27.5 & 0.001 & 25165.293 & adhesive \\
\hline 6 & 6 & 13.101 & 20.5 & 0.001 & 26729.094 & adhesive \\
\hline 6 & 7 & 17.825 & 27.9 & 0.001 & 29920.966 & adhesive \\
\hline 6 & 8 & 28.552 & 44.6 & 0.002 & 25174.640 & adhesive \\
\hline 6 & 9 & 26.150 & 40.9 & 0.002 & 23636.886 & adhesive \\
\hline 7 & 1 & 22.638 & 35.4 & 0.002 & 22613.657 & adhesive \\
\hline 7 & 2 & 16.615 & 26.0 & 0.001 & 25783.128 & adhesive \\
\hline 7 & 3 & 33.004 & 51.6 & 0.002 & 28551.839 & cohesive \\
\hline 7 & 4 & 27.388 & 42.8 & 0.002 & 27975.199 & adhesive \\
\hline 7 & 5 & 24.698 & 38.6 & 0.001 & 27440.270 & cohesive \\
\hline 7 & 6 & 26.378 & 41.2 & 0.002 & 25758.438 & adhesive \\
\hline 7 & 7 & 28.374 & 44.3 & 0.001 & 34185.827 & adhesive \\
\hline 7 & 8 & 20.722 & 32.4 & 0.001 & 26023.292 & adhesive \\
\hline 7 & 9 & 16.728 & 26.1 & 0.001 & 20396.128 & adhesive \\
\hline 8 & 1 & 17.679 & 27.6 & 0.001 & 31290.071 & adhesive \\
\hline 8 & 2 & 20.299 & 31.7 & 0.001 & 29597.517 & adhesive \\
\hline 8 & 3 & 30.724 & 48.0 & 0.002 & 33763.649 & adhesive \\
\hline 8 & 4 & 37.928 & 59.3 & 0.002 & 28915.115 & adhesive \\
\hline 8 & 5 & 24.347 & 38.0 & 0.001 & 28037.364 & adhesive \\
\hline 8 & 6 & 25.917 & 40.5 & 0.002 & 27283.453 & adhesive \\
\hline 8 & 7 & 31.199 & 48.7 & 0.002 & 30847.766 & adhesive \\
\hline 8 & 8 & 24.515 & 38.3 & 0.002 & 25770.824 & cohesive \\
\hline 8 & 9 & 23.337 & 36.5 & 0.001 & 25602.492 & adhesive \\
\hline
\end{tabular}


Table 6: Data from group 1S: Silorane resin composite repaired with silorane resin composite with no surface treatment (cont.)

\begin{tabular}{|c|c|c|c|c|c|c|}
\hline Block & Beam & Peak Load & Peak Stress & Strain & Modulus & Failure type \\
\hline 9 & 1 & 36.763 & 57.4 & 0.003 & 29182.010 & adhesive \\
\hline 9 & 2 & 29.723 & 46.4 & 0.002 & 26059.249 & cohesive \\
\hline 9 & 3 & 19.573 & 30.6 & 0.001 & 28767.687 & adhesive \\
\hline 9 & 4 & 13.578 & 21.2 & 0.001 & 31386.580 & adhesive \\
\hline 9 & 5 & 17.374 & 27.1 & 0.001 & 30082.468 & adhesive \\
\hline 9 & 6 & 42.742 & 66.8 & 0.002 & 31779.876 & adhesive \\
\hline 9 & 7 & 35.356 & 55.2 & 0.002 & 32237.415 & adhesive \\
\hline 9 & 8 & 19.308 & 30.2 & 0.001 & 28560.245 & adhesive \\
\hline 9 & 9 & 13.422 & 21.0 & 0.001 & 32499.874 & adhesive \\
\hline 10 & 1 & 16.627 & 26.0 & 0.001 & 29886.013 & adhesive \\
\hline 10 & 2 & 9.787 & 15.3 & 0.000 & 37870.804 & adhesive \\
\hline 10 & 3 & 23.614 & 36.9 & 0.001 & 30480.967 & adhesive \\
\hline 10 & 4 & 12.742 & 19.9 & 0.001 & 34887.992 & adhesive \\
\hline 10 & 5 & 13.345 & 20.9 & 0.001 & 30668.287 & adhesive \\
\hline 10 & 6 & 19.027 & 29.7 & 0.001 & 31133.323 & adhesive \\
\hline 10 & 7 & 21.196 & 33.1 & 0.001 & 27227.316 & adhesive \\
\hline 10 & 8 & 22.587 & 35.3 & 0.001 & 35329.910 & adhesive \\
\hline 10 & 9 & 17.710 & 27.7 & 0.001 & 28228.897 & adhesive \\
\hline 11 & 1 & 19.315 & 30.2 & 0.001 & 29517.663 & adhesive \\
\hline 11 & 2 & 23.793 & 37.2 & 0.001 & 28309.234 & adhesive \\
\hline 11 & 3 & 10.819 & 16.9 & 0.001 & 23426.764 & adhesive \\
\hline 11 & 4 & 19.563 & 30.6 & 0.001 & 32477.888 & adhesive \\
\hline 11 & 5 & 18.099 & 28.0 & 0.001 & 28336.062 & adhesive \\
\hline 11 & 6 & 28.198 & 44.1 & 0.002 & 29063.996 & adhesive \\
\hline 11 & 7 & 24.947 & 39.0 & 0.001 & 33409.922 & adhesive \\
\hline 11 & 8 & 30.048 & 46.9 & 0.002 & 28737.232 & adhesive \\
\hline 11 & 9 & 23.577 & 36.8 & 0.001 & 30030.615 & adhesive \\
\hline 12 & 1 & 26.140 & 40.8 & 0.001 & 30523.525 & adhesive \\
\hline 12 & 2 & 22.731 & 35.5 & 0.001 & 29461.368 & adhesive \\
\hline 12 & 3 & 20.532 & 32.1 & 0.001 & 30355.074 & cohesive \\
\hline 12 & 4 & 28.708 & 44.9 & 0.001 & 32576.134 & adhesive \\
\hline 12 & 5 & 41.692 & 65.1 & 0.002 & 33881.339 & adhesive \\
\hline 12 & 6 & 37.151 & 58.0 & 0.003 & 24881.536 & cohesive \\
\hline 12 & 7 & 19.623 & 30.7 & 0.001 & 28431.382 & cohesive \\
\hline 12 & 8 & 14.303 & 22.3 & 0.001 & 22124.951 & adhesive \\
\hline 12 & 9 & 15.379 & 19.0 & 0.001 & 18063.326 & adhesive \\
\hline
\end{tabular}


Table 7: Data from group 2S: Silorane resin composite repaired with silorane resin composite with acid etching

\begin{tabular}{|c|c|c|c|c|c|c|}
\hline Block & Beam & Peak Load & Peak Stress & Strain & Modulus & Failure type \\
\hline 1 & 1 & 15.733 & 24.6 & 0.001 & 27614.081 & adhesive \\
\hline 1 & 2 & 7.381 & 11.5 & 0.001 & 20223.570 & adhesive \\
\hline 1 & 3 & 23.163 & 36.2 & 0.001 & 28138.188 & adhesive \\
\hline 1 & 4 & 22.511 & 35.2 & 0.001 & 23045.319 & adhesive \\
\hline 1 & 5 & 18.438 & 28.8 & 0.001 & 28089.832 & cohesive \\
\hline 1 & 6 & 14.626 & 22.9 & 0.001 & 28392.230 & adhesive \\
\hline 1 & 7 & 19.822 & 31.0 & 0.001 & 30917.757 & adhesive \\
\hline 1 & 8 & 25.933 & 40.5 & 0.001 & 30045.964 & adhesive \\
\hline 1 & 9 & 22.459 & 35.1 & 0.001 & 35921.043 & adhesive \\
\hline 2 & 1 & 43.440 & 67.9 & 0.002 & 31259.980 & cohesive \\
\hline 2 & 2 & 36.109 & 56.4 & 0.002 & 31987.463 & adhesive \\
\hline 2 & 3 & 42.597 & 66.6 & 0.002 & 28775.691 & cohesive \\
\hline 2 & 4 & 41.983 & 65.6 & 0.002 & 32421.470 & cohesive \\
\hline 2 & 5 & 6.438 & 10.1 & 0.001 & 18808.517 & adhesive \\
\hline 2 & 6 & 39.441 & 61.6 & 0.002 & 36620.244 & adhesive \\
\hline 2 & 7 & 11.481 & 17.9 & 0.001 & 32364.161 & mixed \\
\hline 2 & 8 & 4.367 & 6.8 & 0.000 & 27091.606 & adhesive \\
\hline 2 & 9 & 21.575 & 33.7 & 0.001 & 32405.511 & adhesive \\
\hline 3 & 1 & 24.557 & 38.4 & 0.001 & 41836.065 & adhesive \\
\hline 3 & 2 & 18.239 & 28.5 & 0.001 & 31604.418 & adhesive \\
\hline 3 & 3 & 23.703 & 37.0 & 0.002 & 25355.978 & adhesive \\
\hline 3 & 4 & 21.719 & 33.9 & 0.001 & 27334.815 & adhesive \\
\hline 3 & 5 & 17.701 & 27.7 & 0.001 & 30431.502 & adhesive \\
\hline 3 & 6 & 12.909 & 20.2 & 0.001 & 23699.294 & adhesive \\
\hline 3 & 7 & 19.386 & 30.3 & 0.001 & 33693.421 & adhesive \\
\hline 3 & 8 & 17.319 & 27.1 & 0.001 & 33032.421 & adhesive \\
\hline 3 & 9 & 24.130 & 37.7 & 0.001 & 34295.089 & cohesive \\
\hline 4 & 1 & 30.526 & 47.7 & 0.002 & 33622.266 & cohesive \\
\hline 4 & 2 & 11.756 & 18.4 & 0.001 & 21057.026 & adhesive \\
\hline 4 & 3 & 29.696 & 46.4 & 0.002 & 26366.834 & cohesive \\
\hline 4 & 4 & 38.191 & 59.7 & 0.003 & 28954.437 & adhesive \\
\hline 4 & 5 & 26.278 & 41.1 & 0.001 & 30616.120 & adhesive \\
\hline 4 & 6 & 44.905 & 70.2 & 0.002 & 31218.658 & cohesive \\
\hline 4 & 7 & 34.599 & 54.1 & 0.003 & 20604.182 & cohesive \\
\hline 4 & 8 & 31.864 & 49.8 & 0.001 & 35257.242 & cohesive \\
\hline 4 & 9 & 46.758 & 73.1 & 0.002 & 35084.445 & adhesive \\
\hline
\end{tabular}


Table 8: Data from group 2S: Silorane resin composite repaired with silorane resin composite with acid etching (cont.)

\begin{tabular}{|c|c|c|c|c|c|c|}
\hline Block & Beam & Peak Load & Peak Stress & Strain & Modulus & Failure type \\
\hline 5 & 1 & 20.817 & 32.5 & 0.001 & 36999.004 & adhesive \\
\hline 5 & 2 & 15.329 & 24.0 & 0.001 & 34116.833 & cohesive \\
\hline 5 & 3 & 37.766 & 59.0 & 0.002 & 31372.650 & adhesive \\
\hline 5 & 4 & 7.753 & 12.1 & 0.000 & 27381.601 & adhesive \\
\hline 5 & 5 & 25.585 & 40.0 & 0.001 & 33505.729 & adhesive \\
\hline 5 & 6 & 37.770 & 59.0 & 0.002 & 35947.473 & adhesive \\
\hline 5 & 7 & 27.437 & 42.9 & 0.001 & 29005.709 & adhesive \\
\hline 5 & 8 & 29.305 & 45.8 & 0.002 & 26644.197 & adhesive \\
\hline 5 & 9 & 10.324 & 16.1 & 0.001 & 29139.177 & adhesive \\
\hline 6 & 1 & 14.177 & 22.2 & 0.001 & 35498.679 & adhesive \\
\hline 6 & 2 & 27.282 & 42.6 & 0.001 & 35149.681 & cohesive \\
\hline 6 & 3 & 28.076 & 43.9 & 0.001 & 40679.402 & cohesive \\
\hline 6 & 4 & 36.575 & 57.1 & 0.003 & 29193.923 & cohesive \\
\hline 6 & 5 & 44.063 & 68.8 & 0.002 & 32533.333 & cohesive \\
\hline 6 & 6 & 16.210 & 25.3 & 0.001 & 34487.570 & adhesive \\
\hline 6 & 7 & 44.525 & 69.6 & 0.002 & 40593.020 & adhesive \\
\hline 6 & 8 & 32.528 & 50.8 & 0.002 & 28889.773 & adhesive \\
\hline 6 & 9 & 12.942 & 20.2 & 0.001 & 24425.997 & adhesive \\
\hline 7 & 1 & 10.111 & 15.8 & 0.001 & 23035.743 & adhesive \\
\hline 7 & 2 & 2.518 & 3.9 & 0.000 & 22677.646 & adhesive \\
\hline 7 & 3 & 7.456 & 11.7 & 0.000 & 25408.254 & adhesive \\
\hline 7 & 4 & 10.588 & 16.5 & 0.001 & 29255.949 & adhesive \\
\hline 7 & 5 & 25.460 & 39.8 & 0.001 & 33983.089 & adhesive \\
\hline 7 & 6 & 24.989 & 39.0 & 0.002 & 23208.424 & cohesive \\
\hline 7 & 7 & 5.616 & 8.8 & 0.000 & 21780.870 & adhesive \\
\hline 7 & 8 & 13.025 & 20.4 & 0.001 & 32850.479 & adhesive \\
\hline 7 & 9 & 14.659 & 22.9 & 0.001 & 20432.433 & adhesive \\
\hline 8 & 1 & 38.367 & 59.9 & 0.002 & 28117.855 & adhesive \\
\hline 8 & 2 & 35.473 & 55.4 & 0.002 & 28381.395 & adhesive \\
\hline 8 & 3 & 22.791 & 35.6 & 0.001 & 26079.993 & adhesive \\
\hline 8 & 4 & 38.220 & 59.7 & 0.003 & 29360.417 & adhesive \\
\hline 8 & 5 & 34.049 & 53.2 & 0.002 & 35109.704 & cohesive \\
\hline 8 & 6 & 39.333 & 61.5 & 0.002 & 32210.411 & adhesive \\
\hline 8 & 7 & 35.193 & 55.0 & 0.002 & 35592.963 & cohesive \\
\hline 8 & 8 & 37.481 & 58.6 & 0.002 & 28173.373 & adhesive \\
\hline 8 & 9 & 40.211 & 62.8 & 0.002 & 27055.937 & adhesive \\
\hline
\end{tabular}


Table 9: Data from group 2S: Silorane resin composite repaired with silorane resin composite with acid etching (cont.)

\begin{tabular}{|c|c|c|c|c|c|c|}
\hline Block & Beam & Peak Load & Peak Stress & Strain & Modulus & Failure type \\
\hline 9 & 1 & 37.171 & 58.1 & 0.002 & 26879.232 & adhesive \\
\hline 9 & 2 & 23.927 & 37.4 & 0.001 & 25980.636 & adhesive \\
\hline 9 & 3 & 33.141 & 51.8 & 0.002 & 29709.371 & adhesive \\
\hline 9 & 4 & 27.011 & 42.2 & 0.002 & 29292.228 & adhesive \\
\hline 9 & 5 & 33.120 & 51.8 & 0.002 & 34838.038 & adhesive \\
\hline 9 & 6 & 29.723 & 46.4 & 0.002 & 31824.458 & cohesive \\
\hline 9 & 7 & 27.514 & 43.0 & 0.001 & 36116.358 & cohesive \\
\hline 9 & 8 & 26.990 & 42.2 & 0.001 & 31485.625 & adhesive \\
\hline 9 & 9 & 17.401 & 27.2 & 0.002 & 16031.791 & adhesive \\
\hline 10 & 1 & 21.493 & 33.6 & 0.002 & 20043.867 & adhesive \\
\hline 10 & 2 & 9.024 & 14.1 & 0.001 & 17937.625 & adhesive \\
\hline 10 & 3 & 4.491 & 7.0 & 0.000 & 20960.449 & adhesive \\
\hline 10 & 4 & 10.437 & 16.3 & 0.001 & 25162.052 & adhesive \\
\hline 10 & 5 & 10.239 & 16.0 & 0.001 & 21659.648 & adhesive \\
\hline 10 & 6 & 11.689 & 18.3 & 0.001 & 26998.773 & adhesive \\
\hline 10 & 7 & 2.463 & 3.8 & 0.000 & 16649.758 & adhesive \\
\hline 10 & 8 & 24.996 & 39.1 & 0.002 & 27042.137 & adhesive \\
\hline 10 & 9 & 28.893 & 45.1 & 0.002 & 28203.153 & adhesive \\
\hline 11 & 1 & 13.478 & 21.1 & 0.001 & 17490.721 & adhesive \\
\hline 11 & 2 & 16.927 & 26.4 & 0.001 & 19401.239 & adhesive \\
\hline 11 & 3 & 9.985 & 15.6 & 0.001 & 21654.990 & adhesive \\
\hline 11 & 4 & 34.333 & 53.6 & 0.002 & 21720.027 & adhesive \\
\hline 11 & 5 & 10.337 & 16.2 & 0.001 & 20219.053 & adhesive \\
\hline 11 & 6 & 31.147 & 48.7 & 0.002 & 32008.851 & adhesive \\
\hline 11 & 7 & 24.574 & 38.4 & 0.001 & 26123.725 & adhesive \\
\hline 11 & 8 & 37.824 & 59.1 & 0.002 & 32236.612 & adhesive \\
\hline 11 & 9 & 41.118 & 64.2 & 0.002 & 29761.192 & cohesive \\
\hline 12 & 1 & 7.448 & 11.6 & 0.001 & 21338.014 & adhesive \\
\hline 12 & 2 & 19.186 & 30.0 & 0.001 & 30755.183 & adhesive \\
\hline 12 & 3 & 8.499 & 13.3 & 0.001 & 19915.417 & adhesive \\
\hline 12 & 4 & 42.010 & 65.6 & 0.003 & 2332.314 & adhesive \\
\hline 12 & 5 & 6.499 & 10.2 & 0.000 & 23266.718 & adhesive \\
\hline 12 & 6 & 29.051 & 45.4 & 0.002 & 26359.642 & adhesive \\
\hline 12 & 7 & 35.965 & 56.2 & 0.002 & 27729.092 & adhesive \\
\hline 12 & 8 & 3.889 & 6.1 & 0.000 & 14336.514 & adhesive \\
\hline 12 & 9 & 28.069 & 43.9 & 0.002 & 27152.893 & adhesive \\
\hline
\end{tabular}


Table 10: Data from group 3S: Silorane resin composite repaired with silorane resin composite with sandblasting

\begin{tabular}{|c|c|c|c|c|c|c|}
\hline Block & Beam & Peak Load & Peak Stress & Strain & Modulus & Failure type \\
\hline 1 & 1 & 23.517 & 36.7 & 0.001 & 30858.069 & adhesive \\
\hline 1 & 2 & 27.345 & 42.7 & 0.002 & 30445.493 & cohesive \\
\hline 1 & 3 & 35.317 & 55.2 & 0.001 & 40189.312 & adhesive \\
\hline 1 & 4 & 26.479 & 41.4 & 0.001 & 42648.595 & adhesive \\
\hline 1 & 5 & 27.216 & 42.5 & 0.002 & 27898.710 & adhesive \\
\hline 1 & 6 & 36.188 & 56.5 & 0.002 & 37459.552 & adhesive \\
\hline 1 & 7 & 30.243 & 47.3 & 0.002 & 33641.682 & cohesive \\
\hline 1 & 8 & 37.724 & 58.9 & 0.002 & 34230.782 & not break \\
\hline 1 & 9 & 20.145 & 31.5 & 0.001 & 32994.525 & adhesive \\
\hline 2 & 1 & 29.417 & 46.0 & 0.001 & 40745.416 & cohesive \\
\hline 2 & 2 & 30.128 & 47.1 & 0.002 & 31037.728 & adhesive \\
\hline 2 & 3 & 32.666 & 51.0 & 0.003 & 28677.105 & not break \\
\hline 2 & 4 & 26.514 & 41.4 & 0.001 & 39483.118 & adhesive \\
\hline 2 & 5 & 28.950 & 45.2 & 0.001 & 48364.487 & adhesive \\
\hline 2 & 6 & 42.647 & 66.6 & 0.002 & 41976.177 & adhesive \\
\hline 2 & 7 & 24.553 & 38.4 & 0.002 & 36197.538 & cohesive \\
\hline 2 & 8 & 11.517 & 18.0 & 0.001 & 29307.636 & cohesive \\
\hline 2 & 9 & 38.899 & 60.8 & 0.002 & 33966.539 & adhesive \\
\hline 3 & 1 & 36.217 & 56.6 & 0.002 & 36676.968 & adhesive \\
\hline 3 & 2 & 32.616 & 51.0 & 0.001 & 42045.434 & adhesive \\
\hline 3 & 3 & 35.470 & 55.4 & 0.002 & 32261.808 & adhesive \\
\hline 3 & 4 & 32.985 & 51.5 & 0.002 & 37654.138 & cohesive \\
\hline 3 & 5 & 19.716 & 30.8 & 0.001 & 43433.660 & cohesive \\
\hline 3 & 6 & 41.449 & 64.8 & 0.002 & 47055.851 & adhesive \\
\hline 3 & 7 & 39.666 & 62.0 & 0.002 & 43242.771 & cohesive \\
\hline 3 & 8 & 40.995 & 64.1 & 0.002 & 32448.595 & mixed \\
\hline 3 & 9 & 31.000 & 48.4 & 0.001 & 31605.589 & mixed \\
\hline 4 & 1 & 35.979 & 56.2 & 0.002 & 28677.639 & adhesive \\
\hline 4 & 2 & 32.748 & 51.2 & 0.002 & 39383.552 & cohesive \\
\hline 4 & 3 & 32.987 & 51.5 & 0.002 & 34239.934 & cohesive \\
\hline 4 & 4 & 27.295 & 42.6 & 0.001 & 31374.372 & adhesive \\
\hline 4 & 5 & 33.715 & 52.7 & 0.001 & 38617.090 & adhesive \\
\hline 4 & 6 & 31.482 & 49.2 & 0.001 & 41402.010 & adhesive \\
\hline 4 & 7 & 37.373 & 58.4 & 0.002 & 40022.149 & adhesive \\
\hline 4 & 8 & 35.763 & 55.9 & 0.001 & 46509.045 & adhesive \\
\hline 4 & 9 & 36.254 & 56.6 & 0.003 & 29924.713 & adhesive \\
\hline
\end{tabular}


Table 11: Data from group 3S: Silorane resin composite repaired with silorane resin composite with sandblasting (cont.)

\begin{tabular}{|c|c|c|c|c|c|c|}
\hline Block & Beam & Peak Load & Peak Stress & Strain & Modulus & Failure type \\
\hline 5 & 1 & 40.086 & 62.6 & 0.002 & 32715.982 & adhesive \\
\hline 5 & 2 & 24.606 & 38.4 & 0.003 & 27539.933 & adhesive \\
\hline 5 & 3 & 33.855 & 52.9 & 0.002 & 37866.323 & adhesive \\
\hline 5 & 4 & 41.311 & 64.5 & 0.002 & 47283.473 & adhesive \\
\hline 5 & 5 & 32.290 & 50.5 & 0.002 & 28212.589 & cohesive \\
\hline 5 & 6 & 40.147 & 62.7 & 0.002 & 35290.518 & adhesive \\
\hline 5 & 7 & 36.954 & 57.7 & 0.002 & 43668.578 & cohesive \\
\hline 5 & 8 & 34.004 & 53.1 & 0.002 & 33778.560 & adhesive \\
\hline 5 & 9 & 32.931 & 51.5 & 0.001 & 44576.529 & adhesive \\
\hline 6 & 1 & 27.805 & 43.4 & 0.001 & 33128.995 & adhesive \\
\hline 6 & 2 & 26.981 & 42.2 & 0.002 & 26935.544 & adhesive \\
\hline 6 & 3 & 28.976 & 45.3 & 0.001 & 47710.378 & adhesive \\
\hline 6 & 4 & 32.272 & 50.4 & 0.001 & 43295.182 & adhesive \\
\hline 6 & 5 & 34.885 & 54.5 & 0.001 & 45792.247 & adhesive \\
\hline 6 & 6 & 15.796 & 24.7 & 0.001 & 30424.443 & adhesive \\
\hline 6 & 7 & 25.078 & 39.2 & 0.001 & 45852.035 & adhesive \\
\hline 6 & 8 & 21.311 & 33.3 & 0.001 & 49394.619 & adhesive \\
\hline 6 & 9 & 42.022 & 65.7 & 0.001 & 55476.906 & adhesive \\
\hline 7 & 1 & 32.853 & 51.3 & 0.001 & 42270.597 & adhesive \\
\hline 7 & 2 & 30.254 & 47.3 & 0.002 & 34396.031 & cohesive \\
\hline 7 & 3 & 33.523 & 52.4 & 0.002 & 35719.126 & adhesive \\
\hline 7 & 4 & 36.337 & 56.8 & 0.002 & 36622.669 & cohesive \\
\hline 7 & 5 & 34.979 & 54.7 & 0.002 & 38788.749 & cohesive \\
\hline 7 & 6 & 26.161 & 40.9 & 0.002 & 38539.625 & cohesive \\
\hline 7 & 7 & 40.960 & 64.0 & 0.002 & 31328.615 & adhesive \\
\hline 7 & 8 & 37.469 & 58.5 & 0.002 & 32995.291 & adhesive \\
\hline 7 & 9 & 57.586 & 90.0 & 0.002 & 52443.774 & adhesive \\
\hline 8 & 1 & 35.675 & 55.7 & 0.001 & 44511.882 & adhesive \\
\hline 8 & 2 & 28.063 & 43.8 & 0.001 & 32207.913 & cohesive \\
\hline 8 & 3 & 35.995 & 56.2 & 0.002 & 36629.976 & adhesive \\
\hline 8 & 4 & 34.692 & 54.2 & 0.001 & 42665.555 & adhesive \\
\hline 8 & 5 & 25.100 & 39.2 & 0.001 & 47506.722 & adhesive \\
\hline 8 & 6 & 34.922 & 54.6 & 0.002 & 39022.520 & adhesive \\
\hline 8 & 7 & 37.220 & 58.2 & 0.002 & 36237.207 & adhesive \\
\hline 8 & 8 & 33.255 & 52.0 & 0.002 & 31499.412 & adhesive \\
\hline 8 & 9 & 35.849 & 56.0 & 0.001 & 42293.733 & adhesive \\
\hline
\end{tabular}


Table 12: Data from group 3S: Silorane resin composite repaired with silorane resin composite with sandblasting (cont.)

\begin{tabular}{|c|c|c|c|c|c|c|}
\hline Block & Beam & Peak Load & Peak Stress & Strain & Modulus & Failure type \\
\hline 9 & 1 & 36.975 & 57.8 & 0.001 & 42501.370 & cohesive \\
\hline 9 & 2 & 43.145 & 67.4 & 0.002 & 42252.996 & adhesive \\
\hline 9 & 3 & 35.080 & 54.8 & 0.002 & 32535.574 & cohesive \\
\hline 9 & 4 & 28.726 & 44.9 & 0.001 & 37162.395 & adhesive \\
\hline 9 & 5 & 35.395 & 55.3 & 0.001 & 44570.276 & cohesive \\
\hline 9 & 6 & 29.821 & 46.6 & 0.001 & 43990.585 & adhesive \\
\hline 9 & 7 & 35.724 & 55.8 & 0.002 & 35956.554 & adhesive \\
\hline 9 & 8 & 38.599 & 60.3 & 0.002 & 40545.096 & adhesive \\
\hline 9 & 9 & 40.001 & 62.5 & 0.003 & 32992.707 & adhesive \\
\hline 10 & 1 & 25.607 & 40.0 & 0.001 & 34277.255 & adhesive \\
\hline 10 & 2 & 21.569 & 33.7 & 0.001 & 32862.854 & adhesive \\
\hline 10 & 3 & 30.601 & 47.8 & 0.001 & 40862.967 & cohesive \\
\hline 10 & 4 & 23.147 & 36.2 & 0.001 & 28875.102 & adhesive \\
\hline 10 & 5 & 27.918 & 43.6 & 0.001 & 37811.586 & cohesive \\
\hline 10 & 6 & 26.866 & 42.0 & 0.001 & 38848.498 & adhesive \\
\hline 10 & 7 & 14.111 & 22.0 & 0.001 & 20285.137 & adhesive \\
\hline 10 & 8 & 23.712 & 37.0 & 0.001 & 34013.740 & adhesive \\
\hline 10 & 9 & 24.826 & 38.8 & 0.001 & 38454.532 & adhesive \\
\hline 11 & 1 & 36.816 & 57.5 & 0.002 & 33350.261 & adhesive \\
\hline 11 & 2 & 31.685 & 49.5 & 0.002 & 29348.646 & adhesive \\
\hline 11 & 3 & 37.357 & 58.4 & 0.002 & 33276.942 & cohesive \\
\hline 11 & 4 & 40.092 & 62.6 & 0.002 & 39697.571 & adhesive \\
\hline 11 & 5 & 38.470 & 60.1 & 0.002 & 29345.906 & adhesive \\
\hline 11 & 6 & 26.670 & 41.7 & 0.001 & 41831.118 & adhesive \\
\hline 11 & 7 & 38.327 & 59.9 & 0.001 & 47906.840 & adhesive \\
\hline 11 & 8 & 31.304 & 48.9 & 0.002 & 35052.329 & adhesive \\
\hline 11 & 9 & 32.456 & 50.7 & 0.001 & 44838.573 & cohesive \\
\hline 12 & 1 & 15.094 & 23.6 & 0.001 & 25737.719 & cohesive \\
\hline 12 & 2 & 32.780 & 51.2 & 0.002 & 31558.157 & adhesive \\
\hline 12 & 3 & 25.796 & 40.3 & 0.001 & 36815.120 & adhesive \\
\hline 12 & 4 & 33.805 & 52.8 & 0.002 & 42324.595 & adhesive \\
\hline 12 & 5 & 31.699 & 49.5 & 0.001 & 38835.037 & adhesive \\
\hline 12 & 6 & 30.891 & 48.3 & 0.002 & 34016.666 & adhesive \\
\hline 12 & 7 & 28.245 & 44.1 & 0.001 & 34912.286 & adhesive \\
\hline 12 & 8 & 30.329 & 47.4 & 0.001 & 36748.657 & cohesive \\
\hline 12 & 9 & 39.005 & 60.9 & 0.002 & 37403.810 & adhesive \\
\hline
\end{tabular}


Table 13: Data from group 4S: Silorane resin composite repaired with silorane resin composite with abrasion

\begin{tabular}{|c|c|c|c|c|c|c|}
\hline Block & Beam & Peak Load & Peak Stress & Strain & \begin{tabular}{|l|} 
Modulus \\
\end{tabular} & Failure type \\
\hline 1 & 1 & 18.727 & 29.3 & 0.001 & 34881.088 & adhesive \\
\hline 1 & 2 & 35.615 & 55.6 & 0.002 & 31013.263 & adhesive \\
\hline 1 & 3 & 28.056 & 43.8 & 0.001 & 35510.973 & adhesive \\
\hline 1 & 4 & 18.180 & 28.4 & 0.001 & 37256.245 & adhesive \\
\hline 1 & 5 & 41.134 & 64.3 & 0.002 & 40272.897 & adhesive \\
\hline 1 & 6 & 30.119 & 47.1 & 0.001 & 34034.782 & adhesive \\
\hline 1 & 7 & 22.339 & 34.9 & 0.002 & 23595.446 & adhesive \\
\hline 1 & 8 & 18.049 & 28.2 & 0.001 & 17741.127 & adhesive \\
\hline 1 & 9 & 25.284 & 39.5 & 0.001 & 28251.527 & adhesive \\
\hline 2 & 1 & 26.028 & 40.7 & 0.001 & 38038.917 & adhesive \\
\hline 2 & 2 & 19.410 & 30.3 & 0.001 & 32748.702 & adhesive \\
\hline 2 & 3 & 25.944 & 40.5 & 0.001 & 36165.272 & adhesive \\
\hline 2 & 4 & 23.035 & 36.0 & 0.001 & 38045.704 & adhesive \\
\hline 2 & 5 & 30.282 & 47.3 & 0.002 & 29807.272 & adhesive \\
\hline 2 & 6 & 29.948 & 46.8 & 0.001 & 38562.353 & adhesive \\
\hline 2 & 7 & 17.248 & 27.0 & 0.001 & 34268.458 & adhesive \\
\hline 2 & 8 & 18.885 & 29.5 & 0.001 & 24792.765 & adhesive \\
\hline 2 & 9 & 19.060 & 29.8 & 0.001 & 19603.516 & adhesive \\
\hline 3 & 1 & 27.353 & 42.7 & 0.001 & 35800.196 & adhesive \\
\hline 3 & 2 & 16.667 & 26.0 & 0.001 & 30516.449 & adhesive \\
\hline 3 & 3 & 22.440 & 35.1 & 0.001 & 33745.179 & cohesive \\
\hline 3 & 4 & 28.677 & 44.8 & 0.002 & 38874.407 & adhesive \\
\hline 3 & 5 & 19.158 & 29.9 & 0.001 & 37551.528 & adhesive \\
\hline 3 & 6 & 13.880 & 21.7 & 0.001 & 36740.561 & adhesive \\
\hline 3 & 7 & 23.998 & 37.5 & 0.001 & 36670.504 & cohesive \\
\hline 3 & 8 & 27.159 & 42.4 & 0.002 & 19564.666 & adhesive \\
\hline 3 & 9 & 17.819 & 27.8 & 0.001 & 26868.475 & adhesive \\
\hline 4 & 1 & 12.534 & 19.6 & 0.001 & 32321.140 & adhesive \\
\hline 4 & 2 & 26.804 & 41.9 & 0.001 & 31078.653 & adhesive \\
\hline 4 & 3 & 28.419 & 44.4 & 0.001 & 38586.612 & adhesive \\
\hline 4 & 4 & 32.178 & 50.3 & 0.001 & 36534.632 & adhesive \\
\hline 4 & 5 & 28.003 & 43.8 & 0.001 & 35257.087 & adhesive \\
\hline 4 & 6 & 29.585 & 46.2 & 0.002 & 26797.881 & adhesive \\
\hline 4 & 7 & 19.221 & 30.0 & 0.001 & 40072.384 & adhesive \\
\hline 4 & 8 & 37.980 & 59.3 & 0.002 & 35958.982 & adhesive \\
\hline 4 & 9 & 33.396 & 52.2 & 0.001 & 45078.355 & adhesive \\
\hline
\end{tabular}


Table 14: Data from group 4S: Silorane resin composite repaired with silorane resin composite with abrasion (cont.)

\begin{tabular}{|c|c|c|c|c|c|c|}
\hline Block & Beam & Peak Load & Peak Stress & Strain & Modulus & Failure type \\
\hline 5 & 1 & 12.167 & 19.0 & 0.001 & 20213.849 & adhesive \\
\hline 5 & 2 & 11.635 & 18.2 & 0.000 & 43874.558 & adhesive \\
\hline 5 & 3 & 26.938 & 42.1 & 0.001 & 35060.369 & adhesive \\
\hline 5 & 4 & 24.308 & 38.0 & 0.001 & 41068.163 & adhesive \\
\hline 5 & 5 & 16.708 & 26.0 & 0.001 & 27262.318 & adhesive \\
\hline 5 & 6 & 7.984 & 12.5 & 0.000 & 46319.445 & adhesive \\
\hline 5 & 7 & 29.980 & 46.8 & 0.001 & 43858.808 & adhesive \\
\hline 5 & 8 & 35.065 & 54.8 & 0.002 & 34218.638 & adhesive \\
\hline 5 & 9 & 31.335 & 49.0 & 0.001 & 41188.384 & adhesive \\
\hline 6 & 1 & 24.194 & 37.8 & 0.001 & 37243.256 & adhesive \\
\hline 6 & 2 & 7.629 & 11.9 & 0.000 & 35474.991 & adhesive \\
\hline 6 & 3 & 19.252 & 30.1 & 0.001 & 20853.269 & adhesive \\
\hline 6 & 4 & 36.223 & 56.6 & 0.002 & 34654.204 & adhesive \\
\hline 6 & 5 & 23.239 & 36.3 & 0.001 & 33271.194 & cohesive \\
\hline 6 & 6 & 34.064 & 53.2 & 0.001 & 38962.819 & adhesive \\
\hline 6 & 7 & 18.621 & 29.1 & 0.001 & 37452.100 & adhesive \\
\hline 6 & 8 & 27.364 & 42.8 & 0.001 & 35014.788 & adhesive \\
\hline 6 & 9 & 23.512 & 36.7 & 0.001 & 35643.820 & adhesive \\
\hline 7 & 1 & 35.014 & 54.7 & 0.002 & 30653.726 & adhesive \\
\hline 7 & 2 & 35.161 & 54.9 & 0.002 & 39626.783 & adhesive \\
\hline 7 & 3 & 23.989 & 37.5 & 0.001 & 28919.867 & adhesive \\
\hline 7 & 4 & 29.928 & 46.8 & 0.001 & 33474.886 & adhesive \\
\hline 7 & 5 & 22.012 & 34.4 & 0.001 & 38946.123 & adhesive \\
\hline 7 & 6 & 21.896 & 34.2 & 0.001 & 32615.506 & adhesive \\
\hline 7 & 7 & 33.433 & 52.2 & 0.001 & 45334.708 & adhesive \\
\hline 7 & 8 & 11.502 & 18.0 & 0.002 & 19889.992 & adhesive \\
\hline 7 & 9 & 25.633 & 40.1 & 0.001 & 38178.315 & adhesive \\
\hline 8 & 1 & 12.480 & 19.5 & 0.001 & 29216.659 & adhesive \\
\hline 8 & 2 & 35.235 & 55.1 & 0.002 & 29558.265 & adhesive \\
\hline 8 & 3 & 32.149 & 50.2 & 0.002 & 33062.749 & adhesive \\
\hline 8 & 4 & 22.730 & 35.5 & 0.001 & 35415.672 & adhesive \\
\hline 8 & 5 & 37.774 & 59.0 & 0.002 & 39093.286 & adhesive \\
\hline 8 & 6 & 31.807 & 49.7 & 0.002 & 27844.848 & adhesive \\
\hline 8 & 7 & 23.762 & 37.1 & 0.001 & 32921.940 & adhesive \\
\hline 8 & 8 & 37.159 & 58.1 & 0.002 & 30503.151 & adhesive \\
\hline 8 & 9 & 12.794 & 20.0 & 0.001 & 35093.951 & adhesive \\
\hline
\end{tabular}


Table 15: Data from group 4S: Silorane resin composite repaired with silorane resin composite with abrasion (cont.)

\begin{tabular}{|c|c|c|c|c|c|c|}
\hline Block & Beam & Peak Load & Peak Stress & Strain & Modulus & Failure type \\
\hline 9 & 1 & 18.711 & 29.2 & 0.001 & 37267.238 & adhesive \\
\hline 9 & 2 & 26.596 & 41.6 & 0.001 & 27602.341 & adhesive \\
\hline 9 & 3 & 24.187 & 37.8 & 0.001 & 38163.698 & adhesive \\
\hline 9 & 4 & 25.803 & 40.3 & 0.001 & 31001.247 & adhesive \\
\hline 9 & 5 & 18.554 & 29.0 & 0.001 & 36857.727 & adhesive \\
\hline 9 & 6 & 20.148 & 31.5 & 0.001 & 33466.796 & adhesive \\
\hline 9 & 7 & 25.424 & 39.7 & 0.001 & 28159.824 & adhesive \\
\hline 9 & 8 & 39.095 & 61.1 & 0.002 & 32932.259 & adhesive \\
\hline 9 & 9 & 26.546 & 41.5 & 0.001 & 32369.905 & adhesive \\
\hline 10 & 1 & 21.020 & 32.8 & 0.001 & 28765.417 & adhesive \\
\hline 10 & 2 & 16.158 & 25.2 & 0.001 & 30053.582 & adhesive \\
\hline 10 & 3 & 16.529 & 25.8 & 0.001 & 25504.984 & adhesive \\
\hline 10 & 4 & 33.053 & 51.6 & 0.001 & 36437.573 & adhesive \\
\hline 10 & 5 & 31.867 & 49.8 & 0.002 & 26418.897 & adhesive \\
\hline 10 & 6 & 35.956 & 56.2 & 0.002 & 44206.732 & adhesive \\
\hline 10 & 7 & 30.736 & 48.0 & 0.001 & 38462.722 & adhesive \\
\hline 10 & 8 & 32.523 & 50.8 & 0.002 & 28548.634 & adhesive \\
\hline 10 & 9 & 20.229 & 31.6 & 0.001 & 33806.494 & adhesive \\
\hline 11 & 1 & 35.056 & 54.8 & 0.002 & 26504.270 & adhesive \\
\hline 11 & 2 & 13.179 & 20.6 & 0.001 & 33038.784 & adhesive \\
\hline 11 & 3 & 23.282 & 36.4 & 0.001 & 38420.645 & adhesive \\
\hline 11 & 4 & 30.456 & 47.6 & 0.001 & 27130.490 & cohesive \\
\hline 11 & 5 & 23.230 & 36.3 & 0.001 & 47135.468 & adhesive \\
\hline 11 & 6 & 23.951 & 37.4 & 0.001 & 32699.537 & adhesive \\
\hline 11 & 7 & 33.047 & 51.6 & 0.002 & 28176.107 & adhesive \\
\hline 11 & 8 & 33.059 & 51.7 & 0.001 & 46425.927 & cohesive \\
\hline 11 & 9 & 20.120 & 31.4 & 0.001 & 29752.108 & adhesive \\
\hline 12 & 1 & 24.597 & 38.4 & 0.001 & 32046.971 & cohesive \\
\hline 12 & 2 & 32.391 & 50.6 & 0.002 & 36171.468 & adhesive \\
\hline 12 & 3 & 27.640 & 43.2 & 0.001 & 29702.976 & adhesive \\
\hline 12 & 4 & 21.107 & 33.0 & 0.001 & 37777.724 & adhesive \\
\hline 12 & 5 & 33.488 & 52.3 & 0.002 & 34707.703 & adhesive \\
\hline 12 & 6 & 22.226 & 34.7 & 0.001 & 35950.260 & adhesive \\
\hline 12 & 7 & 21.878 & 34.2 & 0.001 & 33449.774 & adhesive \\
\hline 12 & 8 & 8.935 & 14.0 & 0.000 & 30170.367 & adhesive \\
\hline 12 & 9 & 20.243 & 31.6 & 0.001 & 36007.095 & adhesive \\
\hline
\end{tabular}


Table 16: Data from group 1M: Silorane resin composite repaired with methacrylate based resin composite with no surface treatment

\begin{tabular}{|c|c|c|c|c|c|c|}
\hline Block & Beam & Peak Load & Peak Stress & Strain & Modulus & Failure type \\
\hline 1 & 1 & 34.398 & 53.7 & 0.002 & 22436.239 & adhesive \\
\hline 1 & 2 & 39.156 & 61.2 & 0.002 & 39961.710 & adhesive \\
\hline 1 & 3 & 36.835 & 57.6 & 0.002 & 40355.347 & adhesive \\
\hline 1 & 4 & 31.801 & 49.7 & 0.001 & 41843.046 & cohesive \\
\hline 1 & 5 & 31.801 & 51.8 & 0.002 & 38870.613 & adhesive \\
\hline 1 & 6 & 31.801 & 45.5 & 0.001 & 44141.313 & adhesive \\
\hline 1 & 7 & 31.801 & 34.9 & 0.001 & 40529.306 & adhesive \\
\hline 1 & 8 & 31.801 & 59.7 & 0.002 & 39421.110 & cohesive \\
\hline 1 & 9 & 31.801 & 41.6 & 0.001 & 39246.495 & adhesive \\
\hline 2 & 1 & 31.801 & 59.4 & 0.002 & 33430.427 & adhesive \\
\hline 2 & 2 & 31.801 & 41.4 & 0.001 & 38282.491 & adhesive \\
\hline 2 & 3 & 31.801 & 43.1 & 0.001 & 36901.824 & adhesive \\
\hline 2 & 4 & 31.801 & 62.7 & 0.002 & 34292.622 & adhesive \\
\hline 2 & 5 & 31.801 & 45.8 & 0.001 & 35325.191 & cohesive \\
\hline 2 & 6 & 31.801 & 53.3 & 0.001 & 45364.117 & adhesive \\
\hline 2 & 7 & 31.801 & 59.6 & 0.002 & 33301.341 & adhesive \\
\hline 2 & 8 & 31.801 & 45.1 & 0.001 & 32314.700 & adhesive \\
\hline 2 & 9 & 31.801 & 45.2 & 0.001 & 42685.970 & adhesive \\
\hline 3 & 1 & 31.801 & 58.1 & 0.002 & 35866.322 & cohesive \\
\hline 3 & 2 & 31.801 & 35.1 & 0.001 & 40143.321 & adhesive \\
\hline 3 & 3 & 31.801 & 43.3 & 0.001 & 34669.227 & adhesive \\
\hline 3 & 4 & 31.801 & 43.3 & 0.001 & 44855.419 & cohesive \\
\hline 3 & 5 & 31.801 & 30.2 & 0.001 & 31911.759 & adhesive \\
\hline 3 & 6 & 31.801 & 44.1 & 0.001 & 41181.447 & cohesive \\
\hline 3 & 7 & 31.801 & 13.5 & 0.000 & 49084.645 & adhesive \\
\hline 3 & 8 & 31.801 & 20.6 & 0.001 & 40917.246 & adhesive \\
\hline 3 & 9 & 31.801 & 58.0 & 0.002 & 38554.045 & cohesive \\
\hline 4 & 1 & 31.801 & 26.6 & 0.001 & 39433.648 & adhesive \\
\hline 4 & 2 & 31.801 & 26.2 & 0.001 & 21283.586 & adhesive \\
\hline 4 & 3 & 31.801 & 18.3 & 0.001 & 29356.597 & adhesive \\
\hline 4 & 4 & 31.801 & 28.4 & 0.001 & 20955.102 & adhesive \\
\hline 4 & 5 & 31.801 & 27.4 & 0.001 & 46687.911 & adhesive \\
\hline 4 & 6 & 31.801 & 46.2 & 0.002 & 23456.977 & adhesive \\
\hline 4 & 7 & 31.801 & 36.6 & 0.001 & 39743.294 & adhesive \\
\hline 4 & 8 & 31.801 & 51.1 & 0.002 & 37091.162 & adhesive \\
\hline 4 & 9 & 31.801 & 45.2 & 0.001 & 40736.837 & adhesive \\
\hline
\end{tabular}


Table 17: Data from group 1M: Silorane resin composite repaired with methacrylate based resin composite with no surface treatment (cont.)

\begin{tabular}{|c|c|c|c|c|c|c|}
\hline Block & Beam & Peak Load & Peak Stress & Strain & Modulus & Failure type \\
\hline 5 & 1 & 36.416 & 56.9 & 0.002 & 41877.773 & not break \\
\hline 5 & 2 & 15.628 & 24.4 & 0.001 & 38497.526 & adhesive \\
\hline 5 & 3 & 27.388 & 42.8 & 0.001 & 28315.210 & adhesive \\
\hline 5 & 4 & 40.859 & 63.8 & 0.002 & 34096.661 & adhesive \\
\hline 5 & 5 & 13.205 & 20.6 & 0.001 & 14204.364 & adhesive \\
\hline 5 & 6 & 30.198 & 47.2 & 0.001 & 35879.459 & adhesive \\
\hline 5 & 7 & 22.881 & 35.8 & 0.001 & 50325.731 & cohesive \\
\hline 5 & 8 & 15.918 & 24.9 & 0.001 & 39009.430 & cohesive \\
\hline 5 & 9 & 27.488 & 43.0 & 0.001 & 35752.262 & cohesive \\
\hline 6 & 1 & 27.935 & 43.6 & 0.001 & 36565.301 & cohesive \\
\hline 6 & 2 & 20.241 & 31.6 & 0.001 & 41692.568 & adhesive \\
\hline 6 & 3 & 29.727 & 46.4 & 0.001 & 35050.274 & adhesive \\
\hline 6 & 4 & 39.968 & 62.5 & 0.002 & 45097.327 & adhesive \\
\hline 6 & 5 & 23.478 & 36.7 & 0.001 & 42828.373 & adhesive \\
\hline 6 & 6 & 23.767 & 37.1 & 0.001 & 39864.060 & adhesive \\
\hline 6 & 7 & 38.846 & 60.7 & 0.002 & 37529.219 & adhesive \\
\hline 6 & 8 & 35.253 & 55.1 & 0.002 & 30473.114 & adhesive \\
\hline 6 & 9 & 25.035 & 39.1 & 0.001 & 29872.734 & adhesive \\
\hline 7 & 1 & 30.226 & 47.2 & 0.001 & 41738.344 & adhesive \\
\hline 7 & 2 & 47.320 & 73.9 & 0.002 & 42095.992 & adhesive \\
\hline 7 & 3 & 7.128 & 11.1 & 0.000 & 29087.522 & adhesive \\
\hline 7 & 4 & 20.744 & 32.4 & 0.001 & 33988.130 & adhesive \\
\hline 7 & 5 & 40.724 & 63.6 & 0.002 & 41325.363 & adhesive \\
\hline 7 & 6 & 35.511 & 55.5 & 0.001 & 41027.656 & adhesive \\
\hline 7 & 7 & 24.240 & 37.9 & 0.001 & 39619.083 & adhesive \\
\hline 7 & 8 & 19.534 & 0.5 & 0.001 & 34559.579 & adhesive \\
\hline 7 & 9 & 36.491 & 57.0 & 0.001 & 39117.427 & adhesive \\
\hline 8 & 1 & 37.932 & 59.3 & 0.002 & 38855.010 & adhesive \\
\hline 8 & 2 & 31.876 & 49.8 & 0.001 & 39646.151 & cohesive \\
\hline 8 & 3 & 20.690 & 32.3 & 0.001 & 35521.217 & cohesive \\
\hline 8 & 4 & 11.577 & 18.1 & 0.000 & 47262.763 & cohesive \\
\hline 8 & 5 & 39.787 & 62.2 & 0.002 & 39089.867 & adhesive \\
\hline 8 & 6 & 30.821 & 48.2 & 0.001 & 42029.193 & adhesive \\
\hline 8 & 7 & 39.891 & 62.3 & 0.002 & 39786.420 & cohesive \\
\hline 8 & 8 & 32.951 & 51.5 & 0.002 & 35306.270 & cohesive \\
\hline 8 & 9 & 19.118 & 29.9 & 0.001 & 32478.659 & adhesive \\
\hline
\end{tabular}


Table 18: Data from group 1M: Silorane resin composite repaired with methacrylate based resin composite with no surface treatment (cont.)

\begin{tabular}{|c|c|c|c|c|c|c|}
\hline Block & Beam & Peak Load & Peak Stress & Strain & Modulus & Failure type \\
\hline 9 & 1 & 29.325 & 45.8 & 0.001 & 35253.938 & adhesive \\
\hline 9 & 2 & 12.235 & 19.1 & 0.001 & 27870.290 & adhesive \\
\hline 9 & 3 & 9.136 & 14.3 & 0.000 & 30860.252 & adhesive \\
\hline 9 & 4 & 20.967 & 32.8 & 0.001 & 37782.447 & adhesive \\
\hline 9 & 5 & 15.845 & 24.8 & 0.001 & 31701.568 & adhesive \\
\hline 9 & 6 & 34.597 & 54.1 & 0.001 & 35866.757 & adhesive \\
\hline 9 & 7 & 10.045 & 15.7 & 0.000 & 34416.112 & adhesive \\
\hline 9 & 8 & 32.409 & 50.6 & 0.001 & 35127.508 & adhesive \\
\hline 9 & 9 & 15.482 & 24.2 & 0.001 & 30908.989 & cohesive \\
\hline 10 & 1 & 25.796 & 40.3 & 0.001 & 32533.853 & cohesive \\
\hline 10 & 2 & 11.928 & 18.6 & 0.000 & 40169.006 & cohesive \\
\hline 10 & 3 & 34.850 & 54.5 & 0.002 & 35100.408 & adhesive \\
\hline 10 & 4 & 15.964 & 24.9 & 0.001 & 32924.805 & adhesive \\
\hline 10 & 5 & 26.640 & 41.6 & 0.001 & 53262.022 & cohesive \\
\hline 10 & 6 & 19.020 & 29.7 & 0.001 & 40931.588 & adhesive \\
\hline 10 & 7 & 5.302 & 8.3 & 0.000 & 16250.347 & adhesive \\
\hline 10 & 8 & 37.643 & 58.8 & 0.002 & 38739.040 & adhesive \\
\hline 10 & 9 & 35.909 & 56.1 & 0.002 & 36633.743 & adhesive \\
\hline 11 & 1 & 39.125 & 61.3 & 0.002 & 40294.263 & adhesive \\
\hline 11 & 2 & 10.175 & 15.9 & 0.001 & 22098.485 & adhesive \\
\hline 11 & 3 & 14.986 & 23.4 & 0.001 & 42942.137 & adhesive \\
\hline 11 & 4 & 10.995 & 17.2 & 0.001 & 30399.752 & adhesive \\
\hline 11 & 5 & 29.174 & 45.6 & 0.002 & 32704.479 & adhesive \\
\hline 11 & 6 & 22.897 & 35.8 & 0.002 & 21594.605 & adhesive \\
\hline 11 & 7 & 31.913 & 49.9 & 0.002 & 31127.214 & adhesive \\
\hline 11 & 8 & 33.855 & 52.9 & 0.002 & 35798.166 & adhesive \\
\hline 11 & 9 & 12.130 & 19.0 & 0.001 & 31128.398 & adhesive \\
\hline 12 & 1 & 18.526 & 28.9 & 0.001 & 36624.996 & adhesive \\
\hline 12 & 2 & 29.758 & 46.5 & 0.001 & 45323.520 & cohesive \\
\hline 12 & 3 & 13.081 & 20.4 & 0.001 & 34420.810 & adhesive \\
\hline 12 & 4 & 8.529 & 13.3 & 0.000 & 34632.035 & adhesive \\
\hline 12 & 5 & 28.055 & 43.8 & 0.001 & 34163.892 & adhesive \\
\hline 12 & 6 & 37.097 & 58.0 & 0.002 & 34936.300 & cohesive \\
\hline 12 & 7 & 23.273 & 36.4 & 0.001 & 39275.324 & cohesive \\
\hline 12 & 8 & 30.308 & 47.4 & 0.002 & 40381.180 & cohesive \\
\hline 12 & 9 & 31.982 & 50.0 & 0.001 & 47765.999 & adhesive \\
\hline
\end{tabular}


Table 19: Data from group 2M: Silorane resin composite repaired with methacrylate based resin composite with acid etching

\begin{tabular}{|c|c|c|c|c|c|c|}
\hline Block & Beam & Peak Load & Peak Stress & Strain & Modulus & Failure type \\
\hline 1 & 1 & 38.805 & 60.6 & 0.003 & 31970.284 & adhesive \\
\hline 1 & 2 & 37.473 & 58.6 & 0.002 & 37295.899 & adhesive \\
\hline 1 & 3 & 33.404 & 52.2 & 0.001 & 45865.117 & adhesive \\
\hline 1 & 4 & 34.319 & 53.6 & 0.001 & 46215.269 & adhesive \\
\hline 1 & 5 & 37.777 & 59.0 & 0.002 & 38473.351 & adhesive \\
\hline 1 & 6 & 3.309 & 52.0 & 0.001 & 49780.673 & adhesive \\
\hline 1 & 7 & 29.444 & 46.0 & 0.001 & 49223.831 & adhesive \\
\hline 1 & 8 & 34.319 & 53.6 & 0.001 & 39905.564 & adhesive \\
\hline 1 & 9 & 39.275 & 61.4 & 0.002 & 45211.400 & adhesive \\
\hline 2 & 1 & 10.608 & 16.6 & 0.000 & 38494.078 & adhesive \\
\hline 2 & 2 & 18.638 & 29.1 & 0.001 & 41060.977 & adhesive \\
\hline 2 & 3 & 24.723 & 38.6 & 0.001 & 45671.076 & adhesive \\
\hline 2 & 4 & 20.621 & 32.2 & 0.001 & 38552.093 & cohesive \\
\hline 2 & 5 & 22.656 & 35.4 & 0.001 & 37775.055 & adhesive \\
\hline 2 & 6 & 19.879 & 31.1 & 0.001 & 35182.785 & adhesive \\
\hline 2 & 7 & 23.798 & 37.2 & 0.001 & 44811.270 & adhesive \\
\hline 2 & 8 & 8.219 & 12.8 & 0.000 & 30607.964 & adhesive \\
\hline 2 & 9 & 8.303 & 13.0 & 0.000 & 42723.842 & adhesive \\
\hline 3 & 1 & 43.582 & 68.1 & 0.002 & 42145.963 & adhesive \\
\hline 3 & 2 & 7.295 & 11.4 & 0.000 & 44374.217 & adhesive \\
\hline 3 & 3 & 30.831 & 48.2 & 0.001 & 35693.648 & adhesive \\
\hline 3 & 4 & 33.130 & 51.8 & 0.001 & 38932.324 & cohesive \\
\hline 3 & 5 & 14.804 & 23.1 & 0.001 & 47548.361 & adhesive \\
\hline 3 & 6 & 14.475 & 22.6 & 0.001 & 22083.725 & adhesive \\
\hline 3 & 7 & 35.158 & 54.9 & 0.002 & 33503.138 & adhesive \\
\hline 3 & 8 & 25.251 & 39.5 & 0.001 & 39670.860 & cohesive \\
\hline 3 & 9 & 37.350 & 58.4 & 0.002 & 35299.580 & cohesive \\
\hline 4 & 1 & 39.822 & 62.2 & 0.002 & 38076.789 & adhesive \\
\hline 4 & 2 & 38.066 & 59.5 & 0.002 & 37122.516 & adhesive \\
\hline 4 & 3 & 27.457 & 42.9 & 0.001 & 29908.415 & adhesive \\
\hline 4 & 4 & 10.036 & 15.7 & 0.000 & 41746.092 & adhesive \\
\hline 4 & 5 & 33.076 & 51.7 & 0.001 & 38685.877 & adhesive \\
\hline 4 & 6 & 35.316 & 55.2 & 0.002 & 36216.846 & adhesive \\
\hline 4 & 7 & 24.414 & 38.1 & 0.001 & 38242.034 & cohesive \\
\hline 4 & 8 & 40.582 & 63.4 & 0.002 & 37233.017 & adhesive \\
\hline 4 & 9 & 27.175 & 42.5 & 0.001 & 37512.005 & cohesive \\
\hline
\end{tabular}


Table 20: Data from group 2M: Silorane resin composite repaired with methacrylate based resin composite with acid etching (cont.)

\begin{tabular}{|c|c|c|c|c|c|c|}
\hline Block & Beam & Peak Load & Peak Stress & Strain & Modulus & Failure type \\
\hline 5 & 1 & 26.248 & 41.0 & 0.001 & 38461.734 & adhesive \\
\hline 5 & 2 & 42.252 & 66.0 & 0.002 & 41848.269 & adhesive \\
\hline 5 & 3 & 39.129 & 61.1 & 0.001 & 40664.418 & adhesive \\
\hline 5 & 4 & 27.729 & 43.3 & 0.001 & 34753.478 & adhesive \\
\hline 5 & 5 & 40.268 & 62.9 & 0.002 & 40640.086 & adhesive \\
\hline 5 & 6 & 29.537 & 46.2 & 0.001 & 33774.934 & adhesive \\
\hline 5 & 7 & 49.603 & 77.5 & 0.002 & 42759.489 & adhesive \\
\hline 5 & 8 & 29.676 & 46.4 & 0.001 & 43079.348 & cohesive \\
\hline 5 & 9 & 19.124 & 29.9 & 0.001 & 28911.487 & adhesive \\
\hline 6 & 1 & 32.629 & 51.0 & 0.002 & 32640.087 & cohesive \\
\hline 6 & 2 & 12.629 & 19.7 & 0.000 & 48388.363 & adhesive \\
\hline 6 & 3 & 30.253 & 47.3 & 0.001 & 42916.205 & cohesive \\
\hline 6 & 4 & 37.637 & 58.8 & 0.002 & 44197.164 & adhesive \\
\hline 6 & 5 & 32.922 & 51.4 & 0.001 & 50993.865 & adhesive \\
\hline 6 & 6 & 7.759 & 12.1 & 0.000 & 27717.374 & adhesive \\
\hline 6 & 7 & 28.940 & 45.2 & 0.001 & 40364.615 & cohesive \\
\hline 6 & 8 & 16.407 & 25.6 & 0.001 & 37311.366 & adhesive \\
\hline 6 & 9 & 40.221 & 62.8 & 0.002 & 38885.682 & adhesive \\
\hline 7 & 1 & 34.372 & 53.7 & 0.002 & 29457.318 & adhesive \\
\hline 7 & 2 & 22.236 & 34.7 & 0.001 & 39850.926 & adhesive \\
\hline 7 & 3 & 36.200 & 56.6 & 0.002 & 43335.866 & cohesive \\
\hline 7 & 4 & 12.747 & 19.9 & 0.001 & 23094.247 & adhesive \\
\hline 7 & 5 & 24.492 & 38.3 & 0.001 & 47756.153 & adhesive \\
\hline 7 & 6 & 28.464 & 44.5 & 0.001 & 35809.558 & adhesive \\
\hline 7 & 7 & 31.445 & 49.1 & 0.001 & 41478.587 & adhesive \\
\hline 7 & 8 & 34.006 & 53.1 & 0.001 & 42925.937 & cohesive \\
\hline 7 & 9 & 41.138 & 64.3 & 0.002 & 44887.631 & adhesive \\
\hline 8 & 1 & 30.211 & 47.2 & 0.002 & 35161.291 & adhesive \\
\hline 8 & 2 & 38.049 & 59.5 & 0.002 & 35769.991 & adhesive \\
\hline 8 & 3 & 21.990 & 34.4 & 0.001 & 39997.535 & cohesive \\
\hline 8 & 4 & 20.164 & 31.5 & 0.001 & 34923.259 & adhesive \\
\hline 8 & 5 & 35.578 & 55.6 & 0.002 & 37887.635 & adhesive \\
\hline 8 & 6 & 26.689 & 41.7 & 0.001 & 33966.796 & adhesive \\
\hline 8 & 7 & 24.141 & 37.7 & 0.001 & 34181.338 & adhesive \\
\hline 8 & 8 & 32.956 & 51.5 & 0.002 & 31635.478 & cohesive \\
\hline 8 & 9 & 36.542 & 57.1 & 0.002 & 34573.226 & cohesive \\
\hline
\end{tabular}


Table 21: Data from group 2M: Silorane resin composite repaired with methacrylate based resin composite with acid etching (cont.)

\begin{tabular}{|c|c|c|c|c|c|c|}
\hline Block & Beam & Peak Load & Peak Stress & Strain & Modulus & Failure type \\
\hline 9 & 1 & 9.038 & 14.1 & 0.000 & 31697.063 & adhesive \\
\hline 9 & 2 & 24.700 & 38.6 & 0.001 & 30373.708 & cohesive \\
\hline 9 & 3 & 23.492 & 36.7 & 0.001 & 36449.604 & adhesive \\
\hline 9 & 4 & 35.228 & 55.0 & 0.002 & 34568.951 & adhesive \\
\hline 9 & 5 & 6.791 & 10.6 & 0.000 & 41324.877 & adhesive \\
\hline 9 & 6 & 22.727 & 35.5 & 0.001 & 40495.925 & adhesive \\
\hline 9 & 7 & 29.500 & 46.1 & 0.001 & 34393.097 & adhesive \\
\hline 9 & 8 & 33.629 & 52.5 & 0.002 & 31916.489 & cohesive \\
\hline 9 & 9 & 29.185 & 45.6 & 0.002 & 37163.173 & adhesive \\
\hline 10 & 1 & 25.366 & 39.6 & 0.001 & 37996.335 & adhesive \\
\hline 10 & 2 & 39.458 & 61.7 & 0.002 & 41675.991 & adhesive \\
\hline 10 & 3 & 36.589 & 57.2 & 0.001 & 48985.274 & adhesive \\
\hline 10 & 4 & 44.242 & 69.1 & 0.003 & 31737.946 & adhesive \\
\hline 10 & 5 & 28.591 & 44.7 & 0.001 & 43817.409 & adhesive \\
\hline 10 & 6 & 33.165 & 51.8 & 0.002 & 43790.977 & adhesive \\
\hline 10 & 7 & 13.295 & 20.8 & 0.000 & 45974.785 & adhesive \\
\hline 10 & 8 & 28.946 & 45.2 & 0.001 & 33643.816 & adhesive \\
\hline 10 & 9 & 32.552 & 50.9 & 0.001 & 38356.266 & adhesive \\
\hline 11 & 1 & 27.623 & 43.2 & 0.001 & 32732.450 & cohesive \\
\hline 11 & 2 & 37.323 & 58.3 & 0.001 & 40319.196 & adhesive \\
\hline 11 & 3 & 31.660 & 49.5 & 0.001 & 43246.130 & adhesive \\
\hline 11 & 4 & 25.814 & 40.3 & 0.001 & 28587.719 & adhesive \\
\hline 11 & 5 & 36.315 & 56.7 & 0.002 & 38341.083 & adhesive \\
\hline 11 & 6 & 14.086 & 22.0 & 0.001 & 19107.746 & adhesive \\
\hline 11 & 7 & 28.355 & 44.3 & 0.001 & 31108.789 & cohesive \\
\hline 11 & 8 & 25.905 & 40.5 & 0.001 & 39468.132 & adhesive \\
\hline 11 & 9 & 37.040 & 57.9 & 0.002 & 30612.922 & adhesive \\
\hline 12 & 1 & 28.543 & 44.6 & 0.001 & 31871.963 & adhesive \\
\hline 12 & 2 & 19.086 & 29.8 & 0.001 & 36924.039 & adhesive \\
\hline 12 & 3 & 29.430 & 46.0 & 0.001 & 38111.900 & adhesive \\
\hline 12 & 4 & 20.800 & 32.5 & 0.001 & 39984.539 & adhesive \\
\hline 12 & 5 & 14.615 & 22.8 & 0.001 & 37396.147 & adhesive \\
\hline 12 & 6 & 27.188 & 42.5 & 0.001 & 26002.111 & adhesive \\
\hline 12 & 7 & 33.380 & 52.2 & 0.002 & 32770.382 & adhesive \\
\hline 12 & 8 & 28.771 & 45.0 & 0.001 & 37971.429 & adhesive \\
\hline 12 & 9 & 16.861 & 26.3 & 0.001 & 32650.731 & adhesive \\
\hline
\end{tabular}


Table 22: Data from group 3M: Silorane resin composite repaired with methacrylate based resin composite with sandblasting

\begin{tabular}{|c|c|c|c|c|c|c|}
\hline Block & Beam & Peak Load & Peak Stress & Strain & Modulus & Failure type \\
\hline 1 & 1 & 26.976 & 42.2 & 0.002 & 36297.307 & cohesive \\
\hline 1 & 2 & 33.738 & 52.7 & 0.002 & 36445.248 & adhesive \\
\hline 1 & 3 & 30.816 & 48.2 & 0.001 & 35556.235 & cohesive \\
\hline 1 & 4 & 35.320 & 55.2 & 0.002 & 34885.896 & adhesive \\
\hline 1 & 5 & 26.583 & 41.5 & 0.001 & 39778.723 & cohesive \\
\hline 1 & 6 & 27.847 & 43.5 & 0.001 & 38877.269 & cohesive \\
\hline 1 & 7 & 31.916 & 49.9 & 0.001 & 43138.062 & cohesive \\
\hline 1 & 8 & 34.670 & 54.2 & 0.002 & 36482.022 & adhesive \\
\hline 1 & 9 & 21.124 & 33.0 & 0.001 & 33322.035 & adhesive \\
\hline 2 & 1 & 19.178 & 30.0 & 0.001 & 37142.836 & adhesive \\
\hline 2 & 2 & 31.733 & 49.6 & 0.001 & 41405.506 & cohesive \\
\hline 2 & 3 & 29.257 & 45.7 & 0.002 & 33095.525 & cohesive \\
\hline 2 & 4 & 11.239 & 17.6 & 0.000 & 37782.972 & adhesive \\
\hline 2 & 5 & 30.579 & 47.8 & 0.001 & 32688.762 & adhesive \\
\hline 2 & 6 & 25.082 & 39.2 & 0.001 & 36007.776 & cohesive \\
\hline 2 & 7 & 17.459 & 27.3 & 0.001 & 44188.087 & adhesive \\
\hline 2 & 8 & 34.881 & 54.5 & 0.002 & 35503.608 & adhesive \\
\hline 2 & 9 & 18.281 & 28.6 & 0.001 & 30393.899 & adhesive \\
\hline 3 & 1 & 21.802 & 34.1 & 0.001 & 47201.770 & adhesive \\
\hline 3 & 2 & 36.154 & 56.5 & 0.002 & 33871.748 & cohesive \\
\hline 3 & 3 & 35.451 & 55.4 & 0.002 & 31547.643 & adhesive \\
\hline 3 & 4 & 28.587 & 44.7 & 0.001 & 42539.708 & adhesive \\
\hline 3 & 5 & 18.259 & 28.5 & 0.001 & 30956.661 & adhesive \\
\hline 3 & 6 & 23.255 & 36.3 & 0.001 & 31422.537 & adhesive \\
\hline 3 & 7 & 24.874 & 38.9 & 0.001 & 42369.666 & cohesive \\
\hline 3 & 8 & 30.485 & 47.6 & 0.001 & 35002.284 & cohesive \\
\hline 3 & 9 & 32.835 & 51.3 & 0.001 & 46612.224 & cohesive \\
\hline 4 & 1 & 22.517 & 35.2 & 0.001 & 29188.599 & adhesive \\
\hline 4 & 2 & 29.369 & 45.9 & 0.001 & 43744.986 & adhesive \\
\hline 4 & 3 & 28.949 & 45.2 & 0.001 & 43316.066 & adhesive \\
\hline 4 & 4 & 30.177 & 47.2 & 0.001 & 43915.899 & cohesive \\
\hline 4 & 5 & 13.249 & 20.7 & 0.001 & 30178.310 & adhesive \\
\hline 4 & 6 & 27.660 & 43.2 & 0.001 & 42315.581 & adhesive \\
\hline 4 & 7 & 32.437 & 50.7 & 0.002 & 26918.284 & cohesive \\
\hline 4 & 8 & 25.017 & 39.1 & 0.001 & 41519.004 & adhesive \\
\hline 4 & 9 & 38.208 & 59.7 & 0.001 & 44821.987 & adhesive \\
\hline
\end{tabular}


Table 23: Data from group 3M: Silorane resin composite repaired with methacrylate based resin composite with sandblasting (cont.)

\begin{tabular}{|c|c|c|c|c|c|c|}
\hline Block & Beam & Peak Load & Peak Stress & Strain & Modulus & Failure type \\
\hline 5 & 1 & 41.232 & 64.4 & 0.002 & 38561.653 & adhesive \\
\hline 5 & 2 & 30.561 & 47.8 & 0.001 & 43929.272 & cohesive \\
\hline 5 & 3 & 38.484 & 60.1 & 0.002 & 46879.234 & cohesive \\
\hline 5 & 4 & 37.110 & 58.0 & 0.001 & 43397.376 & adhesive \\
\hline 5 & 5 & 29.932 & 46.8 & 0.002 & 23527.240 & adhesive \\
\hline 5 & 6 & 31.674 & 49.5 & 0.002 & 33396.901 & adhesive \\
\hline 5 & 7 & 39.684 & 62.0 & 0.002 & 40336.780 & adhesive \\
\hline 5 & 8 & 28.929 & 45.2 & 0.001 & 36889.202 & cohesive \\
\hline 5 & 9 & 38.223 & 59.7 & 0.001 & 48218.057 & cohesive \\
\hline 6 & 1 & 37.593 & 58.7 & 0.002 & 39581.483 & cohesive \\
\hline 6 & 2 & 37.873 & 59.2 & 0.002 & 37717.866 & adhesive \\
\hline 6 & 3 & 34.304 & 53.6 & 0.001 & 42374.338 & cohesive \\
\hline 6 & 4 & 35.665 & 55.7 & 0.001 & 42282.239 & adhesive \\
\hline 6 & 5 & 32.625 & 51.0 & 0.001 & 51007.642 & adhesive \\
\hline 6 & 6 & 19.363 & 30.3 & 0.001 & 43143.266 & adhesive \\
\hline 6 & 7 & 21.607 & 33.8 & 0.001 & 47865.643 & adhesive \\
\hline 6 & 8 & 37.415 & 58.5 & 0.002 & 32464.224 & cohesive \\
\hline 6 & 9 & 34.026 & 53.2 & 0.001 & 39995.729 & adhesive \\
\hline 7 & 1 & 32.634 & 51.0 & 0.001 & 42920.996 & adhesive \\
\hline 7 & 2 & 29.821 & 46.6 & 0.001 & 39147.186 & adhesive \\
\hline 7 & 3 & 39.051 & 61.0 & 0.002 & 37099.852 & adhesive \\
\hline 7 & 4 & 31.138 & 48.7 & 0.001 & 41526.619 & adhesive \\
\hline 7 & 5 & 27.722 & 43.3 & 0.001 & 48315.613 & adhesive \\
\hline 7 & 6 & 27.315 & 42.7 & 0.001 & 37214.053 & cohesive \\
\hline 7 & 7 & 38.930 & 60.8 & 0.002 & 32960.038 & adhesive \\
\hline 7 & 8 & 28.607 & 44.7 & 0.001 & 34692.058 & adhesive \\
\hline 7 & 9 & 32.922 & 51.4 & 0.001 & 41588.414 & adhesive \\
\hline 8 & 1 & 31.381 & 49.0 & 0.002 & 43139.154 & cohesive \\
\hline 8 & 2 & 40.589 & 63.4 & 0.002 & 41404.762 & adhesive \\
\hline 8 & 3 & 36.473 & 57.0 & 0.001 & 44891.501 & adhesive \\
\hline 8 & 4 & 13.719 & 21.4 & 0.001 & 34309.651 & cohesive \\
\hline 8 & 5 & 36.869 & 57.6 & 0.001 & 47334.573 & adhesive \\
\hline 8 & 6 & 40.509 & 63.3 & 0.002 & 42984.902 & adhesive \\
\hline 8 & 7 & 40.267 & 62.9 & 0.002 & 32307.182 & adhesive \\
\hline 8 & 8 & 30.343 & 47.4 & 0.002 & 31992.466 & cohesive \\
\hline 8 & 9 & 35.594 & 55.6 & 0.002 & 36907.277 & cohesive \\
\hline
\end{tabular}


Table 24: Data from group 3M: Silorane resin composite repaired with methacrylate based resin composite with sandblasting (cont.)

\begin{tabular}{|c|c|c|c|c|c|c|}
\hline Block & Beam & Peak Load & Peak Stress & Strain & Modulus & Failure type \\
\hline 9 & 1 & 35.808 & 56.0 & 0.002 & 33083.653 & adhesive \\
\hline 9 & 2 & 26.755 & 41.8 & 0.002 & 43303.813 & adhesive \\
\hline 9 & 3 & 27.924 & 43.6 & 0.001 & 39892.009 & adhesive \\
\hline 9 & 4 & 25.534 & 39.9 & 0.001 & 35510.911 & adhesive \\
\hline 9 & 5 & 33.772 & 52.8 & 0.002 & 38428.292 & cohesive \\
\hline 9 & 6 & 30.794 & 48.1 & 0.001 & 37912.595 & adhesive \\
\hline 9 & 7 & 39.900 & 62.3 & 0.001 & 51029.118 & adhesive \\
\hline 9 & 8 & 35.383 & 55.3 & 0.001 & 40918.455 & adhesive \\
\hline 9 & 9 & 26.917 & 42.1 & 0.002 & 37657.176 & cohesive \\
\hline 10 & 1 & 31.803 & 49.7 & 0.001 & 41299.094 & adhesive \\
\hline 10 & 2 & 30.867 & 48.2 & 0.001 & 58581.740 & cohesive \\
\hline 10 & 3 & 41.507 & 64.9 & 0.002 & 32806.009 & cohesive \\
\hline 10 & 4 & 31.015 & 48.5 & 0.001 & 55008.087 & adhesive \\
\hline 10 & 5 & 33.838 & 52.9 & 0.002 & 36106.184 & adhesive \\
\hline 10 & 6 & 27.710 & 43.3 & 0.001 & 37983.636 & adhesive \\
\hline 10 & 7 & 36.016 & 56.3 & 0.001 & 44178.734 & adhesive \\
\hline 10 & 8 & 28.142 & 44.0 & 0.001 & 44709.475 & adhesive \\
\hline 10 & 9 & 31.655 & 49.5 & 0.002 & 36374.809 & cohesive \\
\hline 11 & 1 & 28.579 & 44.7 & 0.001 & 36815.593 & cohesive \\
\hline 11 & 2 & 28.797 & 45.0 & 0.001 & 38416.749 & cohesive \\
\hline 11 & 3 & 30.228 & 47.2 & 0.001 & 40308.087 & adhesive \\
\hline 11 & 4 & 32.509 & 50.8 & 0.001 & 43940.877 & adhesive \\
\hline 11 & 5 & 36.398 & 56.9 & 0.002 & 36508.943 & cohesive \\
\hline 11 & 6 & 32.139 & 50.2 & 0.001 & 37134.053 & adhesive \\
\hline 11 & 7 & 35.115 & 54.9 & 0.002 & 36907.631 & adhesive \\
\hline 11 & 8 & 34.349 & 53.7 & 0.001 & 41360.948 & cohesive \\
\hline 11 & 9 & 27.183 & 42.5 & 0.001 & 40345.728 & cohesive \\
\hline 12 & 1 & 18.326 & 28.6 & 0.001 & 32287.790 & adhesive \\
\hline 12 & 2 & 30.368 & 47.5 & 0.001 & 37816.752 & adhesive \\
\hline 12 & 3 & 27.844 & 43.5 & 0.001 & 40346.556 & cohesive \\
\hline 12 & 4 & 24.814 & 38.8 & 0.001 & 44601.178 & cohesive \\
\hline 12 & 5 & 29.886 & 46.7 & 0.001 & 37169.608 & cohesive \\
\hline 12 & 6 & 37.287 & 58.3 & 0.001 & 48171.499 & adhesive \\
\hline 12 & 7 & 33.573 & 52.5 & 0.002 & 40474.288 & adhesive \\
\hline 12 & 8 & 27.010 & 42.2 & 0.001 & 35080.930 & adhesive \\
\hline 12 & 9 & 27.601 & 43.1 & 0.001 & 53354.869 & mixed \\
\hline
\end{tabular}


Table 25: Data from group 4M: Silorane resin composite repaired with methacrylate based resin composite with abrasion

\begin{tabular}{|c|c|c|c|c|c|c|}
\hline Block & Beam & Peak Load & Peak Stress & Strain & Modulus & Failure type \\
\hline 1 & 1 & 11.443 & 17.9 & 0.001 & 33070.094 & adhesive \\
\hline 1 & 2 & 11.140 & 17.4 & 0.000 & 35799.506 & adhesive \\
\hline 1 & 3 & 22.237 & 34.7 & 0.001 & 37119.955 & adhesive \\
\hline 1 & 4 & 19.453 & 30.4 & 0.001 & 33428.540 & adhesive \\
\hline 1 & 5 & 13.694 & 21.4 & 0.001 & 32148.323 & adhesive \\
\hline 1 & 6 & 20.736 & 32.4 & 0.001 & 38949.960 & adhesive \\
\hline 1 & 7 & 21.934 & 34.3 & 0.001 & 41286.149 & adhesive \\
\hline 1 & 8 & 26.026 & 40.7 & 0.001 & 33045.189 & mixed \\
\hline 1 & 9 & 28.681 & 44.8 & 0.001 & 34135.259 & adhesive \\
\hline 2 & 1 & 29.474 & 46.1 & 0.001 & 43740.181 & adhesive \\
\hline 2 & 2 & 26.179 & 40.9 & 0.002 & 27521.755 & mixed \\
\hline 2 & 3 & 28.064 & 43.8 & 0.004 & 27082.979 & adhesive \\
\hline 2 & 4 & 25.775 & 40.3 & 0.001 & 43532.850 & adhesive \\
\hline 2 & 5 & 20.460 & 32.0 & 0.001 & 41747.648 & cohesive \\
\hline 2 & 6 & 18.807 & 29.4 & 0.001 & 44072.607 & adhesive \\
\hline 2 & 7 & 29.690 & 46.4 & 0.001 & 38405.109 & adhesive \\
\hline 2 & 8 & 10.803 & 16.9 & 0.000 & 35371.814 & adhesive \\
\hline 2 & 9 & 12.220 & 19.1 & 0.000 & 49612.315 & adhesive \\
\hline 3 & 1 & 9.227 & 14.4 & 0.000 & 38363.741 & adhesive \\
\hline 3 & 2 & 30.151 & 47.1 & 0.001 & 37261.015 & adhesive \\
\hline 3 & 3 & 29.277 & 45.7 & 0.001 & 41114.433 & adhesive \\
\hline 3 & 4 & 21.072 & 32.9 & 0.001 & 41458.382 & adhesive \\
\hline 3 & 5 & 31.443 & 49.1 & 0.002 & 39459.914 & adhesive \\
\hline 3 & 6 & 32.804 & 51.3 & 0.001 & 44306.056 & adhesive \\
\hline 3 & 7 & 31.412 & 49.1 & 0.001 & 51805.711 & adhesive \\
\hline 3 & 8 & 14.424 & 22.5 & 0.001 & 38706.186 & adhesive \\
\hline 3 & 9 & 27.480 & 42.9 & 0.001 & 41378.872 & adhesive \\
\hline 4 & 1 & 11.105 & 17.4 & 0.001 & 27828.064 & adhesive \\
\hline 4 & 2 & 20.687 & 32.3 & 0.001 & 41770.296 & adhesive \\
\hline 4 & 3 & 26.448 & 41.3 & 0.001 & 33940.708 & adhesive \\
\hline 4 & 4 & 32.142 & 50.2 & 0.001 & 37353.146 & adhesive \\
\hline 4 & 5 & 18.340 & 28.7 & 0.001 & 33479.274 & mixed \\
\hline 4 & 6 & 12.911 & 20.2 & 0.001 & 34217.413 & mixed \\
\hline 4 & 7 & 29.955 & 46.8 & 0.001 & 41679.117 & adhesive \\
\hline 4 & 8 & 33.399 & 52.2 & 0.002 & 40643.206 & adhesive \\
\hline 4 & 9 & 31.428 & 49.1 & 0.001 & 42682.301 & adhesive \\
\hline
\end{tabular}


Table 26: Data from group 4M: Silorane resin composite repaired with methacrylate based resin composite with abrasion (cont.)

\begin{tabular}{|c|c|c|c|c|c|c|}
\hline Block & Beam & Peak Load & Peak Stress & Strain & Modulus & Failure type \\
\hline 5 & 1 & 16.781 & 26.2 & 0.001 & 36126.174 & adhesive \\
\hline 5 & 2 & 11.179 & 17.5 & 0.000 & 40206.321 & adhesive \\
\hline 5 & 3 & 21.774 & 34.0 & 0.001 & 34813.179 & adhesive \\
\hline 5 & 4 & 33.525 & 52.4 & 0.002 & 32910.830 & adhesive \\
\hline 5 & 5 & 25.650 & 40.1 & 0.001 & 42608.050 & adhesive \\
\hline 5 & 6 & 17.570 & 27.5 & 0.001 & 49631.118 & adhesive \\
\hline 5 & 7 & 16.134 & 25.2 & 0.001 & 39538.378 & adhesive \\
\hline 5 & 8 & 24.658 & 38.5 & 0.001 & 42759.828 & adhesive \\
\hline 5 & 9 & 24.902 & 38.9 & 0.001 & 42955.772 & adhesive \\
\hline 6 & 1 & 31.595 & 49.4 & 0.001 & 45697.823 & adhesive \\
\hline 6 & 2 & 27.577 & 43.1 & 0.001 & 39039.109 & adhesive \\
\hline 6 & 3 & 33.125 & 51.8 & 0.002 & 33785.864 & adhesive \\
\hline 6 & 4 & 29.143 & 45.5 & 0.002 & 36683.866 & adhesive \\
\hline 6 & 5 & 27.536 & 43.0 & 0.001 & 41152.051 & adhesive \\
\hline 6 & 6 & 31.180 & 48.7 & 0.001 & 38211.290 & adhesive \\
\hline 6 & 7 & 29.169 & 45.6 & 0.001 & 44207.031 & adhesive \\
\hline 6 & 8 & 23.366 & 36.5 & 0.001 & 37169.921 & cohesive \\
\hline 6 & 9 & 21.943 & 34.3 & 0.002 & 34328.373 & cohesive \\
\hline 7 & 1 & 34.263 & 53.5 & 0.002 & 27281.236 & adhesive \\
\hline 7 & 2 & 12.382 & 19.3 & 0.001 & 37500.371 & adhesive \\
\hline 7 & 3 & 19.157 & 29.9 & 0.001 & 34968.801 & adhesive \\
\hline 7 & 4 & 27.338 & 42.7 & 0.001 & 34041.267 & adhesive \\
\hline 7 & 5 & 29.023 & 45.3 & 0.001 & 33617.498 & adhesive \\
\hline 7 & 6 & 37.924 & 59.3 & 0.002 & 33235.265 & adhesive \\
\hline 7 & 7 & 17.508 & 27.4 & 0.001 & 30353.592 & adhesive \\
\hline 7 & 8 & 19.487 & 30.4 & 0.001 & 35166.281 & adhesive \\
\hline 7 & 9 & 17.491 & 27.3 & 0.001 & 36981.164 & adhesive \\
\hline 8 & 1 & 19.331 & 30.2 & 0.001 & 40196.131 & adhesive \\
\hline 8 & 2 & 25.191 & 39.4 & 0.002 & 24449.446 & adhesive \\
\hline 8 & 3 & 17.926 & 28.0 & 0.001 & 29787.435 & cohesive \\
\hline 8 & 4 & 17.839 & 27.9 & 0.001 & 33279.508 & mixed \\
\hline 8 & 5 & 27.111 & 42.4 & 0.001 & 34827.659 & adhesive \\
\hline 8 & 6 & 27.151 & 42.4 & 0.001 & 34445.839 & adhesive \\
\hline 8 & 7 & 17.331 & 27.1 & 0.001 & 24199.892 & adhesive \\
\hline 8 & 8 & 25.533 & 39.9 & 0.002 & 27684.501 & adhesive \\
\hline 8 & 9 & 22.683 & 35.4 & 0.002 & 27621.336 & cohesive \\
\hline
\end{tabular}


Table 27: Data from group 4M: Silorane resin composite repaired with methacrylate based resin composite with abrasion (cont.)

\begin{tabular}{|c|c|c|c|c|c|c|}
\hline Block & Beam & Peak Load & Peak Stress & Strain & Modulus & Failure type \\
\hline 9 & 1 & 25.563 & 39.9 & 0.002 & 36278.791 & adhesive \\
\hline 9 & 2 & 22.967 & 35.9 & 0.001 & 34103.152 & adhesive \\
\hline 9 & 3 & 35.714 & 55.8 & 0.002 & 31046.680 & adhesive \\
\hline 9 & 4 & 25.796 & 40.3 & 0.001 & 31815.259 & adhesive \\
\hline 9 & 5 & 17.786 & 27.8 & 0.001 & 32855.127 & adhesive \\
\hline 9 & 6 & 23.505 & 36.7 & 0.001 & 33640.440 & adhesive \\
\hline 9 & 7 & 15.351 & 24.0 & 0.001 & 33700.176 & adhesive \\
\hline 9 & 8 & 35.748 & 55.9 & 0.002 & 40917.089 & adhesive \\
\hline 9 & 9 & 27.217 & 42.5 & 0.001 & 36616.188 & adhesive \\
\hline 10 & 1 & 30.126 & 47.1 & 0.001 & 33777.318 & adhesive \\
\hline 10 & 2 & 32.007 & 50.0 & 0.001 & 42596.984 & adhesive \\
\hline 10 & 3 & 34.145 & 53.4 & 0.002 & 35871.186 & adhesive \\
\hline 10 & 4 & 22.080 & 34.5 & 0.001 & 32050.037 & adhesive \\
\hline 10 & 5 & 21.559 & 33.7 & 0.001 & 35618.062 & adhesive \\
\hline 10 & 6 & 28.954 & 45.2 & 0.001 & 42763.857 & adhesive \\
\hline 10 & 7 & 17.368 & 27.1 & 0.001 & 31561.688 & adhesive \\
\hline 10 & 8 & 32.470 & 50.7 & 0.002 & 39661.745 & adhesive \\
\hline 10 & 9 & 20.459 & 32.0 & 0.001 & 50223.531 & adhesive \\
\hline 11 & 1 & 25.920 & 40.5 & 0.001 & 40971.245 & adhesive \\
\hline 11 & 2 & 22.869 & 35.7 & 0.001 & 43079.530 & adhesive \\
\hline 11 & 3 & 27.583 & 43.1 & 0.001 & 35607.965 & mixed \\
\hline 11 & 4 & 31.034 & 48.5 & 0.002 & 35782.829 & adhesive \\
\hline 11 & 5 & 23.567 & 36.8 & 0.001 & 27901.552 & adhesive \\
\hline 11 & 6 & 29.758 & 46.5 & 0.002 & 31004.204 & adhesive \\
\hline 11 & 7 & 29.600 & 46.2 & 0.001 & 48478.863 & adhesive \\
\hline 11 & 8 & 16.581 & 25.9 & 0.001 & 25369.186 & adhesive \\
\hline 11 & 9 & 17.594 & 27.5 & 0.001 & 30068.234 & adhesive \\
\hline 12 & 1 & 35.468 & 55.4 & 0.002 & 35894.422 & adhesive \\
\hline 12 & 2 & 23.493 & 36.7 & 0.001 & 43458.103 & cohesive \\
\hline 12 & 3 & 18.445 & 28.8 & 0.001 & 25993.496 & cohesive \\
\hline 12 & 4 & 35.353 & 55.2 & 0.002 & 37005.657 & adhesive \\
\hline 12 & 5 & 24.006 & 37.5 & 0.001 & 42828.326 & adhesive \\
\hline 12 & 6 & 25.259 & 39.5 & 0.001 & 39490.576 & adhesive \\
\hline 12 & 7 & 31.776 & 49.6 & 0.002 & 36488.913 & adhesive \\
\hline 12 & 8 & 28.861 & 45.1 & 0.001 & 39998.063 & adhesive \\
\hline 12 & 9 & 10.406 & 16.3 & 0.001 & 31549.742 & adhesive \\
\hline
\end{tabular}


Table 28: P-value and comparison for microtensile bond strength and failure mode

\begin{tabular}{|c|c|c|c|}
\hline \multicolumn{2}{|c|}{ Microtensile Peak Stress } & \multicolumn{2}{|c|}{ Failure Mode } \\
\hline p-value & Comparison & p-value & Comparison \\
\hline 0.58 & $1 \mathrm{M} \& 1 \mathrm{~S}$ & 0.10 & $1 \mathrm{M} \& 1 \mathrm{~S}$ \\
\hline 0.69 & $1 \mathrm{M} \& 2 \mathrm{M}$ & 0.39 & $1 \mathrm{M} \& 2 \mathrm{M}$ \\
\hline 0.63 & $1 \mathrm{M} \& 2 \mathrm{~S}$ & 0.71 & $1 \mathrm{M} \& 2 \mathrm{~S}$ \\
\hline 0.48 & $1 \mathrm{M} \& 3 \mathrm{M}$ & 0.06 & $1 \mathrm{M} \& 3 \mathrm{M}$ \\
\hline 0.33 & $1 \mathrm{M} \& 3 \mathrm{~S}$ & 0.52 & $1 \mathrm{M} \& 3 \mathrm{~S}$ \\
\hline 0.63 & $1 \mathrm{M} \& 4 \mathrm{M}$ & 0.08 & $1 \mathrm{M} \& 4 \mathrm{M}$ \\
\hline 0.79 & $1 \mathrm{M} \& 4 \mathrm{~S}$ & $0.004 *$ & $1 \mathrm{M}<4 \mathrm{~S}$ \\
\hline $0.03 *$ & $1 \mathrm{M}<$ Control & & \\
\hline 0.34 & $1 \mathrm{~S} \& 2 \mathrm{M}$ & 0.33 & $1 \mathrm{~S} \& 2 \mathrm{M}$ \\
\hline 0.96 & $1 S \& 2 S$ & 0.20 & $1 S \& 2 S$ \\
\hline 0.21 & $1 \mathrm{~S} \& 3 \mathrm{M}$ & $0.001 *$ & $1 \mathrm{~S}>3 \mathrm{M}$ \\
\hline 0.12 & $1 \mathrm{~S} \& 3 \mathrm{~S}$ & $0.007 *$ & $1 \mathrm{~S}>3 \mathrm{~S}$ \\
\hline 0.94 & $1 \mathrm{~S} \& 4 \mathrm{M}$ & 0.84 & $1 \mathrm{~S} \& 4 \mathrm{M}$ \\
\hline 0.77 & $1 \mathrm{~S} \& 4 \mathrm{~S}$ & 0.09 & $1 \mathrm{~S} \& 4 \mathrm{~S}$ \\
\hline $0.006^{*}$ & 1S $<$ Control & & \\
\hline 0.38 & $2 \mathrm{M} \& 2 \mathrm{~S}$ & 0.65 & $2 \mathrm{M} \& 2 \mathrm{~S}$ \\
\hline 0.76 & $2 \mathrm{M} \& 3 \mathrm{M}$ & $0.001 *$ & $2 \mathrm{M}>3 \mathrm{M}$ \\
\hline 0.55 & $2 \mathrm{M} \& 3 \mathrm{~S}$ & 0.07 & $2 \mathrm{M} \& 3 \mathrm{~S}$ \\
\hline 0.38 & $2 \mathrm{M} \& 4 \mathrm{M}$ & 0.27 & $2 \mathrm{M} \& 4 \mathrm{M}$ \\
\hline 0.51 & $2 \mathrm{M} \& 4 \mathrm{~S}$ & $0.015^{*}$ & $2 \mathrm{M}<4 \mathrm{~S}$ \\
\hline 0.07 & $2 \mathrm{M} \&$ Control & & \\
\hline 0.24 & $2 \mathrm{~S} \& 3 \mathrm{M}$ & $0.018^{*}$ & $2 S>3 M$ \\
\hline 0.14 & $2 S \& 3 S$ & 0.28 & $2 S \& 3 S$ \\
\hline 0.99 & $2 \mathrm{~S} \& 4 \mathrm{M}$ & 0.16 & $2 \mathrm{~S} \& 4 \mathrm{M}$ \\
\hline 0.82 & $2 S \& 4 S$ & $0.009^{*}$ & $2 \mathrm{~S}<4 \mathrm{~S}$ \\
\hline $0.008^{*}$ & $2 \mathrm{~S}<$ Control & & \\
\hline 0.77 & $3 \mathrm{M} \& 3 \mathrm{~S}$ & 0.11 & $3 \mathrm{M} \& 3 \mathrm{~S}$ \\
\hline 0.23 & $3 \mathrm{M} \& 4 \mathrm{M}$ & $0.001 *$ & $3 \mathrm{M}<4 \mathrm{M}$ \\
\hline 0.33 & $3 \mathrm{M} \& 4 \mathrm{~S}$ & $0.001 *$ & $3 \mathrm{M}<4 \mathrm{~S}$ \\
\hline 0.13 & 3M \& Control & & \\
\hline 0.14 & $3 \mathrm{~S} \& 4 \mathrm{M}$ & $0.006^{*}$ & $3 \mathrm{~S}<4 \mathrm{M}$ \\
\hline 0.21 & $3 S \& 4 S$ & $0.001 *$ & $3 \mathrm{~S}<4 \mathrm{~S}$ \\
\hline 0.23 & 3S \& Control & & \\
\hline 0.83 & $4 \mathrm{M} \& 4 \mathrm{~S}$ & 0.13 & $4 \mathrm{M} \& 4 \mathrm{~S}$ \\
\hline $0.007^{*}$ & $4 \mathrm{M}<$ Control & & \\
\hline $0.014^{*}$ & $4 \mathrm{~S}<$ Control & & \\
\hline
\end{tabular}


ABSTRACT 


\title{
EFFECT OF SURFACE TREATMENTS ON MICROTENSILE BOND STRENGTH OF REPAIRED AGED SILORANE RESIN COMPOSITE
}

\author{
By \\ Jadesada Palasuk \\ Indiana University School of Dentistry \\ Indianapolis, Indiana
}

Background: A silorane based resin composite, Filtek LS restorative, has been introduced to overcome the polymerization shrinkage of the methacrylate based resin composite. The repair of resin composite may hold clinical advantages. Currently, there is no available information regarding the repair potential of silorane resin composite with either silorane or methacrylate based resin composite. Objectives: The purpose of this study was to compare the repaired microtensile bond strength of aged silorane resin composite using different surface treatments 
and either silorane or methacrylate based resin composite. Methods: One hundred and eight silorane resin composite blocks (Filtek LS) were fabricated and aged by thermocycling between $8^{\circ} \mathrm{C}$ and $48^{\circ} \mathrm{C}$ (5000 cycles). A control (solid resin composite) and four surface treatment groups (no treatment, acid treatment, aluminum oxide sandblasting and diamond bur abrasion) were tested. Each treatment group was randomly divided in half and repaired with either silorane resin composite (LS adhesive) or methacrylate based resin composite (Filtek Z250/Single Bond Plus). Specimens were 12 blocks and 108 beams per group. After 24 hours in $37^{\circ} \mathrm{C}$ distilled water, microtensile bond strength testing was performed using a non-trimming technique. Fracture surfaces were examined using an optical microscopy (20X) to determine failure mode. Data was analyzed using Weibull-distribution survival analysis. Results: Aluminum oxide sandblasting followed by silorane or methacrylate based resin composite and acid treatment with methacrylate based resin composite provided insignificant differences from the control $(\mathrm{p}>0.05)$. All other groups were significantly lower than the control. Failure was primarily adhesive in all groups. Conclusion: Aluminum oxide sandblasting produced comparable microtensile bond strength compared to the cohesive strength of silorane resin composite. After aluminum oxide sandblasting, aged silorane resin composite can be repaired with either silorane resin composite with LS system adhesive or methacrylate based resin composite with methacrylate based dentin adhesive. 
CURRICULUM VITAE 


\section{JADESADA PALASUK}

\section{EDUCATION}

- 2007-2010 Indiana University Purdue University Indianapolis, IN, USA

Master of Science in Dentistry (MSD)

Certificate in Graduate Prosthodontics,

- 1998-2004 Chulalongkorn University, Bangkok, Thailand

Doctor of Dental Surgery (DDS)

\section{WORKING EXPERIENCE}

- 2004-2007 Department of Restorative Dentistry, Faculty of Dentistry, Naresuan University, Phitsanulok, Thailand

\section{PROFESSIONAL ORGANIZATIONS/AWARDS}

- Thai Dental Association

- American College of Prosthodontists

- The International and American Association for Dental Research

- The John F. Johnston Society

- I. Lester Furnas Scholarship Award

- Carl J. \& Ida A. Andres Scholarship Award 